\title{
Comparação cefalométrica da estabilidade do tratamento da má oclusão de Classe II realizado sem e com a extração de dois pré-molares superiores.
}

\section{JANINE DELLA VALLE ARAKI}

Tese apresentada à Faculdade de Odontologia de Bauru da Universidade de São Paulo, como parte dos requisitos para obtenção do título de Mestre em Odontologia, área de Ortodontia. 



\section{Comparação cefalométrica da estabilidade do tratamento da má oclusão de Classe II realizado sem e com a extração de dois pré-molares superiores.}

\section{JANINE DELLA VALLE ARAKI}

Tese apresentada à Faculdade de Odontologia de Bauru da Universidade de São Paulo, como parte dos requisitos para obtenção do título de Mestre em Odontologia, área de Ortodontia.

Orientador: Prof. Dr. Guilherme Janson 


\section{Araki, Janine Della Valle}

Ar12c Comparação cefalométrica da estabilidade do tratamento da má oclusão de Classe II sem e com a extração de dois pré-molares superiores / Janine Della Valle Araki. -- Bauru, 2007.

119 p. mais apêndices: il. ; $30 \mathrm{~cm}$.

Dissertação (Mestrado) -- Faculdade de Odontologia de Bauru . Universidade de São Paulo.

Orientador: Prof. Dr. Guilherme Janson

Autorizo, exclusivamente para fins acadêmicos e científicos, a reprodução total ou parcial desta dissertação, por processos fotocopiadores e/ou outros meios eletrônicos.

Assinatura da autora:

Data:

Comitê de Ética da FOB-USP

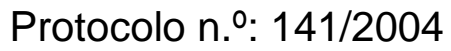

Data: $24 / 11 / 04$ 




\section{$J_{\text {anine }} D_{\text {ella }} V_{\text {alle }} A_{\text {raki }}$}

14 de dezembro de 1979

em Jales/SP

$1998-2001$

$2002-2004$

$2005-2007$
Nascimento

Graduação em Odontologia na Faculdade de Odontologia de Araraquara - UNESP

Curso de Aperfeiçoamento em Ortodontia na ACOPEN - Bauru/SP

Curso de pós-graduação em Ortodontia, em nível de mestrado, na Faculdade de Odontologia de Bauru - USP 
"Títulos não fazem os homens ilustres; os homens é que fazem seus títulos ilustres."

(Provérbio italiano) 
Com todo o meu amor e gratidão...

\section{Dedico este trabalho,}

Ao melhor pai do mundo e à mãe mais amada:

$\mathbf{S}_{\text {ioji Araki e }} \mathbf{V}_{\text {anir Della Valle Araki. }}$ 



\section{Agradeço a Deus...}

Pela saúde perfeita...

Pelo privilégio de ter uma família repleta de amor...

Pelas infinitas oportunidades...

Por colocar tantas pessoas admiráveis e generosas no meu caminho...

Sei que a minha dívida é imensa porque os privilégios são muitos...

Só desejo continuar fazendo por merecer tanto! 



\title{
Agradeço especialmente...
}

\author{
Ao meu pai Sioji Araki: \\ Muito obrigada por estar sempre comigo, pois, mais uma vez, a sua disponibilidade, \\ a sua compreensão e a sua generosidade foram fundamentais para que mais uma \\ etapa se completasse com êxito. Obrigada por me amar sem cobrança e apoiar \\ minhas decisões com entusiasmo. Minha admiração por você é extrema. \\ Você que sempre desejou que seus filhos não vivessem "nas trevas", pode hoje se \\ vangloriar de seu desejo realizado! \\ À minha querida mãe: Vanir Della Valle Araki. \\ Sua busca incessante por melhores maneiras de amadurecermos e crescermos \\ profissionalmente foi essencial para as nossas conquistas. Seu amor arraigou em nós \\ valores verdadeiros que fizeram com que eu nunca nos desviassemos do caminho \\ reto! Hoje, somos o reflexo de sua alma e compartilhamos dos seus ideais. \\ À você, que é exemplo de amor e doação: obrigada para sempre!
}

Aos meus irmãos Alexandre e Karina: Tenho orgulho de tê-los como irmãos. Obrigada por cuidarem de mim...

À minha avó Amélia e ao meu avô Luís:

Obrigada por tudo! Os domingos são infinitamente mais felizes com vocês e os demais dias são felizes simplesmente por vocês existirem para mim! 


\begin{abstract}
À minha "tia" Neide: minha irmã, minha amiga, minha mãe!
Obrigada por doar, sem limites, todos os tipos de amor que existe. Todos sentimos seus cuidados diariamente, mesmo à distância! Você é essencial na nossa vida!

Ao meu querido "Zé", por me amar todos os dias e transformar o simples em especial, tristezas em alegrias e dificuldades em aprendizado. Meu amor por você é infinito e inabalável!
\end{abstract}

Vocês são o meu equilíbrio!

MINHA GRATIDÃO NÃO CABE EM PALAVRAS... 


\section{Agradeço especialmente...}

\section{Ao Prof. Dr. Guilherme Janson:}

O seu brilhantismo e a maneira séria como encara a ciência o fizeram exemplar.

Com você aprendi que não basta simplesmente estudar, é necessário que se faça isso intensamente, com empenho e responsabilidade se o objetivo é colher frutos diferenciados.

Agradeço a maneira séria com que me orientou neste trabalho, sempre exigindo além dos meus supostos limites para que eu aprendesse sempre mais.

Muito obrigada também pelo carinho e pela amizade. 


\section{Agradeço também...}

A todos os professores da disciplina de Ortodontia da FOB/USP:

\section{Prof. Dr. José Fernando Castanha Henriques:}

Muito obrigada pelos valiosos ensinamentos transmitidos de maneira agradável e séria e pela disposição com que recebe os alunos.

\section{Prof. Dr. Marcos Roberto de Freitas:}

Sua simplicidade e clareza ao trasmitir seus preciosos ensinamentos serão eternamentes lembradas por mim, com muito carinho. Obrigada!

\section{Prof. Dr. Décio Rodrigues Martins:}

Obrigada por nos mostrar que a arte de ensinar deve ser realizada com muita seriedade e dedicação e obrigada também pelo carinho.

\section{Prof. Dr. Arnaldo Pinzan:}

Obrigada pela seriedade durante a transmissão de seus conhecimentos e pela luta constante para formar profissionais completos.

\section{Prof. Dr. Renato Rodrigues de Almeida:}

Obrigada por transmitir seus valiosos ensinamentos, frutos de grande experiência acumulada, com simplicidade e entusiasmo. 


\section{Agradeço também...}

A todos os funcionários da Ortodontia:

Vera, Sérgio, Cris, Neide, Lu, Bonné e Danilo pela amizade e pela constante disponibilidade em ajudar. Muito obrigada!

Aos funcionários de ACOPEN:

Sônia, Lu e Cesinha, pela convivência prazerosa e por tanto carinho.

À Faculdade de Odontologia de Bauru - Universidade de São Paulo, na pessoa do diretor Prof. Dr. Luiz Fernando Pegoraro e do vice-diretor Prof. Dr. José Carlos Pereira:

Agradeço a receptividade com que fui acolhida e as inúmeras oportunidades que aqui encontrei. Formar-se por esta faculdade é motivo de muito orgulho para mim.

Aos funcionários da pós-graduação e da biblioteca, pela prontidão em ajudar.

Aos professores e funcionários da Radiologia, pela disposição e carinho com que me auxiliaram durante a realização desta pesquisa.

Ao Prof. Dr. José Roberto Pereira Lauris, pela paciência e pelos ensinamentos de estatística.

Ao Prof. Dr. Alberto Consolaro, por despertar em mim o desejo de ser uma professora completa.

Aos pacientes da FOB que foram essenciais para o meu aprendizado e para a realização deste trabalho.

Às funcionárias do SDO Leia e Érica e também ao Prof. Dr. Fabrício Pinelli Valarelli pelo auxílio e pela amizade. 
Aos meus amigos da turma de mestrado Caio Valle, Danilo Valarelli, Douglas Tibola, Eduardo Franco, Leonardo Camardella, Luiz Fernando Bonfante, Luiz Feliphe Canuto, Mayara Patel, Patrícia Martins, Rachelle Lopes, Tassiana Simão e Vladimir Salazar:

Muito obrigada por gostarem de mim apesar de todos os meus defeitos!

Aos alunos do doutorado Kelly Chiqueto, Sérgio Estelita, Alexandre Nakamura, Lívia Freitas e Analu Brandão pela amizade, pela ajuda e pelos conselhos de todo tipo.

À FAPESP pela concessão de bolsa de estudos. 


\section{Agradeço aos meus amigos especiais...}

\section{Marcela Claudino da Silva...}

Muito obrigada por se preocupar comigo constantemente! Com sua amizade, os dias em Bauru ficaram mais prazerosos e menos vazios, pois a sua companhia foi o bálsamo para as dificuldades e as saudades!

Minha irmã, minha mãe: tenho certeza de que não nos conhecemos por acaso, pois minha vida se tornou outra depois de você...obrigada!

\section{Mayara Paim Patel...}

Amiga querida para todas as horas, todas as dúvidas e inseguranças. A vida nos aproximou para que a união fizesse a força...e isso fez toda a diferença! Admiro muito você! Obrigada pela força!

\section{Danilo Valarelli e Leonardo Camardella:}

A amizade de vocês tornou o meu trabalho mais feliz. Vocês são especialmente queridos por mim!

\section{Caio Valle, Renata Louro, Wagner Baseggio, Ronan Jacques, Marcela} Calabria, Lu Rezende, Patrícia Calderon e Rachelle Lopes: Todos vocês, com suas peculiaridades, me ensinaram coisas importantes e contribuíram para que eu fosse mais mais feliz! Contem sempre comigo!

Andressa Borzilo: Obrigada por ouvir as minhas idéias, os meus palpites e as minhas reclamações. Gosto muito de você!

Ana Carolina Araújo: Obrigada por sua amizade sincera e por sua prontidão em ajudar! A qualidade da nossa amizade é que a torna única! 
Dra. Elisa Albuquerque: Obrigada pela confiança e por torcer por minhas conquistas profissionais. Sou eternamente grata a você e desejo retribuir, um dia, tudo o que você faz por mim!

\section{Dra. Ana Paula Marques:}

Obrigada por me amar e por desejar sinceramente que eu siga adiante sem sofrimentos. Agradeço a Deus todos os dias por ter uma amiga como você.

Minha admiração por você é tão grande quanto a sua por mim! E meus desejos para você são seus sonhos realizados um a um!

Minba sogra Lurdinba:: Obrigada por me acolher, por me apoiar e por se importar comigo de forma tão sincera! Você é insubstituível!

Com a amizade de vocês, tudo é muito mais fácil! 


\section{SUMÁRIO}

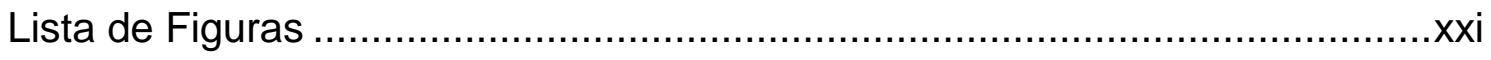

Lista de Tabela .............................................................................

Lista de Abreviaturas .......................................................................

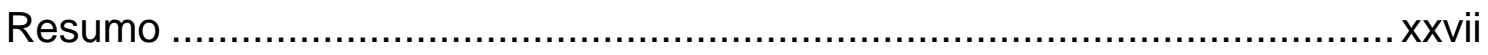

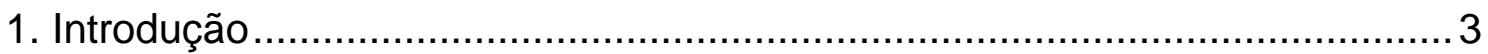

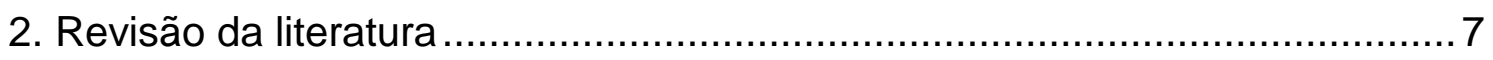

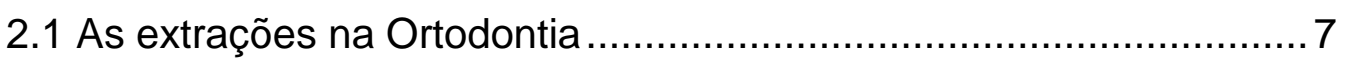

2.1.1. "Extraction Debate of 1911"................................... 7

2.1.2. "Extraction Panel" ................................................ 9

2.2. Tratamento da classe II sem extrações dentárias ........................ 10

2.3. A época de tratamento da classe II e o tratamento em uma ou duas fases ..................................................................... 14

2.4. Tratamento da classe II com extrações dentárias ......................17

2.5. Estabilidade do tratamento ortodôntico .................................. 22

2.5.1. Estabilidade das correções ortodônticas.....................22

2.5.2. Estabilidade do tratamento da má oclusão de

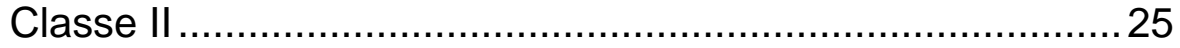

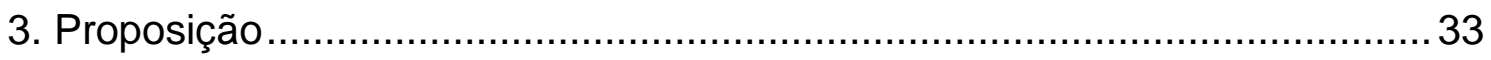

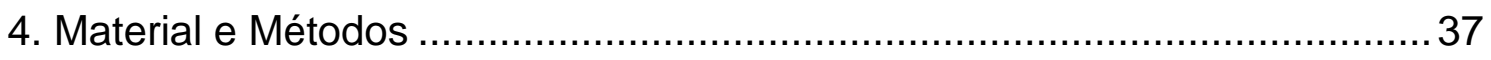

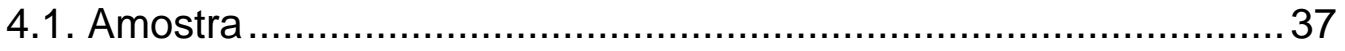

4.2. Tomada e obtenção das telerradiografias em norma lateral .........39

4.3. Traçado e medição das telerradiografias .................................... 39

4.4. Erro do método..................................................................... 50

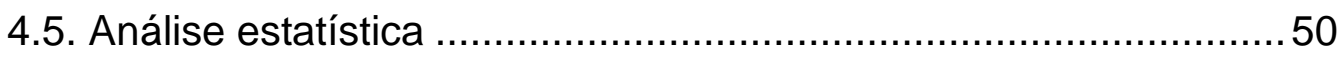


5. Resultados.

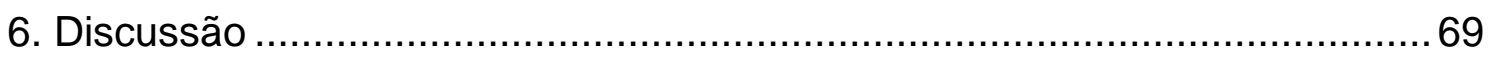

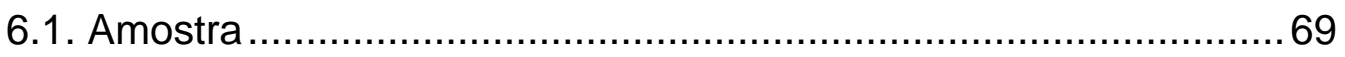

6.2. Compatibilidade entre os grupos ............................................... 74

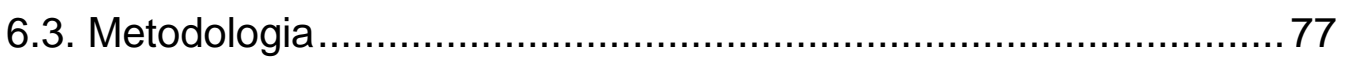

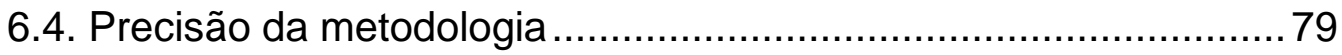

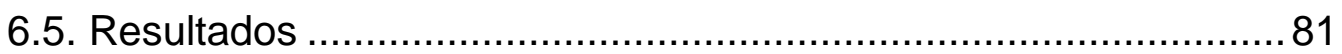

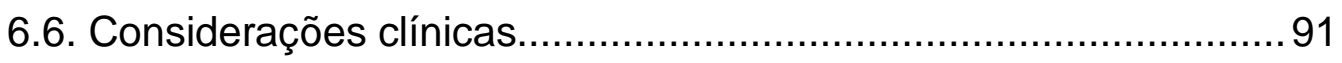

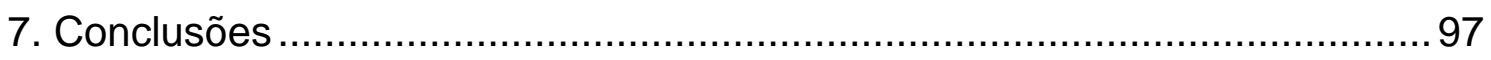

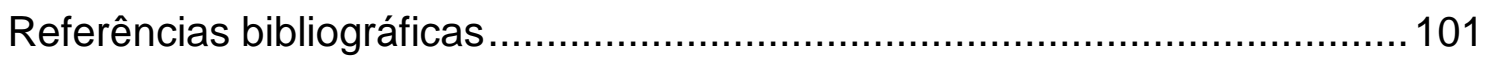

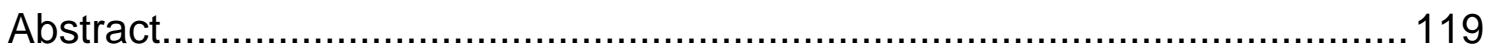

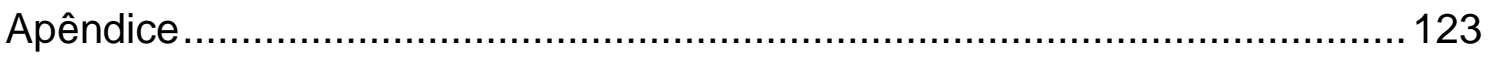




\section{LISTA DE FIGURAS}

FIGURA 1 - Traçado anatômico, pontos cefalométricos, pontos de referência, linhas e planos utilizados.

FIGURA 2 - Grandezas cefalométricas esqueléticas: 1- SNA; 2- Co-A; 3- A-Nperp; 4- SNB; 5- Co-Gn; 6- ANB; 7- Wits; 8- FMA; 9- SN.GoGn; 10- AFAI (ENA-Me). 45

FIGURA 3 - Grandezas cefalométricas dentárias: 1- 1.PP; 2- 1-ENAperp; 3- 1-PP; 4- 6-PP; 5- 6-ENAperp; 6- IMPA; 7- 1-Pogperp; 8- 1-GoMe; 9- 6Pogperp; 10- 6-GoMe.

FIGURA 4 - Relações dentárias: 1 - Trespasse horizontal; 2 - Trespasse vertical; 3

- Relação molar ; 4 - Relação de caninos. 49 


\section{LISTA DE TABELAS}

Tabela 1 - Médias, desvios-padrão, valores mínimos e máximos das idades dos pacientes integrantes do Grupo 1 nos três estágios de avaliação.

Tabela 2 - Médias, desvios-padrão, valores mínimos e máximos das idades dos pacientes integrantes do Grupo 2 nos três estágios de avaliação.

TABELA 3 - Médias, desvios-padrão e resultados do teste $t$ pareado (erro sistemático) e da fórmula de Dahlberg (erro casual) para a avaliação do erro intra-examinador.

TABELA 4 - Médias, desvios-padrão e resultados da análise de variância e do teste de Tukey para a avaliação do erro interexaminador.

TABELA 5 - Médias, desvios-padrão e resultado do teste t para a avaliação da compatibilidade entre as idades nos estágios pré-tratamento, póstratamento e de observação e do tempo de observação.

TABELA 6 - Resultado do teste Qui-quadrado para avaliar a compatibilidade entre os grupos quanto à proporção dos gêneros.

TABELA 7 - Resultado do teste Qui-quadrado para avaliar a compatibilidade entre os grupos quanto à proporção dos tipos de Classe II.

TABELA 8 - Resultados do teste Qui-quadrado para avaliar a compatibilidade entre os grupos quanto à proporção de pacientes que utilizavam contenção ântero-inferior (3×3) no estágio de observação.

TABELA 9 - Médias, desvios-padrão e resultado do teste t para a avaliação da compatibilidade entre os grupos no estágio pré-tratamento ( $\mathrm{T} 1)$.

TABELA 10 - Médias, desvios-padrão e resultado do teste t para a comparação intergrupos dos valores das variáveis no estágio pós-tratamento (T2).

TABELA 11 - Médias, desvios-padrão e resultado do teste t para a comparação intergrupos dos valores das variáveis no estágio de observação (T3).

TABELA 12 - Médias, desvios-padrão e resultado do teste t para a comparação intergrupos das alterações do tratamento. 
TABELA 13 - Médias, desvios-padrão e resultado do teste t para a comparação intergrupos das alterações ocorridas no período pós-tratamento (T3-T2).

TABELA 14 - Médias, desvios-padrão e resultado do teste t para a comparação intergrupos das alterações ocorridas no período pós-tratamento (T3T2), após a compatibilização do tempo de observação.

TABELA 15 - Médias, desvios-padrão e resultado do teste t para a comparação intergrupos das alterações ocorridas no período pós-tratamento (T3T2), após a exclusão dos pacientes com Classe II, Divisão 2.

TABELA 16 - Médias, desvios-padrão e resultado da análise de correlação entre as alterações das relações dentárias ocorridas durante o tratamento (T2-T1) e no período pós-tratamento (T3-T2). 66

TABELA 17 - Análise da correlação entre a alteração pós-tratamento da relação de caninos (Rel can T3 - Rel can T2) e as alterações póstratamento das demais variáveis cefalométricas estudadas.... 66

TABELA 18 - Médias, desvios-padrão e resultado do teste t para a comparação intergrupos dos valores das variáveis no estágio pré-tratamento (T1), após a compatibilização da relação de caninos no estágio póstratamento. 89

TABELA 19 - Médias, desvios-padrão e resultado do teste t para a comparação intergrupos dos valores das variáveis no estágio pós-tratamento (T2), após a compatibilização da relação de caninos nesse mesmo estágio.

TABELA 20 - Médias, desvios-padrão e resultado do teste t para a comparação intergrupos dos valores das variáveis no estágio de observação (T3), após a compatibilização da relação de caninos no estágio póstratamento.

TABELA 21 - Médias, desvios-padrão e resultado do teste t para a comparação intergrupos das alterações do tratamento, após a compatibilização da relação de caninos no estágio pós-tratamento.

TABELA 22 - Médias, desvios-padrão e resultado do teste t para a comparação intergrupos das alterações ocorridas no período pós-tratamento (T3T2), após a compatibilização da relação de caninos no estágio póstratamento. 
LISTA DE ABREVIATURAS

\begin{tabular}{|l|l|}
\hline Abreviaturas & Descrições \\
\hline T1 & Estágio pré-tratamento \\
\hline T2 & Estágio pós-tratamento \\
\hline T3 & Estágio de observação \\
\hline T2 - T1 & Alterações do tratamento \\
\hline T3 - T2 & Alterações pós-tratamento \\
\hline Sem Xp & Tratamento sem extração dentária \\
\hline Xp 2PMS & Tratamento com extração de dois pré-molares superiores \\
\hline T hor & Trespasse horizontal \\
\hline T vert & Trespasse vertical \\
\hline Rel mol & Relação molar \\
\hline Rel can & Relação de caninos \\
\hline
\end{tabular}


$\boldsymbol{R}_{\text {esumo }}$ 



\section{RESUMO}

Este estudo teve como objetivo comparar a estabilidade das relações dentárias corrigidas e a influência de variáveis cefalométricas dentoalveolares e esqueléticas na estabilidade de dois grupos de pacientes com má oclusão de Classe II completa, tratados sem extração e com extrações de dois pré-molares superiores. Cada grupo foi composto por 30 pacientes, com características compatíveis no início do tratamento, cujas telerradiografias laterais dos estágios pré-tratamento, pós-tratamento e de observação foram avaliadas. O tempo médio de observação pós-tratamento foi de 8,2 anos. Para a comparação intergrupos das variáveis cefalométricas nos três estágios de avaliação, assim como das alterações do tratamento e pós-tratamento foi aplicado $o$ teste $t$ de Student. Os resultados apontaram que não houve diferença intergrupos significante entre as relações dentárias no estágio de observação e que as alterações pós-tratamento se apresentaram proporcionais às alterações do tratamento. Além disso, as variáveis cefalométricas estudadas não influenciaram a estabilidade das correções dentárias.

Palavras-chave: Classe II de Angle. Extração Dentária. Cefalometria. 



$$
1 \text { - Introdução }
$$





\section{1- INTRODUÇÃO:}

Ao se avaliarem os resultados de determinado tratamento ortodôntico a fim de classificá-lo como bem ou mal sucedido, a estabilidade é um importante fator a ser considerado. Dessa forma, após a realização de um diagnóstico criterioso, é importante se optar pelo protocolo de tratamento que apresente mais chances de propiciar resultados estáveis, além de estética agradável e função ideal ${ }^{2,93}$.

Diante da vasta disponibilidade de protocolos de tratamento para a má oclusão de Classe II, fatores como a idade do paciente e o potencial de crescimento associado a ela ${ }^{207}$, a severidade da discrepância ânteroposterior $^{108,223}$, a motivação e a colaboração do paciente com o tratamento ${ }^{110}$ devem ser considerados durante o planejamento.

O tratamento da Classe II com os aparelhos ortopédicos seguido do aparelho fixo é indicado para pacientes que se encontram próximos à fase de grande expressão do crescimento craniofacial ${ }^{65,112}$. No tratamento de pacientes com crescimento restrito ou insignificante, podem-se empregar os distalizadores intrabucais ${ }^{54,124}$, os aparelhos extrabucais ${ }^{12,92}$, os aparelhos fixos associados aos elásticos de Classe II $^{163,221}$ ou às extrações dentárias ${ }^{49,214}$, a cirurgia ortognática ${ }^{60}$ ou uma combinação de duas ou mais dessas abordagens.

Alguns protocolos de tratamento sem extração, como os que empregam os aparelhos ortopédicos, o aparelho extrabucal ou os elásticos intermaxilares, requerem grande colaboração do paciente. Quando a colaboração é suficiente, os resultados obtidos são satisfatórios, assim como a estabilidade ${ }^{73,88,230}$.

Uma vez que se opta pelo tratamento com aparelhos fixos associados às extrações dentárias, o próximo passo inclui a seleção dos dentes a serem extraídos. No tratamento da Classe II completa e bilateral, comumente, há possibilidade de se extrair quatro pré-molares, sendo dois superiores e dois inferiores ${ }^{116,205}$ ou de se extrair dois pré-molares superiores apenas $^{128,207}$.

Quando há protrusão bimaxilar ou apinhamento severo em ambos os arcos dentários, está indicada a extração de quatro pré-molares e este 
protocolo de tratamento requer a utilização do aparelho extrabucal para a correção da relação molar de Classe II até uma relação molar de Classe I, similarmente ao que ocorre no tratamento sem extrações ${ }^{50,104,161,205}$.

Já a extração de dois pré-molares superiores é indicada quando não há discrepância cefalométrica nem apinhamento no arco dentário inferior e o uso do aparelho extrabucal servirá unicamente como reforço de ancoragem durante a retração ântero-superior, sendo que será requisitado um uso menos intenso desse aparelho, minimizando a dependência da colaboração do paciente para a obtenção do sucesso do tratamento ${ }^{110,113}$.

Todavia, as críticas principais a este protocolo advêm da manutenção da relação molar não corrigida no término do tratamento, e do fato de esta condição oclusal ser considerada instável e funcionalmente insatisfatória por alguns autores que fazem essas afirmações, mas não apresentam comprovações científicas ${ }^{91,144,147,175}$.

Diversos estudos não verificaram relação entre estabilidade e a realização ou não de extrações dentárias ${ }^{10,75,170}$. Todavia, estes estudos avaliaram pacientes tratados com a extração de quatro pré-molares ou com a extração de dois e quatro pré-molares integrando um mesmo grupo e há escassez, na literatura, de estudos que comparem especificamente a estabilidade do tratamento sem extrações com a do tratamento com extração de dois pré-molares superiores.

Dessa forma, este trabalho visa a comparar cefalometricamente a estabilidade das relações dentárias obtidas com a correção da má oclusão de Classe II completa pelo emprego desses dois protocolos, assim como estudar a influência de algumas variáveis cefalométricas sobre essa estabilidade. 


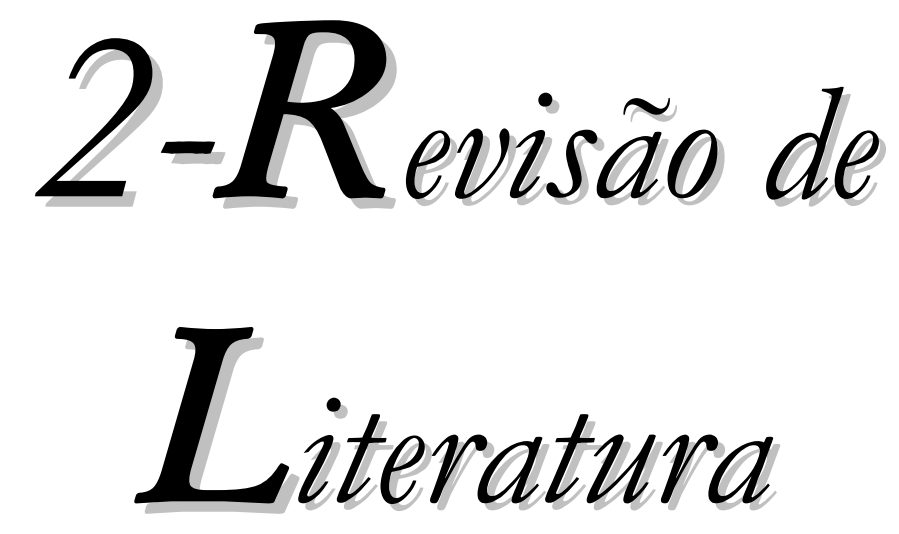





\section{2- REVISÃO DE LITERATURA:}

Esta revisão de literatura foi dividida em cinco tópicos. O primeiro tópico intitulado "As extrações na Ortodontia" ilustra quão antiga é a polêmica em torno do assunto e se subdivide em dois subtópicos que abordam os debates de grande notoriedade sobre isso: O Extraction Debate of 1911 e o Extraction Panel.

Os segundo, terceiro e quarto tópicos, denominados "Tratamento da má oclusão de Classe II sem extrações", "A época de tratamento da Classe II e o tratamento da Classe II em uma ou duas fases" e "Tratamento da má oclusão de Classe II com extrações", respectivamente, atêm-se a discorrer sobre as indicações e as contra-indicações desses tipos de tratamentos.

O quinto tópico intitulado "Estabilidade do tratamento ortodôntico" foi subdividido em "Estabilidade das correções ortodônticas", que abrange os artigos em que a estabilidade é avaliada considerando amostras heterogêneas quanto ao tipo de má oclusão estudada e "Estabilidade do tratamento da Classe II", em que estão inseridos os trabalhos cujas amostras são constituídas exclusivamente por pacientes com esse tipo de má oclusão.

\section{1) As extrações na Ortodontia}

\subsection{1) "Extraction debate of 1911".}

O "Extraction Debate of 1911" constituiu-se de uma série de artigos publicados nesta época sobre as extrações dentárias na Ortodontia. O principal motivo das discussões era a discordância de opiniões entre os seguidores e os opositores da filosofia de Angle, o líder da denominada "nova escola" da Ortodontia e que instituiu o conceito de que a manutenção de todos os dentes na boca era o princípio básico para a correção das más oclusões.

Esses artigos foram publicados em 1912 na revista Dental Cosmos e republicados, em 1964, no American Journal of Orthodontics. O primeiro artigo sobre o assunto foi escrito por Case ${ }^{56}$ sob o título "The Question of Extraction in Orthodontia" e outros autores como CRYER; DEWEY ${ }^{61}$ (1964), FERRIS ${ }^{74}$ (1964) fizeram críticas ao artigo de Case, que respondeu a elas 
posteriormente ${ }^{55}$. Os motivos que deram notabilidade a este capítulo da Ortodontia foram tanto o assunto em pauta quanto a participação de importantes precursores dessa ciência.

Segundo $\operatorname{ANGLE}^{8}$ (1907), a natureza não concederia dentes em desarmonia com a boca e com a face de um indivíduo e, portanto, as extrações dentárias não deveriam ser realizadas com finalidade ortodôntica.

Para CASE $^{56}$ (1964), as extrações dentárias poderiam ser empregadas, nas más oclusões de Classe I de Angle, para a correção de biprotrusão maxilar associada às deformidades faciais de etiologia hereditária. De acordo com os seguidores de Angle, as biprotrusões não eram consideradas más oclusões e, portanto, não requereriam tratamento, já que a relação sagital dentária dos primeiros molares era normal.

O tratamento das más oclusões de Classe II, segundo $\mathrm{ANGLE}^{8}$ (1907), poderia ser realizado pela protrusão dos dentes inferiores, pela distalização dos dentes superiores ou pela estimulação do crescimento mandibular. Para CASE $^{56}$ (1964), somava-se a esses protocolos de tratamento a realização das extrações dentárias, que poderiam ser de dois pré-molares superiores seguidas de retração do segmento ântero-superior, objetivando-se alcançar uma melhor estética facial e estabilidade. As extrações, porém, seriam contra-indicadas em casos de retrusão dos dentes inferiores associada a uma mandíbula bem posicionada e a dentes superiores bem posicionados ou ligeiramente protruídos.

Para CRYER; DEWEY61 (1964) as extrações poderiam ser realizadas apenas com o objetivo de tornar o tratamento mais fácil em casos especiais, ou seja, no tratamento de pacientes que não colaboravam durante a consulta, debilitados ou portadores de epilepsia. De acordo com esses autores, a relação molar de Classe I constitui a base da Odontologia e as biprotrusões maxilares não deveriam ser tratadas com extrações dentárias por serem características próprias da raça negra e, portanto, normais.

FERRIS $^{74}$ (1964) demonstrou ser absolutamente contra as extrações dentárias afirmando que cada dente exerceria uma função importante e que as extrações promoveriam alterações das condições fisiológicas normais como o aumento da secreção salivar e prejuízo na digestão dos alimentos. Para ele, as 
extrações de pré-molares seriam necessárias apenas em um a cada 500 casos.

$\operatorname{CASE}^{55}$ (1964), em resposta às críticas ao seu artigo, afirmou que DEWEY ${ }^{61}$ (1964) considerava as biprotrusões maxilares normais, pois não poderiam ser tratadas segundo os princípios de seu professor Angle. Concluiu que o progresso da Ortodontia ocorreria graças à existência de ortodontistas que não seguiriam a regra de nunca se extrair dentes. Afirmou ainda que as más oclusões poderiam (e não deveriam) ser tratadas com extrações dentárias e que as conseqüências indesejáveis desse procedimento decorriam, geralmente, de erro no planejamento ou do uso de uma mecânica inadequada.

\subsection{2) "Extraction Panel".}

Em 1944, foi publicado no American Journal of Orthodontics and Oral Surgery (atual American Journal of Orthodontics and Dentofacial Orthopedics) uma série de artigos que discutiam a realização de extrações com finalidade ortodôntica, o Extraction Panel.

$\mathrm{HAHN}^{96}$ (1944) relatou que a questão das extrações na Ortodontia era polêmica desde o século XVIII (1740, aproximadamente) quando a extração dos primeiros pré-molares superiores, associada à expansão do arco dentário inferior para a correção das más oclusões de Classe II, Divisão 1, era freqüentemente indicada. A polêmica decorria do fato de existirem autores na época que afirmavam que a manutenção de todos os dentes era fundamental.

A partir de então, durante o século $\mathrm{XIX}$, vários profissionais expuseram suas opiniões a respeito da realização das extrações dentárias com a finalidade de corrigir as más oclusões. Havia aqueles que afirmavam que as extrações só deveriam ser realizadas em casos extremos, e outros que se apresentavam indecisos a respeito do assunto, condenando as extrações dentárias a princípio e admitindo-as posteriormente.

TWEED $^{215}$ (1944) afirmava que durante os anos em que seguia a filosofia da não-extração a taxa de sucesso dos tratamentos era menor do que $20 \%$, ou seja, os resultados obtidos não apresentavam estabilidade, não promoviam saúde dos tecidos bucais, eficiência funcional e/ou estética facial agradável. Quando passou a admitir a realização das extrações dentárias como uma alternativa eficiente para a correção de discrepâncias entre a base óssea 
e os dentes, deixou de protruir os dentes na base óssea, e de ocasionar uma nova má oclusão, a biprotrusão, que apresentava altos índices de recidiva. Segundo ele, a extração de quatro pré-molares no tratamento de biprotrusões maxilares permitia que se atingissem cinco dos seis requisitos de uma oclusão normal, enquanto que, sem extração atingir-se-iam apenas dois. Os requisitos considerados eram a presença de todos os dentes, a relação normal de oclusão entre cúspides e fossas, as inclinações axiais normais dos dentes, a relação normal entre os dentes e suas bases ósseas, a relação normal das bases ósseas entre si e com o crânio e a função normal.

BRODIE $^{48}$ (1944) afirmava ser imprescindível avaliar criteriosamente se a magnitude da má oclusão justificaria as extrações dentárias. Quando se optava por este tipo de tratamento, tornava-se necessário realizar uma mecânica que maximizasse a retração anterior e minimizasse a perda de ancoragem. Segundo ele, era importante avaliar criteriosamente as novas filosofias antes de adotá-las.

Em 1947, SAGE ${ }^{185}$ relatou sua experiência clínica e assegurou que a maioria dos casos poderia ser tratada eficientemente sem extrações dentárias. Entretanto, em alguns casos, as extrações eram inevitáveis, como no tratamento de alguns pacientes adultos, por exemplo.

Diante disso, fica evidente que a realização de extrações dentárias com finalidade ortodôntica é um assunto polêmico desde os primórdios da Ortodontia e ele continuou sendo amplamente discutido na literatura nos anos subseqüentes, como será descrito nos próximos tópicos.

\section{2) Tratamento da Classe II sem extrações dentárias:}

Enquanto alguns autores condenam veementemente a realização de extrações dentárias com finalidade ortodôntica, outros contraindicam essa prática somente em algumas ocasiões específicas.

Como dito anteriormente, Angle e seus seguidores figuram como aqueles que condenam absolutamente essa prática assim como os integrantes de um grupo, o "Functional Orthodontists" (membros da "American Association of Functional Orthodontists") que sugerem que a realização de extrações ocasiona um travamento distal da mandíbula, potencialmente causador de 
desordens temporomandibulares (DTMs), comprometimento da estética facial e redução da dimensão vertical ${ }^{39,172 ~ 40,70,202}$.

Todavia, na literatura, outros autores ${ }^{23,66,133,146}$ contradizem essa filosofia, pois não encontraram relação entre extrações e DTMs, entre DTMs e a utilização de elásticos de Classe $\|^{157,164}$ e nem a ocorrência de resultado estético desagradável devido às extrações dentárias ${ }^{60,145}$. Segundo BOLEY et al. $^{37}$ (1998), o correto diagnóstico e tratamento são fatores que determinam o grau de harmonia facial resultante do tratamento e não a presença ou a ausência dos pré-molares.

Quanto às contra-indicações específicas das extrações, pode-se citar o tratamento de pacientes que ainda apresentam potencial de crescimento ativo dos maxilares e/ou estão com o desenvolvimento dentário incompleto e o tratamento de pacientes que apresentam padrão horizontal de crescimento com sobremordida excessiva, por haver maior dificuldade no fechamento dos espaços das extrações devido ao fato da musculatura peribucal se apresentar mais forte, além de aumentar a complexidade e o tempo de tratamento ${ }^{12,24}$.

Segundo ALEXANDER; SINCLAIR; GOATES ${ }^{2}$ (1986), no tratamento de pacientes adultos, a extração de quatro pré-molares não é vantajosa por promover o aumento da amplitude dos movimentos dentários, do desconforto para o paciente, do tempo de tratamento, do potencial de reabsorção radicular e aumentar a possibilidade de ocorrência de problemas periodontais. Dessa forma, as extrações dentárias no arco dentário inferior devem ser evitadas e em casos de apinhamentos suaves, pode-se optar pela extração de um incisivo inferior ou pela realização de desgastes interproximais.

Considerando a existência de várias formas de tratamento para a correção da Classe II, a seleção do protocolo dependerá, entre outros fatores, da época de intervenção, da gravidade da má oclusão, da falta de espaço nos arcos dentários superior, inferior ou em ambos e da idade do paciente ${ }^{49,205}$. A decisão pelo tratamento ortodôntico com ou sem extrações dentárias é guiada pela morfologia facial, pelo padrão de crescimento, pelo grau de motivação do paciente com o tratamento, pela magnitude da protrusão dos lábios, pela presença de apinhamento e pela estabilidade dos resultados obtidos com os tipos de tratamento disponíveis ${ }^{20,28,138}$. 
Para a realização do tratamento das más oclusões de Classe II sem extrações dentárias, pode-se optar pelo emprego de aparelhos extrabucais $^{12,92,104}$, dos distalizadores intrabucais ${ }^{38,54,124}$, dos aparelhos fixos associados aos elásticos de Classe $\|^{163,221}$ ou dos aparelhos ortopédicos, em pacientes que ainda apresentam expressivo potencial de crescimento ${ }^{65,112,123}$. Contudo, quando não há crescimento e nota-se uma deficiência mandibular severa associada a um padrão de crescimento vertical, pode ser necessária uma abordagem cirúrgica para garantir estética facial agradável, função normal e estabilidade das correções ${ }^{60,77}$.

Os aparelhos extrabucais são aparelhos utilizados com grande freqüência por promoverem alteração no crescimento e desenvolvimento facial, modificação permanente da relação dos dentes com suas respectivas bases ósseas, distalização efetiva dos dentes superiores, rotação horária do plano oclusal e do plano mandibular, além de guiar a erupção dentária durante a dentadura mista ${ }^{65,104,154,156,173}$. Entretanto, os efeitos desses aparelhos dependem de um crescimento favorável e de excelente cooperação do paciente por requerer, geralmente, uso intenso e a cooperação pode ser prejudicada por sua característica antiestética ${ }^{104,107,173}$, reduzindo, desta forma, sua efetividade em casos de grandes apinhamentos ou de protrusão maxilar acentuada $^{230}$.

Esses aparelhos podem ainda provocar inclinação distal excessiva dos primeiros molares superiores, impacção dos segundos e terceiros molares superiores e não corrigir completamente a relação molar ${ }^{92}$. Alguns autores constataram que a distalização dos molares superiores apenas, pode ser insuficiente para corrigir a relação molar, pois uma movimentação mesial do molar inferior geralmente é requerida ${ }^{15}$.

Os elásticos de Classe II produzem inclinação do plano oclusal, aumento da altura facial ântero-inferior, extrusão e lingualização dos incisivos superiores e mesialização dos molares inferiores. Pela utilização dessa mecânica, a maioria das correções obtidas é dentária e a correção da relação molar ocorre, principalmente, devido à mesialização dos molares inferiores $^{163,221}$.

Os aparelhos ortopédicos funcionais (Bionator, Ativador, Fränkel entre outros) são indicados apenas se o paciente portador da má oclusão de 
Classe II ainda se encontrar na fase de crescimento craniofacial ativo. Esses aparelhos redirecionam o crescimento maxilar e/ou mandibular e proporcionam, dessa forma, a diminuição ou até mesmo a correção da discrepância ânteroposterior existente, além de promover a reeducação das funções motoras e do tônus muscular, otimizando o desenvolvimento das estruturas bucofaciais. Entretanto, os aparelhos ortopédicos funcionais não podem ser considerados como substitutos da cirurgia ortognática e nem das extrações dentárias, pois não criam espaços numa dentição excessivamente protruída e apinhada ${ }^{123}$.

Os aparelhos ortopédicos mecânicos (Herbst, Jasper Jumper, CBJ, APM entre outros) possuem as mesmas indicações, os mesmos efeitos e mecanismo de ação que os funcionais, apresentando a vantagem adicional de serem fixos e diminuírem a necessidade de colaboração do paciente ${ }^{132,168}$.

Os distalizadores intrabucais (Distal Jet, Jones Jig, Pendulum e outros) são indicados para a correção das más oclusões de Classe II dentárias e são descritos como vantajosos por não requererem a colaboração do paciente para que a distalização dos molares superiores ocorra com sucesso. Entretanto, não promovem total eliminação da necessidade de colaboração dos pacientes, pois, posteriormente à utilização desses aparelhos, é necessária a correção da posição das raízes dos molares realizada, geralmente, com um aparelho extrabucal ${ }^{86}$. Esses aparelhos, de modo geral, promovem a distalização e inclinação da coroa dos molares superiores, associada a uma mesialização e inclinação dos dentes de ancoragem, protrusão dos incisivos e aumento da altura facial ântero-inferior ${ }^{3}$.

A utilização de ancoragem absoluta como dos mini-implantes, das miniplacas entre outros elimina completamente a necessidade de colaboração e parece ser uma alternativa útil a esse problema, sendo indicada também para o tratamento da Classe II em pacientes adultos, pois estes podem se apresentar relutantes à utilização de aparelhos antiestéticos ${ }^{36,57,180}$.

Segundo JACOBS; SAWAENGKIT ${ }^{108}$, em 2002, a taxa de sucesso da correção da Classe II sem extrações e com a utilização de Bionator ou AEB, associado a um plano de mordida, é de aproximadamente $57 \%$ em pacientes com $1 / 2$ Classe II e de $40 \%$ em pacientes com mais que $1 / 2$ Classe II, no início do tratamento. Segundo VALARELLI ${ }^{219}$ (2006), a proporção de 
sucesso do tratamento da Classe II sem extração é maior, quanto menor for a severidade da má oclusão inicial.

\section{3) A época de tratamento da Classe II e o tratamento da} Classe Il em uma ou duas fases:

A época ideal para se iniciar o tratamento da Classe II ainda é um assunto que apresenta divergência de opiniões. Geralmente, essa decisão envolve a opção por um tratamento realizado em uma ou duas fases. $O$ tratamento em duas fases se inicia idealmente na pré-adolescência, na dentadura mista, com a ortopedia que é seguida do aparelho fixo. A fase mais precoce do tratamento tem como objetivo simplificar o tratamento a ser realizado com os aparelhos fixos e otimizar o desenvolvimento esquelético e a fase posterior promove o alinhamento e o nivelamento dos dentes, fechamento dos espaços e a correção de más posições dentárias ${ }^{143}$. O tratamento em uma fase, que compreende o aparelho fixo associado às mecânicas para a correção da Classe II, deve ser iniciado após o irrompimento de todos os dentes permanentes, ou seja, em uma idade mais avançada e, segundo MCCULLOGH ${ }^{150}$ (1994), ele também promove melhoria do padrão esquelético do paciente, embora de menor magnitude.

De acordo com KLOEHN ${ }^{131}$ (1947), antes do desenvolvimento da cefalometria, os pacientes jovens eram freqüentemente tratados com aparelhos ortopédicos por seis ou oito anos, pois acreditava-se que este tipo de tratamento estimularia 0 crescimento dos ossos faciais. Após 0 desenvolvimento da cefalometria, por BROADBENT ${ }^{45}$ (1931) e os estudos sobre o crescimento de $\operatorname{BRODIE}^{46}$ (1946) foi constatado que a correção das más oclusões não influenciavam o crescimento futuro dos ossos faciais e que o padrão de crescimento era imutável. Associado a isso, os constantes fracassos dos tratamentos realizados na dentadura mista e o conhecimento de que 0 crecimento é determinado geneticamente, ocasionaram a interrupção do uso dos aparelhos que visavam a modificar o crescimento. Os ortodontistas americanos racionalizaram as indicações dos aparelhos ortopédicos funcionais e passaram a utilizar as extrações seriadas e a aperfeiçoar os aparelhos fixos para a compensação, e não correção, das discrepâncias esqueléticas nos pacientes jovens $^{143}$. 
Os ortodontistas europeus, entretanto, continuaram a explorar as alternativas existentes para a modificação do crescimento, seguindo os conceitos de Andresen e Häupl ${ }^{6}$. Porém, a existente necessidade de corresponder às expectativas dos pais dos pacientes jovens de verem seus filhos sendo tratados no momento em que procuravam pelo profissional (preferindo o tratamento precoce ao tratamento em uma fase realizado posteriormente e com a possível necessidade de extrações dentárias) contribuiu para que os ortodontistas americanos mudassem novamente de filosofia, reintroduzindo o emprego dos tratamentos ortopédicos. Diante disso, a ortopedia era empregada visando à promoção de aprimoramento estético, à diminuição da necessidade de extrações dentárias e à diminuição da duração e da complexidade do tratamento ortodôntico subseqüente ${ }^{143}$.

Segundo VIAZIS ${ }^{220}$ (1995), HANIGAN ${ }^{97}$ (2001), a melhor época para se iniciar o tratamento da Classe II é a fase tardia da dentadura mista, pois torna-se possível se aproveitar ao máximo o crescimento do paciente, sem se prolongar excessivamente o tempo de tratamento, evitando o sobretratamento e o desgaste da relação entre o profissional e o paciente.

De acordo com GIANELLY ${ }^{85}$ (1995), 90\% dos pacientes jovens podem ser adequadamente tratados em uma fase com o tratamento se iniciando no final do segundo período transitório da dentadura mista, isto é, após a esfoliação de todos os dentes decíduos, exceto os segundos molares. Para a correção dos problemas mais comuns, que são o apinhamento e a Classe II, o tratamento em duas fases é desnecessário desde que o tratamento em uma fase seja iniciado nesta fase do desenvolvimento oclusal. No tratamento da Classe II, a correção da relação molar ocorre de maneira fácil em em pouco tempo pela distalização dos molares superiores associada ao crescimento mandibular. Os $10 \%$ dos pacientes jovens que requerem a correção em duas fases são aqueles portadores de uma mordida cruzada posterior ou de uma má oclusão de Classe III.

Entretanto, há autores, como RICKETTS ${ }^{177}$ (1979), ARVYSTAS ${ }^{14}$ (1998), que optam pelo tratamento em duas fases para eliminar a necessidade de futuras extrações dentárias, eliminar os fatores etiológicos da má oclusão, corrigir as mordidas cruzadas, as discrepâncias esqueléticas e de comprimento dos arcos dentários e também para supervisionar o crescimento facial. 
MOORREES $^{160}$ (1998) afirma que o tratamento precoce permite a normalização do crescimento e proporciona a obtenção de mais estabilidade nos resultados. Segundo ele, o aparecimento dos primeiros pré-molares na cavidade bucal indica que o tratamento deve ser iniciado e a mobilidade dos segundos molares decíduos representa a última chance de se evitar, se possível, a extração de quatro pré-molares posteriormente.

LIVIERATOS; JOHNSTON ${ }^{143}$, em 1995, avaliaram 96 pacientes tratados em uma fase ou em duas fases (Bionator seguido de fixo) e observaram que: 1) há uma tendência de pacientes jovens serem tratados em dois estágios quanto maior for a severidade da Classe II; 2) os dois tratamentos promovem similar correção da relação molar e da sobressaliência; 3) aparentemente há maior crescimento mandibular no tratamento em duas fases, no entanto, após o cálculo da quantidade de crescimento por ano, constata-se que a quantidade de crescimento é semelhante, pois o tratamento em duas fases tem maior duração; 4) a decisão pelo tratamento em duas fases pode ser fundamentada na preferência do ortodontista, mas não em vantagem biológica para o paciente.

BOWMAN $^{41}$ (1998) revisou os trabalhos que abordavam o tratamento em uma ou duas fases e concluiu que não há evidências suficientes para comprovar a efetividade e a estabilidade a longo prazo dos resultados obtidos com a primeira fase do tratamento. Além disso, ele afirma que, apesar da melhora oclusal ser evidente após o término da primeira fase, no final da segunda fase não há diferença oclusal entre pacientes tratados em uma ou duas fases, pois os efeitos da primeira fase tendem a desaparecer. Quanto ao desejo dos pais dos pacientes de verem seus filhos sendo tratados no momento em que procuram o tratamento, é importante considerar que o tratamento não deve ser realizado simplemente por ele existir e sim se os benefícios, desse tratamento para o paciente, forem maiores do que os custos biológicos.

TULLOCH; PHILIPS; PROFFIT'211 (1998) compararam os efeitos de dois tipos de aparelhos (Aparelho extrabucal e Bionator) utilizados na primeira fase do tratamento de duas fases e constataram que ambos ocasionaram melhora da relação maxilomandibular. Nos pacientes tratados com aparelho extrabucal, a melhora se deu devido às alterações maxilares e naqueles 
tratados com o Bionator, essa alteração decorreu do crescimento mandibular. Além disso, quanto ao tratamento em uma ou duas fases, observaram que o tratamento em duas fases apresenta um tempo menor de utilização dos aparelhos fixos, mas um maior tempo de tratamento total e que os resultados oclusais são semelhantes, independentemente do protocolo empregado. Em estudo posterior ${ }^{212}$, os mesmos autores concluíram que o tratamento em duas fases não é clinicamente mais efetivo do que o tratamento em uma fase e que não há diferença no tempo de utilização dos aparelhos fixos nos dois tipos de tratamento. Além disso, quando comparadas as porcentagens de pacientes que requerem a realização de extrações dentárias durante o tratamento com aparelhos fixos após uma fase ortopédica ou não, não se constatou diferença significante entre elas.

DOLCE et al. ${ }^{67}$, em 2005, compararam os resultados do tratamento em uma ou duas fases de 200 pacientes e constataram que os efeitos esqueléticos da primeira fase desaparecem após o tratamento com aparelhos fixos.

CANÇADO ${ }^{52}$, em 2005, avaliou comparativamente os resultados oclusais e a eficiência do tratamento em uma e duas fases e concluiu que em ambos os resultados oclusais são semelhantes, mas que a eficiência é maior no tratamento em uma fase.

Pode-se optar pelo tratamento em duas fases, considerando-se que a correção dos problemas funcionais é tão importante quanto a correção do retrognatismo mandibular, do perfil e da relação esquelética entre os maxilares. Apesar de a literatura demonstrar que há ausência de superioridade do tratamento em duas fases em relação ao tratamento em uma fase, ainda há autores que afirmam que o tratamento ortopédico funcional, que visa à reabilitação funcional, é menos traumático e permite a correção mais natural da má oclusão, além de apresentar mais estabilidade ${ }^{136}$.

\section{4) Tratamento da Classe II com extrações dentárias:}

Nos casos em que o potencial de crescimento é limitado e o apinhamento dentário ou a protrusão dentoalveolar é de grande magnitude, as extrações podem ser realizadas para promover aprimoramento estético, funcional e oclusal ${ }^{49}$. 
TWEED ${ }^{213,214}$, em 1936, passou a indicar as extrações dentárias dos primeiros pré-molares superiores e inferiores, objetivando obter um melhor posicionamento dos dentes, ou seja, posicioná-los idealmente quanto às suas inclinações axiais na base óssea. Para que essa nova filosofia de tratamento fosse aplicada, mudanças na mecanoterapia foram instituídas pelo próprio Tweed, que desenvolveu o preparo de ancoragem, modificando a filosofia e a mecânica vigentes até então, preconizadas por $\operatorname{ANGLE}^{9}$ (1907).

Para indicar a realização ou não de extrações dentárias, Tweed se baseava em valores cefalométricos padrões, desenvolvidos por ele em sua análise cefalométrica ${ }^{216}$. Contudo, com o passar do tempo, outros autores passaram a admitir posicionamentos dentários diferentes daqueles preconizados por Tweed, tomando os valores padrões como guia e não como fatores decisivos durante a opção pela realização de extrações dentárias ${ }^{93,188}$.

Segundo STRANG ${ }^{205}$ (1957), alguns fatores devem ser considerados durante a seleção dos dentes a serem extraídos, como: 1) a magnitude da má oclusão: nos casos de biprotrusões, é indicada a extração dos quatro primeiros pré-molares; 2) $\mathrm{O}$ crescimento dos maxilares: se a mandíbula cresceu o bastante para dar lugar a todos os dentes, mas a maxila apresenta apinhamento e rotações dentárias, pode ser aconselhável extrair os segundos molares superiores e utilizar o amplo espaço adquirido para a movimentação distal de todo o arco superior e 3) a idade do paciente: no tratamento de pacientes com idade mais avançada e dentes bem alinhados, em que se deseja minimizar o tempo de tratamento, podem-se extrair os primeiros pré-molares superiores apenas

Especificamente para a correção da Classe II bilateral com significantes apinhamentos superior e inferior, pode-se realizar a extração de quatro pré-molares, sendo dois superiores e dois inferiores ${ }^{116,205,214}$, e quando o apinhamento é suave ou inexistente no arco dentário inferior, pode-se optar pela extração de apenas dois pré-molares superiores, geralmente os primeiros pré-molares ${ }^{80,81,128,207}$.

TERRY $^{207}$ (1969) sugere que, nos casos em que a discrepância se encontra limitada à maxila, pode-se empregar a extração dos dois segundos pré-molares superiores, por eles serem menores do que os primeiros prémolares e possibilitarem uma melhor intercuspidação. 
BELL; JACOBS; LEGAN ${ }^{24}$ (1984) afirmam que a extração dos segundos pré-molares superiores associada à extração dos primeiros prémolares inferiores fornece ancoragem máxima ao arco dentário inferior para aliviar o apinhamento, que é, geralmente, maior nesse arco, maximizando a retração dos incisivos inferiores em direção a uma posição de mais estabilidade.

Vários estudos já foram e continuam sendo realizados para comparar os efeitos dos tratamentos realizados com ou sem extrações.

LITT $^{138}$ (1984) avaliou os resultados do tratamento de dois jovens gêmeos com má oclusão de Classe II, com quantidades semelhantes de apinhamento, sendo que um deles foi tratado com a extração dos quatro primeiros pré-molares e, o outro, sem extrações dentárias. Constatou que os dois tratamentos apresentaram o mesmo resultado, ou seja, nenhuma modalidade de tratamento apresentou melhores efeitos do que a outra.

YAMAGUCHI; NANDA ${ }^{229}$ (1991), não comprovaram a ocorrência de diferenças esqueléticas significantes na dimensão vertical entre o tratamento da Classe II com elásticos intermaxilares ou aparelho extrabucal e o tratamento com extrações dentárias.

GOTTLIEB; NELSON; VOGELS ${ }^{89}$ (1991) realizaram um levantamento por meio de questionários aplicados à ortodontistas com o objetivo de listar os procedimentos mais utilizados na prática diária da especialidade. Quanto ao protocolo de extrações dentárias mais empregado constatou-se que houve uma diminuição da indicação da extração dos quatro pré-molares (de 74,7\% das indicações, em 1986, para 42,9\%, em 1990) e que o segundo protocolo de extrações mais utilizado foi a extração de dois prémolares superiores com $20,2 \%$ do total de indicações. Apesar da extração dos quatro primeiros pré-molares ser o tipo de tratamento aparentemente mais indicado, PROFFIT ${ }^{174}$ (1994) constatou que, nos últimos 40 anos, a freqüência desse tipo de extração diminuiu significativamente e se igualou à porcentagem de outros tipos de extrações, como a extração de dois pré-molares superiores ou a extração dos primeiros pré-molares superiores associada à extração dos segundos pré-molares inferiores.

No tratamento da Classe II com a extração de quatro pré-molares, o espaço das extrações no arco dentário inferior deve ser inteiramente ocupado 
pelos molares e pré-molares. Se mais de um terço desse espaço da extração for utilizado para a correção do apinhamento anterior ou para a retração dos incisivos, a obtenção de uma relação de Classe I de molares e caninos se torna difícil de ser obtida e pode se tornar necessário o emprego da mecânica de Classe II, como os elásticos intermaxilares ou o aparelho extrabucal ${ }^{50}$. O sucesso do tratamento dependerá de compensações dentoalveolares e da minimização dos efeitos indesejáveis que acompanham as mecânicas de Classe II. Além disso, surge a dificuldade de se manter a posição distal dos molares superiores enquanto eles são utilizados como ancoragem para a retração dos dentes anteriores ${ }^{43,81,116,182}$.

Segundo GRABER ${ }^{92}$ (1955), aproximadamente dois terços dos pacientes Classe II, Divisão 1, possuem discrepâncias restritas à maxila e, portanto, arcos dentários inferiores normais quanto à forma e às posições dentárias. A extração de dois pré-molares superiores permite a redução efetiva da protrusão da pré-maxila, a correção da sobressaliência excessiva, possibilita o restabelecimento da harmonia muscular, além de demandar menos movimentação dentária e menos tempo de tratamento. Entretanto, ela pode ocasionar o aumento do apinhamento dos incisivos inferiores no período póscontenção, por restringir o arco dentário inferior às dimensões do arco superior, apesar de essa alteração ocorrer em parte pelo crescimento mandibular tardio normal e ser observada também quando se realiza o tratamento ortodôntico sem extrações dentárias. JANSON et al. ${ }^{111}$ (2006), constataram que o alinhamento ântero-inferior apresenta estabilidade semelhante quando $\mathrm{O}$ tratamento é realizado com extrações de dois pré-molares superiores e com a extração de quatro pré-molares.

Nos casos em que se indica a extração de apenas dois pré-molares superiores e em que o arco dentário inferior possui pequeno apinhamento, é necessária a instituição de medidas que propiciam o ganho de espaço para a correção desse apinhamento. Os procedimentos mais utilizados para isso são os desgastes interproximais, a vestibularização dos incisivos, a extração de um incisivo ou a expansão maxilar².

Os desgastes interproximais apresentam mais vantagem em relação às extrações dentárias porque reduzem o tempo de tratamento e permitem que se crie exatamente a quantidade de espaço necessária para a correção do 
apinhamento, além de aumentar a estabilidade sem aumentar a chance de ocorrência de cáries interproximais ${ }^{122}$. As desvantagens incluem o aumento das chances de ocorrerem problemas periodontais devido à aproximação das raízes e a criação de discrepância de massa dentária entre os arcos dentários, quando o desgaste é realizado em apenas um deles ${ }^{11,195}$.

A vestibularização dos incisivos inferiores é uma opção que deve ser utilizada criteriosamente e de maneira limitada por apresentar potencial aumentado de recidiva ${ }^{2}$. A extração de um incisivo inferior permite que se corrijam apinhamentos de magnitude moderada com a vantagem de o espaço ser criado exatamente na região em que o problema está presente. Todavia, pode haver dificuldade de fechamento do espaço ou ocorrer do espaço reabrir posteriormente, ocasionando comprometimento estético ${ }^{53}$.

A expansão maxilar promove principalmente ganho de espaço no arco dentário superior. Entretanto, algum aumento do perímetro do arco inferior sempre ocorre e este espaço, embora de pequena magnitude, pode ser suficiente para a correção do apinhamento ântero-inferior ${ }^{151}$.

Há autores que afirmam que o tratamento com extração de dois prémolares superiores proporciona um melhor posicionamento ântero-posterior dos caninos, uma melhor correção da sobremordida e da sobressaliência, depende menos da colaboração dos pacientes e é mais eficiente do que o tratamento realizado com a extração de quatro pré-molares ${ }^{16,116}$. Além disso, segundo a literatura, a relação molar de Classe II que é mantida, com esse protocolo de tratamento, não prejudica a eficiência mastigatória ${ }^{50,90,128,133}$.

Outros autores, entretanto, afirmam que esse tipo de tratamento proporciona resultados instáveis a longo prazo, promove um degrau distal no dente mais posterior em oclusão, é morfologica e fisiologicamente prejudicial e não fornece uma intercuspidação posterior ideal no final do tratamento ${ }^{91,144,147,175}$. Além disso, promove a rotação posterior da mandíbula e o aumento do ângulo SNB, pois a extração desses dentes inibe o crescimento anterior da mandíbula ${ }^{35,155}$, apesar de que essas associações não foram encontradas por BATTAGEL ${ }^{19}$ (1990). Segundo CONLEY; JERNIGAN ${ }^{60}$ (2006), esse protocolo de extrações ocasiona retrusão dos lábios superior e inferior, aumento da altura facial ântero-inferior e aumento do ângulo nasolabial porém, 
essas alterações podem ser admissíveis no tratamento de pacientes com lábios espessos e com deficiência mandibular relativa.

GIANELLY; COZZANI, BOFFA ${ }^{87}$ (1991) compararam, em tomografias, a posição condilar de pacientes Classe II, tratados e não tratados com a extração de dois pré-molares superiores e não constataram diferença entre os grupos, corroborando os resultados de LUECKE; JONHSTON ${ }^{145}$ (1992).

\section{5.) Estabilidade do tratamento ortodôntico:}

\subsection{1.) Estabilidade das correções ortodônticas:}

Alguma alteração nas posições dentárias sempre ocorre após o término do tratamento ortodôntico ${ }^{88,103}$. Entretanto, a recidiva dificilmente é suficientemente expressiva a ponto de ocasionar o retorno das relações dentárias à condição presente no início do tratamento ${ }^{187,206}$ e a magnitude e o tipo dessa alteração é imprevisível por sofrer ampla variabilidade individual ${ }^{141}$.

Vários fatores estão associados ou são responsáveis pela estabilidade das correções ortodônticas, como o correto posicionamento dos dentes nas bases ósseas ${ }^{215}$, o estabelecimento do equilíbrio entre os músculos intra e extrabucais ${ }^{47,181}$, a manutenção da distância intercaninos e intermolares ${ }^{83}$ e a obtenção de uma excelente oclusão dentária ${ }^{149,178}$.

É de fundamental importância conhecer as alterações decorrentes do crescimento para diferir a recidiva dessas alterações, ou seja, para não se classificar as alterações normais como recidiva, mesmo porque sempre ocorrem alterações nas dimensões dos arcos dentários da dentadura decídua para a permanente ${ }^{17}$ e alterações normais nas posições dentárias e nas bases ósseas após a remoção dos aparelhos. Essas alterações podem ser favoráveis ou desfavoráveis à estabilidade, dependendo da direção e da magnitude do crescimento craniofacial $^{34}$.

Determinadas alterações instituídas durante o tratamento também se encontram associadas à ocorrência de alterações pós-tratamento como, por exemplo, a extrusão dos molares superiores devido à falta de controle vertical ou a aplicação de forças descontroladas, ambas associadas à presença de menos estabilidade ${ }^{156}$. 
De acordo com MIYAZAKI ${ }^{159}$ (1998), no tratamento de pacientes adultos, observa-se menos estabilidade nas correções obtidas, pois 0 crescimento mandibular para baixo e para frente, que é favorável para a manutenção das correções da Classe II, não ocorre nesses pacientes.

Contudo, para HARRIS et al. ${ }^{100}$ (1994), as alterações dentárias após o tratamento nos adolescentes são maiores do que nos adultos, embora apresentem magnitude insignificante, pois são compensadas pelo crescimento mandibular mais acentuado. A maior ocorrência de apinhamento após o tratamento, verificada na maioria dos pacientes adolescentes, pode estar relacionada a alterações decorrentes do crescimento e do desenvolvimento normal, como a diminuição do comprimento do arco dentário, a diminuição da distância intercaninos e a pequenas alterações na sobremordida e sobressaliência ${ }^{199}$. Essas alterações, quando indesejadas, podem ser minimizadas pela utilização de contenção por um período mais prolongado, ou seja, até cessar o crescimento ${ }^{159}$.

Quando avaliaram a estabilidade das correções das más oclusões de Classe I e de Classe II, EL-MANGOURY ${ }^{71}$ (1979), UHDE; SADOWSKY; BEGOLE $^{217}$ (1983), SHIELDS; LITTLE, CHAPKO ${ }^{196}$ (1985) não observaram relação entre a quantidade de recidiva e o tipo de má oclusão tratada. $A$ relação entre a magnitude da recidiva e o tipo de tratamento empregado, seja ele realizado com ou sem extrações dentárias, não foi encontrada por ELMANGOURY ${ }^{71}$ (1979). Outros autores, todavia, verificaram que a estabilidade é maior quando não se realizam extrações dentárias ${ }^{125}$, assim como no tratamento de más oclusões de Classe $\mathrm{I}^{44,125}$.

Quanto à estabilidade da relação molar, diversos autores constataram que a relação molar apresenta recidiva dentro de limites aceitáveis, ou seja, clinicamente insignificante ${ }^{59,198,217}$. LITTLE; WALLEN; RIEDEL ${ }^{141}$ (1981) concluíram que a estabilidade da sobressaliência obtida com o tratamento se expressa independentemente do tipo de má oclusão inicial e outros autores encontraram uma relação inversamente proporcional entre a estabilidade e a magnitude da sobressaliência inicial ${ }^{217}$.

A maioria dos estudos concorda que a recidiva da sobremordida corrigida está diretamente relacionada ao retorno dos incisivos às suas inclinações presentes no início do tratamento ${ }^{71,198}$, o que independe da 
realização de intrusão nesses dentes durante o tratamento ${ }^{71,201}$ e não está relacionado à realização ou não de extrações dentárias ${ }^{71,198,217}$. Entretanto, há estudos que asseguram que a recidiva da sobremordida é maior nos tratamentos com extrações ${ }^{59}$ e nos casos em foi empregada a intrusão dos incisivos para a correção da sobremordida excessiva ${ }^{196}$. Quando há predominância de um vetor de crescimento horizontal durante e após o tratamento, a sobremordida também parece apresentar mais recidiva ${ }^{198}$.

SONDHI; CLEALL; BEGOLE ${ }^{201}$ (1980) estudaram as alterações póscontenção dos arcos dentários e concluíram que o aumento da distância intercaninos ocasionada pelo movimento distal dos caninos inferiores não é estável e que a estabilidade da sobremordida corrigida é aumentada se houver, posteriormente ao tratamento, movimento eruptivo (extrusão) dos primeiros molares.

SADOWSKY; SAKOLS ${ }^{183}$ (1982) avaliaram pacientes Classe I e Classe II tratados sem extrações dentárias e concluíram que a recidiva da sobremordida corrigida é a que ocorre com mais freqüência, seguida do apinhamento ântero-inferior e da sobressaliência.

SCHÜTZ-FRASSON; BJERKLIN; LINDSTEN ${ }^{194}$ (2006) avaliaram a estabilidade da correção da sobremordida profunda e não constataram diferença entre a estabilidade nos pacientes tratados com aparelhos funcionais e os tratados com aparelhos fixos e sem extrações. Quando compararam esses pacientes com os não tratados, observaram que a sobremordida corrigida tendeu a recidivar, mas continuou apresentando valores dentro do padrão de normalidade.

Para SHIELDS; LITTLE; CHAPKO ${ }^{196}$ (1985), a realização de extração de quatro pré-molares no tratamento da Classe II permite tratar efetivamente os casos de protrusão severa com discrepâncias dente-osso de grande magnitude, além de promover 0 aumento da estabilidade dos resultados obtidos.

Segundo alguns autores, para assegurar a estabilidade dos casos tratados de Classe II completa com protrusão maxilar excessiva, arco mandibular bem alinhado e com ausência de diastemas é melhor se extrair os dois pré-molares superiores, manter os dentes posteriores em suas posições e retrair o segmento anterior do que movimentar os dentes inferiores e propiciar 
uma possível recidiva. A relação molar de Classe II completa mantida é firme e permanente, as inclinações favoráveis dos dentes anteriores superiores e inferiores ajudam a aumentar a estabilidade da sobremordida corrigida e a utilização eventual de mecânica de Classe II diminui o tempo de contenção necessária no arco inferior ${ }^{2,90,102}$.

Segundo KESSEL ${ }^{128}$ (1963), a rotação mesiolingual do primeiro molar permanente, que ocorre nesse tipo de tratamento, aumenta a estabilidade da sobressaliência corrigida, pois a cúspide mesiovestibular estabelece firme contato com a aresta distal da cúspide vestibular do segundo pré-molar.

Esse protocolo de tratamento pode ser empregado em pacientes adultos, uma vez que as extrações são minimizadas, e isto é desejável, pois a tendência que os espaços das extrações apresentam de se abrirem após a remoção da contenção é maior nos pacientes adultos do que nos adolescentes $^{2}$.

\subsection{2) Estabilidade do tratamento da má oclusão de Classe II:}

Considerando-se que o paciente que possui uma má oclusão de Classe II, Divisão 1, geralmente, pode apresentar uma associação de alterações dentárias, musculares, ósseas e nervosas, torna-se necessário o restabelecimento da harmonia entre todos esses sistemas para se obter estabilidade dos resultados do tratamento. Desta forma, um dos objetivos do tratamento dessa má oclusão é a eliminação da atividade muscular anormal adaptativa, em que o lábio inferior se posiciona lingualmente aos incisivos superiores e da pressão excessiva que os músculos jugais exercem sobre o arco dentário inferior ${ }^{94}$.

Além disso, para minimizar a recidiva, é imprescindível a utilização de forças bem controladas durante o tratamento, visando-se a evitar a inclinação do plano oclusal e o aumento do ângulo formado entre o plano mandibular e a base do crânio ${ }^{105}$. A ocorrência de crescimento favorável da mandíbula, ou seja, em sentido ântero-inferior, é igualmente essencial para a manutenção permanente das alterações empregadas ${ }^{58,100,105}$.

Enquanto alguns autores observaram estabilidade nos valores de SNA e ANB, em pacientes Classe II tratados sem extrações dentárias ${ }^{154,225}$, na 
literatura há relato de que a relação molar pode ser instável quando corrigida pela distalização dos molares superiores, durante a dentadura mista ${ }^{58}$.

Segundo MELSEN ${ }^{153}$ (1978), após a distalização dos molares superiores pelo aparelho extrabucal, geralmente há o retorno da direção de crescimento em sentido anterior e inferior, que havia sido alterada durante 0 tratamento. Isso, porém, não ocasiona a recidiva da relação molar devido à associação dessa alteração ao crescimento mandibular em direção anterior. Contudo, se os pacientes apresentarem idade mais avançada, quando o crescimento ocorre de maneira mais limitada ou há discrepância de crescimento maxilomandibular, essa alteração pode ser indesejável e ocasionar uma recidiva e, nesses casos, pode ser mais favorável o emprego de um tratamento com extrações. De acordo com PAQUETTE; BEATTIE; JOHNSTON $^{170}$ (1992), MIHALIK; PROFFIT; PHILIPS ${ }^{157}$ (2003), no tratamento desses pacientes, a extração de dois pré-molares superiores pode ser extremamente vantajosa, visto que a relação molar de Classe II completa é mantida.

Enquanto UHDE; SADOWSKY; BEGOLE ${ }^{217}$ (1983) afirmam que a relação molar tende sempre à Classe II, FISHER $^{76}$ (1941) assegura que a relação molar de Classe II corrigida é a condição mais estável obtida com o tratamento ortodôntico. A recidiva da sobressaliência independe do tipo de tratamento realizado e é proporcional à sua magnitude inicial ${ }^{103,162}$.

As inclinações dos incisivos superiores ocasionadas pelo tratamento ortodôntico, com a finalidade de remover as compensações dentárias presentes na má oclusão de Classe II e de corrigir a sobremordida profunda, apresentam tendência a retornar às suas posições iniciais, assim como a correção da sobremordida profunda em pacientes que apresentam padrão de crescimento horizontal por meio da extrusão dos dentes posteriores e do aumento da altura facial ântero inferior ${ }^{24,26,191}$. A relação entre a estabilidade da sobremordida corrigida e a realização ou não de extrações não foi encontrada por HELLEKANT et al. ${ }^{103}$ (1989).

De acordo com $\operatorname{COBEN}^{58}$ (1971), a correção da Classe II pela movimentação dentária, quando não há espaços ou crescimento ativo, requer a movimentação distal dos dentes superiores associada à movimentação mesial dos dentes inferiores. Quando a correção da Classe II é realizada na dentadura 
mista, principalmente com a movimentação distal dos molares superiores instituída antes do irrompimento dos segundos molares, os resultados tendem a ser instáveis, a menos que o crescimento facial subseqüente estabilize as correções.

A correção da Classe II sem extrações dentárias e com a utilização do aparelho extrabucal de tração cervical promove diminuição dos ângulos ANB e SNB, alteração da relação molar e redução da sobremordida e essas alterações apresentam relativa estabilidade ${ }^{158,225}$. Isso porque sempre ocorre alguma recidiva da restrição do desenvolvimento dos molares superiores para frente e para baixo e da inclinação distal da coroa dos molares ${ }^{154}$. Contudo, a relação molar de Classe I instituída se mantém inalterada no período póstratamento, devido à alteração no padrão de desenvolvimento dos molares superiores e ao aprimoramento da relação muscular e oclusal desses dentes com as demais estruturas faciais ${ }^{224}$.

Segundo GLENN; SINCLAIR, ALEXANDER ${ }^{88}$ (1987), pacientes Classe II com valores altos de ANB e comprimento mandibular deficiente, tratados sem extrações dentárias, tendem a apresentar um aumento do apinhamento, arcos dentários diminuídos e sobremordida profunda, no estágio pós-contenção. Entretanto, a sobressaliência e a sobremordida permanecem relativamente estáveis após o tratamento e o padrão de recidiva desses pacientes é semelhante ao de pacientes não tratados e de tratados com extração de quatro pré-molares, embora com magnitude intermediária à deles.

ELMS; BUSHANG; ALEXANDER ${ }^{73}$ (1996), ao estudarem a estabilidade do tratamento da Classe II, Divisão 1, realizado sem extrações dentárias (com AEB), observaram que, após 6,5 anos, em média, a sobremordida e a sobressaliência recidivaram 0,5mm e 0,4mm, respectivamente e que as medidas angulares não apresentaram alterações estatisticamente significantes. A recidiva da sobremordida observada foi parcial e limitada aos casos em que os incisivos foram excessivamente inclinados para vestibular, durante o tratamento. Diante disso, concluíram que os resultados do tratamento são mantidos quando é realizado um diagnóstico criterioso, há colaboração do paciente com o tratamento, o padrão de crescimento é favorável e que, de modo geral, esse tipo de tratamento da Classe II apresenta boa estabilidade. 
PAQUETTE; BEATTIE; JOHNSTON ${ }^{170}$ (1992) compararam a estabilidade das correções da Classe II em casos limítrofes, realizadas sem extrações e com a extração de quatro pré-molares e concluíram que, em geral, o padrão de recidiva não apresentou associação com o tipo de tratamento ou com as posições dentárias presentes no final do tratamento. A alteração póstratamento, provavelmente, decorreu da compensação dentoalveolar ocasionada pelo crescimento diferencial dos maxilares, ocorrido após o tratamento.

FIDLER et al. $^{75}$ (1995) avaliaram a estabilidade dos resultados do tratamento da Classe II com a extração de quatro pré-molares e sem extrações dentárias e notaram que as alterações observadas no período pós-tratamento são de magnitude clinicamente insignificante. Dessa forma, concluíram que a correção desse tipo de má oclusão se apresenta estável, mas ressaltaram que - crescimento mandibular favorável durante e após o tratamento foi imprescindível para a obtenção desses resultados.

ARTUN; GAROL; LITTLE ${ }^{10}$ (1996) também compararam a estabilidade do tratamento da Classe II sem extrações e com a extração de quatro pré-molares e não encontraram diferenças intergrupos quanto à estabilidade da sobressaliência e nem da sobremordida, concordando com BISHARA; CUMMINS; ZAHER ${ }^{30}$ (1997).

Apesar de alguns autores observarem que os pacientes tratados com a extração de dois pré-molares superiores apresentam, a longo prazo, maior apinhamento ântero-inferior do que pacientes não tratados devido ao fato de este tipo de tratamento gerar um componente mesial de focas oclusais ${ }^{94,166}$, estudos posteriores não comprovaram essa informação ${ }^{193}$. SWAIN ${ }^{206}$ (1971) afirma que essa ocorrência não caracteriza uma recidiva, uma vez que, nos casos tratados com a extração de dois pré-molares, antes do tratamento não há apinhamento ântero-inferior ou, quando há, ele é mínimo.

MIHALIK; PROFFIT; PHILLIPS ${ }^{157}$ (2003) compararam a estabilidade da correção cirúrgica da Classe II com a do tratamento realizado com a extração de dois pré-molares superiores e constataram que as alterações que ocorreram na fase pós-contenção foram maiores no grupo tratado cirurgicamente. A estabilidade da correção da sobremordida profunda foi semelhante nos grupos. Todavia, no grupo tratado com cirurgia, ocorreu quase 
o dobro de recidiva da correção da sobressaliência do que no grupo tratado com extrações.

O tratamento com aparelhos ortopédicos, como, por exemplo, o ativador associado ao aparelho extrabucal de tração alta, apresenta boa estabilidade das correções obtidas. Há uma pequena recidiva da correção da sobressaliência relacionada à alteração sagital entre a maxila e a mandíbula que ocorre provavelmente devido ao crescimento tardio da mandíbula em relação à maxila ${ }^{192}$. A recidiva da sobremordida corrigida é maior quanto maior for a correção realizada durante o tratamento e, apesar de o crescimento mandibular aumentar significantemente durante o tratamento, após o término deste ele é menor em pacientes tratados com ortopedia do que em pacientes não tratados ${ }^{63,112,224,227}$.

Quando se compara a estabilidade do tratamento da Classe II com o aparelho extrabucal de tração cervical e com o ativador de Andresen, por exemplo, observa-se que a recidiva da sobressaliência e da sobremordida é mínima e está relacionada à tendência dos incisivos de se inclinarem em direção às suas posições iniciais ${ }^{65}$.

Quanto à estabilidade das correções obtidas com o tratamento realizado em uma ou duas fases, há autores ${ }^{18,68}$ que afirmam que ela é maior com o tratamento em duas fases e outros contestam essa afirmação, pois constataram ser insignificante a influência da fase ortopédica sobre os resultados finais ${ }^{67,129,143}$.

A recidiva não deve ser considerada um fenômeno anormal e sim uma alteração indesejável que deve ser minimizada com um diagnóstico e plano de tratamento criteriosos ${ }^{71}$. Além disso, as alterações contínuas nas posições dentárias são parte de um fenômeno biológico natural e os pacientes submetidos ao tratamento ortodôntico não deixam de sofrer essas adaptações $^{224}$.

Após essa revisão de literatura pode-se constatar que há divergências de opinião quanto às vantagens e desvantagens do tratamento da Classe II sem extrações e com extrações dentárias. Apesar da maioria dos estudos que compararam o tratamento sem extrações com o realizado com a extração de quatro pré-molares demonstrar que a estabilidade das correções independe do tipo de tratamento ${ }^{10,32,75,88,170}$ e de haver escassez, na literatura, 
de estudos sobre a estabilidade da correção com extração de dois pré-molares, existem autores que afirmam que as extrações de dois pré-molares devem ser evitadas principalmente por ocasionarem comprometimento do perfil facial e estabilidade insatisfatória ${ }^{91,94,144,147,166}$.

Fica evidente que a literatura é deficiente de trabalhos de investigação a respeito da estabilidade do tratamento da Classe II completa com extração de dois pré-molares superiores e também de trabalhos que comparam a estabilidade dos resultados desse tipo de tratamento com a do tratamento sem extração. 


$$
\text { 3-Proposição }
$$





\section{3- PROPOSIÇÃO:}

Este estudo tem como objetivo testar a seguinte hipótese nula: não há diferença na estabilidade da correção das relações dentárias cefalométricas da má oclusão de Classe II completa, obtida com o tratamento sem extração e com a extração de dois pré-molares superiores, em longo prazo.

Para tanto, serão utilizadas telerradiografias laterais tomadas no início e no final do tratamento ortodôntico e tomadas a 8,2 anos, em média, do término do tratamento. Serão também avaliadas as influências das alterações de variáveis dentoalveolares e esqueléticas nos resultados obtidos. 



$$
\begin{aligned}
& \text { 4- } M_{\text {aterial e }} \\
& M_{\text {étodos }}
\end{aligned}
$$





\section{4- MATERIAL E MÉTODOS:}

\section{1- A amostra:}

A amostra desse estudo de caráter retrospectivo se constituiu de 180 telerradiografias laterais de 60 pacientes, ou seja, três telerradiografias de cada paciente: uma telerradiografia tomada no estágio pré-tratamento (T1), outra no estágio pós-tratamento (T2) e a última telerradiografia tomada no estágio de observação (T3), ou seja, 8,2 anos, em média, após o término do tratamento (tempo mínimo de observação de 2,4 e máximo de 15,9).

Os pacientes, cujas telerradiografias foram avaliadas, apresentavam o mesmo tipo e magnitude de má oclusão previamente ao tratamento ortodôntico: má oclusão de Classe II completa (cúspide distovestibular do primeiro molar superior ocluindo no sulco vestibular mesial do primeiro molar inferior) e bilateral ${ }^{223}{ }^{222}$.

Esses 60 pacientes, com idade média de 12,51 $\pm 1,46$ anos (idade

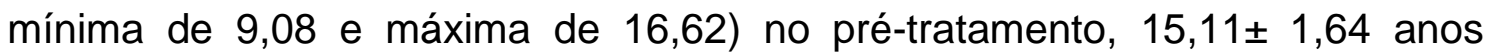
(idade mínima de 12,44 e máxima de 19,23) no pós-tratamento e de 23,31 \pm 3,94 anos (idade mínima de 16,67 e máxima de 33,58) no estágio de observação e dos quais 30 eram do gênero masculino e 30 do gênero feminino, foram divididos em dois grupos distintos de acordo com o tipo de tratamento a que foram submetidos. O Grupo 1 foi composto por 30 pacientes tratados sem a realização de extrações dentárias e o Grupo 2 por 30 pacientes tratados com a extração de dois pré-molares superiores. Todos os pacientes da amostra utilizaram aparelho ortodôntico fixo.

Grupo 1:

O Grupo 1 foi composto de 90 telerradiografias laterais de 30 pacientes tratados sem extrações dentárias, sendo 16 pacientes do gênero feminino e 14 do gênero masculino. Vinte e cinco pacientes eram Classe II, Divisão 1, e apenas cinco pacientes apresentavam Classe II, Divisão 2.

Esses pacientes foram tratados com diversos aparelhos para correção da Classe II, como aparelho extrabucal (três pacientes utilizaram o aparelho extrabucal isoladamente e 12 utilizaram aparelho extrabucal seguido de elásticos intermaxilares de Classe II) e aparelhos ortopédicos (um paciente 
utilizou o Bionator de Balters apenas, 14 pacientes utilizaram o Bionator de Balters, o Ativador, o Splint maxilar ou o Cantilever Bite Jumper - CBJ® associados ao aparelho extrabucal ou aos elásticos intermaxilares). O tempo de observação pós-tratamento foi, em média, 7,2 anos e as idades médias dos pacientes, assim como as idades máxima e mínima nos estágios avaliados, estão representadas na Tabela 1.

Tabela 1 - Médias, desvios-padrão, valores mínimos e máximos das idades dos pacientes integrantes do Grupo 1 nos três estágios de avaliação.

\begin{tabular}{|l|l|l|l|l|}
\hline \multicolumn{5}{|c|}{$\begin{array}{l}\text { Grupo 1 (Sem Xp) } \\
(\mathrm{n}=30)\end{array}$} \\
\hline \multicolumn{1}{|c|}{ Estágio } & \multicolumn{4}{c|}{ Idades } \\
\hline & Média & dp & Mínima & Máxima \\
\hline Pré-tratamento (T1) & 12,14 & 1,36 & 9,08 & 15,55 \\
\hline Pós-tratamento (T2) & 14,82 & 1,55 & 12,77 & 18,56 \\
\hline Observação (T3) & 21,98 & 3,38 & 17,04 & 31,33 \\
\hline
\end{tabular}

\section{Grupo 2:}

O Grupo 2 foi constituído de 90 telerradiografias de 30 pacientes tratados com a extração de dois pré-molares superiores, sendo 13 pacientes do gênero feminino e de 17 do gênero masculino. Vinte e três pacientes eram Classe II, Divisão 1, e sete pacientes eram Classe II, Divisão 2. O tempo de observação pós-tratamento foi, em média, de 9,3 anos.

As médias e desvios-padrão das idades dos pacientes nos três estágios de avaliação, assim como as idades máxima e mínima, estão descritas na Tabela 2.

Tabela 2 - Médias, desvios-padrão, valores mínimos e máximos das idades dos pacientes integrantes do Grupo 2 nos três estágios de avaliação.

\begin{tabular}{|l|l|l|l|l|}
\hline \multicolumn{5}{|c|}{$\begin{array}{c}\text { Grupo 2 (Xp 2PM) } \\
(\mathrm{n}=30)\end{array}$} \\
\hline \multicolumn{1}{|c|}{ Estágio } & \multicolumn{4}{c|}{ Idades } \\
\hline & Média & dp & Mínima & Máxima \\
\hline Pré-tratamento (T1) & 12,87 & 1,49 & 10,90 & 16,62 \\
\hline Pós-tratamento (T2) & 15,40 & 1,71 & 12,44 & 19,23 \\
\hline Observação (T3) & 24,65 & 4,05 & 16,67 & 33,58 \\
\hline
\end{tabular}


4.2- Tomada e obtenção das telerradiografias em norma lateral:

As telerradiografias foram tomadas com o paciente em máxima intercuspidação habitual, lábios em repouso, posicionados com o auxílio do cefalostato de BROADBENT ${ }^{45}$ (1931). A revelação e o processamento das telerradiografias seguiram as normas utilizadas na Disciplina de Radiologia da Faculdade de Odontologia de Bauru, onde a maioria das telerradiografias foi tomada, assim como as normas dos demais centros de documentação ortodôntica da cidade de Bauru/SP.

\section{3- Traçado e medição das telerradiografias:}

Para o traçado cefalométrico e a medição de cada telerradiografia foi utilizada uma folha de papel acetato Ultraphan de $0,07 \mathrm{~mm}$ de espessura, recortada no tamanho $17,5 \times 17,5 \mathrm{~cm}$ fixada na telerradiografia. Manualmente, com a utilização de uma lapiseira de $0,5 \mathrm{~mm}$ e sobre um negatoscópio, em sala escura, realizou-se o traçado anatômico, a demarcação dos pontos cefalométricos e dos pontos de referência para a digitalização dos traçados. Esses traçados cefalométricos, após serem conferidos por um examinador, foram digitalizados em uma mesa digitalizadora ${ }^{a}$ acoplada a um computador AMD K62 500.

As telerradiografias que compuseram essa amostra foram traçadas e digitalizadas por três operadores diferentes, sendo eles T.S., M.J. e J.A. A operadora T.S. traçou e digitalizou as telerradiograifas do estágio prétratamento do grupo 1, o operador M.J. as telerradiografias pré e póstratamento do grupo 2 e a operadora J.A. as telerradiografias pós-tratamento e de observação do grupo 1 e as de observação do grupo 2. Devido a isso, tornou-se necessária a verificação do erro interexaminador.

O programa Dentofacial Planner foi empregado para a correção da magnificação das imagens radiográficas e para a medição das grandezas cefalométricas. Devido ao longo intervalo de tempo entre os estágios avaliados, as telerradiografias haviam sido tomadas em diferentes aparelhos de raios $\mathrm{Xe}$

\footnotetext{
${ }^{a}$ Numonics Accugrid

${ }^{b}$ Version $7.02^{*}$, Dentofacial Planner Software Inc., Toronto, Ontario, Canada.
} 
que apresentavam fatores de magnificação entre 6,0 e $9,8 \%$, os quais foram corrigidos para que essas telerradiografias pudessem ser comparadas.

As grandezas cefalométricas foram divididas em esqueléticas (maxilares, mandibulares, maxilomandibularese padrão facial) e grandezas cefalométricas dentárias (dentoalveolares superiores e inferiores e relações dentárias).

Traçado anatômico (Figura 1):

O traçado anatômico foi constituído pelas seguintes estruturas esqueléticas e dentárias:

- Perfil mole

- perfil da glabela e dos ossos nasais

- sela túrcica, porção posterior do osso esfenóide e osso occiptal

- fissura pterigomaxilar

- meato acústico externo

- limite póstero-inferior da cavidade orbitária

- maxila

- mandíbula

- incisivos centrais, caninos, primeiros molares permanentes superiores e inferiores e primeiros e segundos pré-molares superiores e inferiores.

Para todas as estruturas bilaterais foi efetuado o traçado médio ${ }^{77,208}$.

Pontos cefalométricos e pontos de referência (Figura 1):

Para demarcação dos pontos cefalométricos foram seguidas as especificações de RIOLO $^{179}$ (1974), MCNAMARA ${ }^{152}$ (1984); JACOBSON ${ }^{109}$ (1975).

1- S (sela túrcica): o ponto mais central da sela túrcica.

2- $\mathrm{N}$ (násio): o ponto mais anterior da sutura frontonasal.

3- Or (orbitário): ponto mais inferior do assoalho da órbita.

4- ENA (espinha nasal anterior): o ponto mais anterior da espinha nasal anterior.

5- ENP (espinha nasal posterior): o ponto mais posterior do assoalho da fossa nasal. 
6- Ponto A (subspinhal): o ponto mais profundo da concavidade da prémaxila.

7- Ponto B (supramentoniano): o ponto mais profundo da concavidade da sínfise mentoniana.

8- Pog (pogônio): o ponto mais anterior do contorno do mento ósseo.

9- Gn (gnátio): o ponto mais inferior e anterior do contorno do mento ósseo 10-Me (mentoniano): o ponto médio mais inferior da sínfise mentoniana.

11-Go (gônio): o ponto mais posterior e inferior da mandíbula, localizado na bissetriz do ângulo formado entre o corpo e o ramo da mandíbula.

12-Po (pório anatômico): o ponto mais superior do meato acústico externo.

13-Co (condílio): o ponto mais superior e posterior do côndilo mandibular.

14-BIS (borda do incisivo superior): o ponto mais inferior da borda incisal do incisivo central superior.

15-AIS (ápice do incisivo superior): o ponto mais superior do ápice radicular do incisivo central superior.

16-BII (borda do incisivo inferior): o ponto mais superior da borda incisal do incisivo central inferior.

17-All (ápice do incisivo inferior): o ponto mais inferior do ápice radicular do incisivo central inferior.

18-SMPMS (superfície mesial do primeiro molar superior): o ponto mais anterior da coroa do primeiro molar permanente superior.

19-CMPMS (cúspide mesial do primeiro molar superior): o ponto mais inferior da cúspide mesial do primeiro molar permanente superior.

20-SMPMI (superfície mesial do primeiro molar inferior): o ponto mais anterior da coroa do primeiro molar permanente inferior.

21-CMPMI (cúspide mesial do primeiro molar inferior): o ponto mais superior da cúspide mesial do primeiro molar permanente inferior.

22-COM (contato oclusal molar): o ponto médio da superfície de intercuspidação dos primeiros molares.

23-COPM (contato oclusal pré-molar): ponto médio da superfície de intercuspidação dos segundos pré-molares.

24-CCl (cúspide do canino inferior): ponto mais superior da cúspide do canino inferior. 
25-ACl (ápice do canino inferior): ponto mais inferior do ápice radicular do canino inferior.

26-CCS (cúspide do canino superior): ponto mais inferior da cúspide do canino superior.

27-ACS (ápice do canino superior): ponto mais superior do ápice do canino superior.

Os pontos Pogperp e ENAperp foram construídos para serem utilizados na digitalização dos traçados:

28-Pogperp (ponto pogônio perpendicular): ponto localizado arbitrariamente, porém perpendicular ao plano Go-Me, passando pelo ponto Pog.

29-ENAperp (ponto espinha nasal anterior perpendicular): ponto localizado arbitrariamente, porém perpendicular ao plano palatino, a partir do ponto ENA.

\section{Linhas e Planos (Figura 1):}

Horizontais:
A- Linha SN: do ponto sela ao násio.
B- PF (Plano de Frankfurt): do ponto pório anatômico ao orbitário.
C- PP (plano palatino): do ponto ENP ao ENA.
D- POF (plano oclusal funcional): do contato oclusal molar ao contato oclusal pré-molar.
E- Plano GoGn: do ponto gônio ao gnátio.
F- Plano GoMe (plano mandibular): do ponto gônio ao mentoniano.

\section{Verticais:}

G- Linha NA: do ponto násio ao ponto $A$.

$\mathrm{H}$ - Linha NB: do ponto násio ao ponto $\mathrm{B}$.

I- Linha BIS-AIS (longo eixo do incisivo superior): une os pontos correspondentes da borda incisal ao ápice dos incisivos centrais superiores. J- Linha Bll-All (longo eixo do incisivo inferior): une os pontos correspondentes da borda incisal ao ápice dos incisivos centrais inferiores. K- Linha Nperp: linha perpendicular ao plano de Frankfurt, passando pelo ponto násio. 
L- Linha Pogperp: linha perpendicular ao plano mandibular Go-Me, passando pelo ponto pogônio.

M- Linha ENAperp: linha perpendicular ao plano palatino, passando pela espinha nasal anterior.

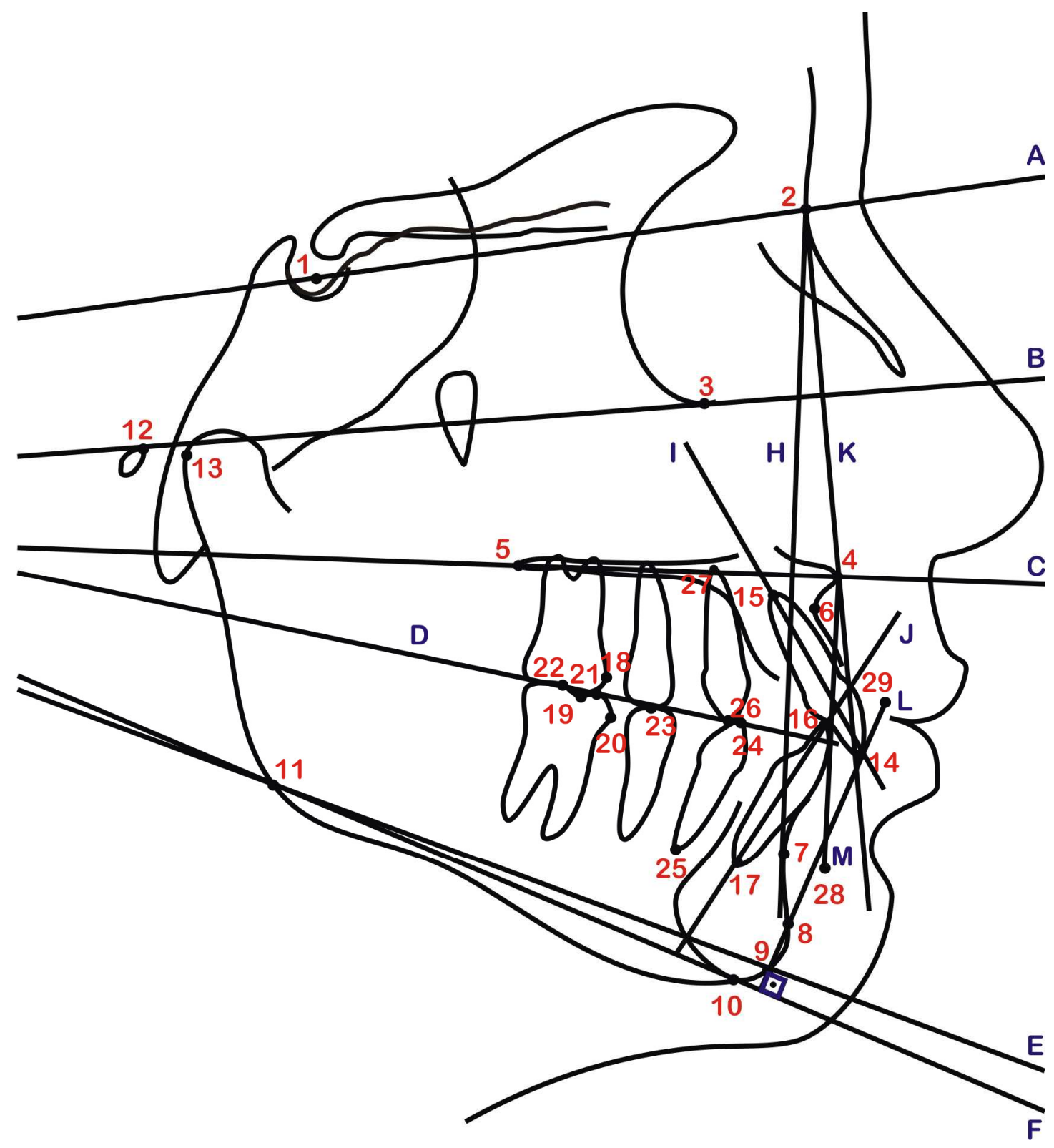

FIGURA 1 - Traçado anatômico, pontos cefalométricos, pontos de referência, linhas e planos utilizados. 


\section{Grandezas cefalométricas esqueléticas (Figura 2):}

Maxilares:

1- SNA: ângulo formado pelas linhas SN e NA. Indica a relação sagital da maxila em relação à base do crânio. Seu aumento indica um aumento da protrusão maxilar.

2- CO-A: distância entre os pontos condílio e A. Representa o comprimento efetivo da maxila.

3- A-Nperp: distância entre o ponto A e a linha násio perpendicular. Define a posição sagital da maxila. Seu aumento também indica um aumento da protrusão maxilar.

Mandibulares:

4- SNB: ângulo formado pelas linhas SN e NB. Indica a relação sagital da mandíbula em relação à base do crânio. Seu aumento indica um aumento da protrusão mandibular.

5- Co-Gn: distância entre os pontos condílio e gnátio. Define o comprimento efetivo da mandíbula.

Maxilomandibulares:

6- ANB: ângulo entre as linhas NA e NB. Representa o grau de discrepância sagital entre a maxila e mandíbula.

7- Wits: distância entre as projeções perpendiculares dos pontos A e B sobre o plano oclusal funcional. Define o relacionamento sagital entre a maxila e a mandíbula.

Padrão facial:

8- FMA: ângulo formado pelos planos horizontal de Frankfurt e mandibular (Go-Me). Define a orientação do padrão de crescimento facial.

9- SN.GoGn: ângulo formado pela linha SN e o plano mandibular GoGn e também define a orientação do padrão de crescimento facial.

10-AFAI (ENA-Me): distância entre os pontos espinha nasal anterior e mentoniano. Indica a altura do terço ântero-inferior da face. 


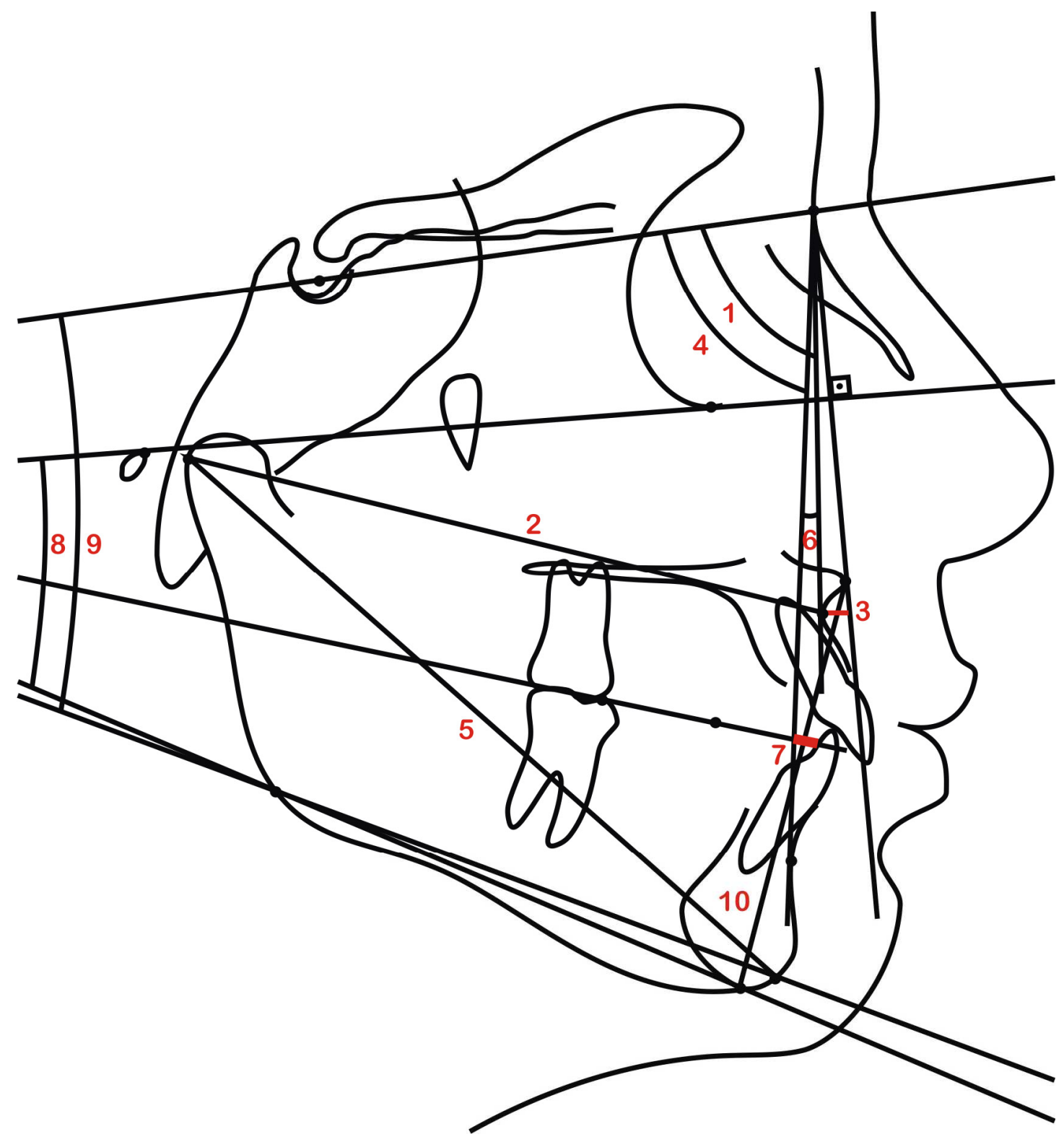

FIGURA 2: Grandezas cefalométricas esqueléticas:

1- SNA; 2- Co-A; 3- A-Nperp; 4- SNB; 5- Co-Gn; 6- ANB; 7- Wits; 8- FMA; 9- SN.GoGn; $10-$ AFAI (ENA-Me). 


\section{Grandezas cefalométricas dentárias (Figura 3):}

Superiores:

1- 1.PP: ângulo formado entre o longo eixo do incisivo central superior e o plano palatino. Indica a inclinação do incisivo superior em relação à maxila. 2- 1-ENAperp: distância entre o ponto mais anterior da coroa do incisivo central superior e a linha espinha nasal anterior perpendicular. Determina a posição anteroposterior do incisivo central superior em relação à maxila. Valores posteriores a esta linha são negativos, e anteriores são positivos. 0 seu aumento indica protrusão dos incisivos.

3- 1-PP: distância entre a borda incisal do incisivo central superior e o plano palatino. Determina a altura do processo alveolar superior, em sua região anterior.

4- 6-PP: distância entre o ponto localizado na ponta da cúspide mesiovestibular do primeiro molar superior e o plano palatino. Quantifica o desenvolvimento vertical do primeiro molar superior.

5- 6-ENAperp: distância entre a face mesial do primeiro molar superior e a linha espinha nasal anterior perpendicular. Determina a posição anteroposterior do primeiro molar superior em relação à maxila e valores posteriores à linha ENAperp possuem sinal negativo.

Inferiores:

6- IMPA: ângulo formado entre o longo eixo do incisivo central inferior e o plano mandibular GoMe. Indica a inclinação deste dente em relação à mandíbula.

7- 1-Pogperp: distância entre o ponto mais anterior da coroa do incisivo central inferior e a linha pogônio perpendicular. Determina a posição anteroposterior do incisivo central inferior em relação à mandíbula. Valores posteriores a esta linha são positivos e anteriores são negativos. Seu aumento indica uma protrusão do incisivo.

8- 1-GoMe: distância entre a borda incisal do incisivo inferior e o plano mandibular. Determina a altura do processo alveolar inferior, em sua região anterior. Quanto maior seu valor, maior a extrusão do incisivo. 
9- 6-Pogperp: distância entre a face mesial do primeiro molar inferior e a linha pogônio perpendicular. Determina a posição anteroposterior do primeiro molar inferior em relação à mandíbula, sendo que seu aumento indica uma distalização do molar já que esta medida apresenta valores negativos.

10- 6-GoMe: distância entre o ponto localizado na ponta da cúspide mesiovestibular do primeiro molar inferior e o plano mandibular. Determina o grau de desenvolvimento vertical do molar inferior e quanto maior seu valor, maior a extrusão desse dente.

Relações dentárias (Figura 4):

1- Trespasse horizontal ( $T$ hor): distância da borda incisal do incisivo inferior à borda incisal do incisivo superior, medida paralelamente ao plano oclusal funcional. Quanto maior a sobressaliência, maior o valor desta medida.

2- Trespasse vertical (T vert): distância da borda incisal do incisivo inferior à borda incisal do incisivo superior, medida paralelamente ao plano de Frankfurt. Quanto maior o trespasse vertical, maior o valor dessa medida.

3- Relação molar (Rel mol): distância da superfície mesial do primeiro molar superior à superfície mesial do primeiro molar inferior, medida paralelamente ao plano de Frankfurt. Sua diminuição indica uma maior mesialização do molar superior em relação ao inferior.

4- Relação de caninos (Rel can): distância da ponta da cúspide do canino superior à ponta de cúspide do canino inferior, medida paralelamente ao plano oclusal funcional. A coincidência entre as pontas dos caninos tem valor igual à zero, valores positivos representam uma tendência a uma relação de Classe II e negativos representam uma tendência a uma relação de Classe I. 


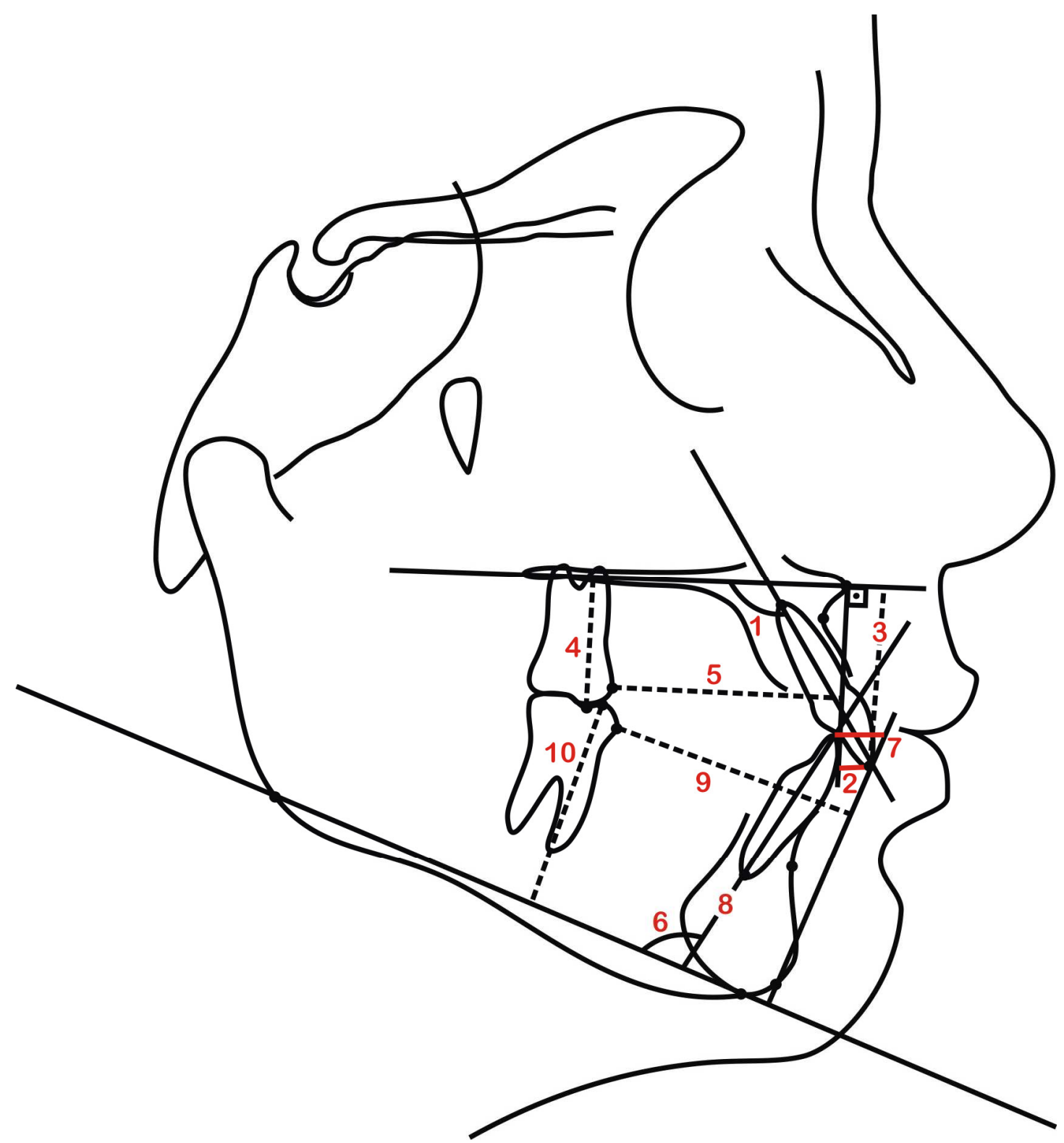

FIGURA 3 - Grandezas cefalométricas dentárias:

1- 1.PP; 2- 1-ENAperp; 3- 1-PP; 4- 6-PP; 5- 6-ENAperp; 6- IMPA; 7- 1-Pogperp; 8- 1-GoMe; 9- 6-Pogperp; 10- 6-GoMe. 

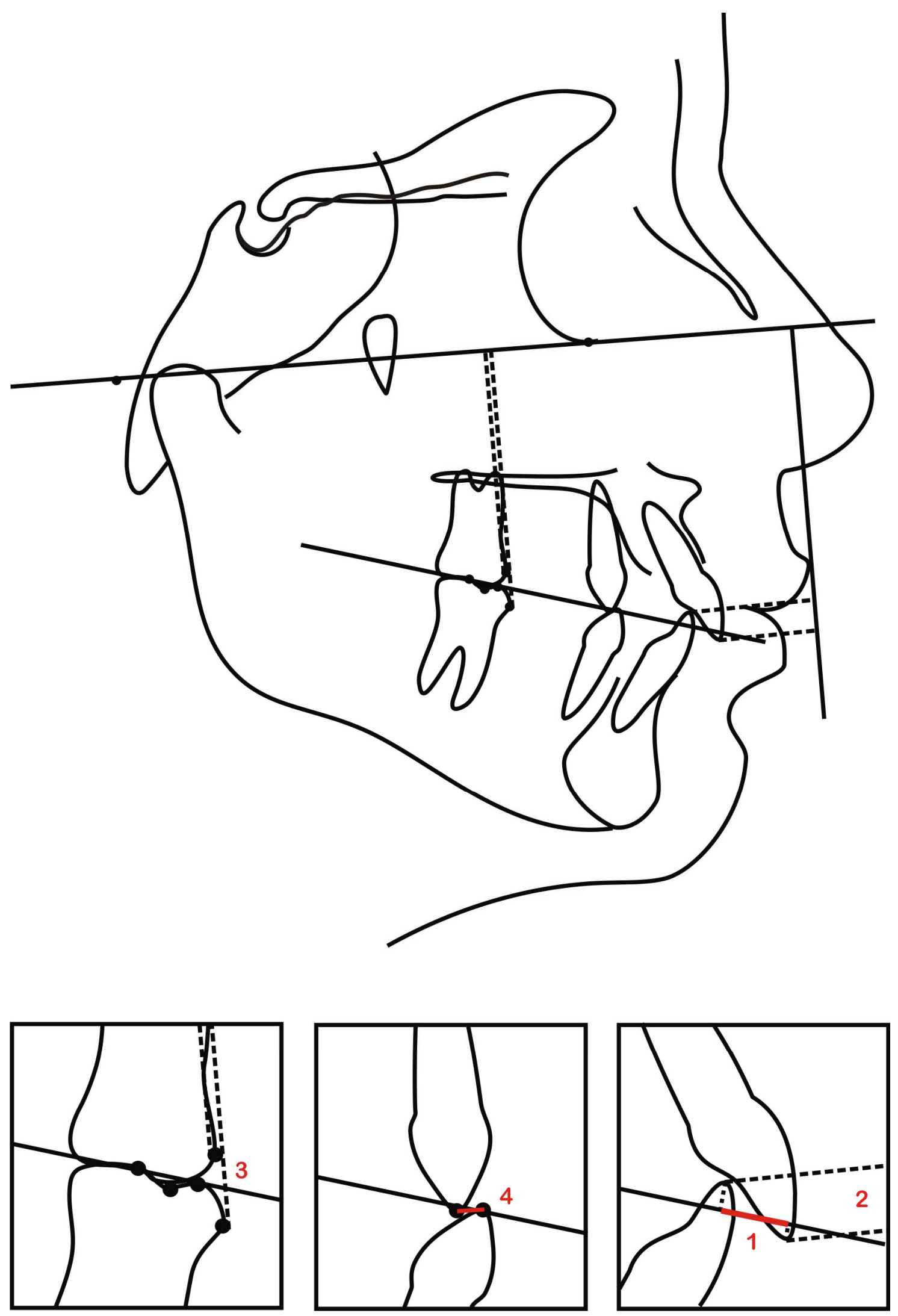

FIGURA 4 - Relações dentárias:

1 - Trespasse horizontal;

2 - Trespasse vertical; 3 - Relação molar ; 4 - Relação de caninos. 


\section{4- Erro do método}

Erro intra-examinador:

Para verificar a confiabilidade do método utilizado, realizou-se novamente o traçado, a digitalização e a medição de 20 telerradiografias da amostra selecionadas aleatoriamente ${ }^{165}$. Conforme preconizado por HOUSTON $^{106}$ (1983), para avaliar o erro sistemático, utilizou-se o teste $\mathrm{t}$ pareado com valor de $\mathrm{p}<0,05$. Para a avaliação do erro casual, aplicou-se a seguinte fórmula proposta por Dahlberg ${ }^{62}: S e^{2}=\sum d^{2} / 2 n$.

Erro interexaminador:

Como os traçados cefalométricos foram realizados por três examinadores diferentes, 20 telerradiografias foram selecionadas aleatoriamente e cada uma foi traçada e digitalizada novamente pelos três operadores. As medidas obtidas foram comparadas pela Análise de Variância.

\section{5- Análise estatística}

O teste $t$ de Student foi utilizado para a avaliação intergrupos da compatibilidade entre as idades nos estágios pré-tratamento, pós-tratamento e de observação, da compatibilidade dos tempos de observação e para a comparação das medidas nos estágios pré-tratamento, pós-tratamento e de observação. Além disso, esse teste foi utilizado para a comparação intergrupos das alterações do tratamento (T2-T1) e das alterações ocorridas no período pós-tratamento (T3-T2), ou seja, para a comparação da estabilidade.

A compatibilidade dos grupos quanto à proporção dos gêneros, dos tipos de Classe II (Classe II, Divisão 1 e 2) e quanto à proporção de pacientes que utilizavam contenção no período de observação foi avaliada pelo teste Quiquadrado. 
O teste de correlação de Pearson foi empregado para verificar a existência de correlação entre as alterações das relações dentárias durante e após o tratamento e também para correlacionar a alteração pós-tratamento da relação de caninos com as demais variáveis, nesse mesmo período.

O programa utilizado para a realização dos testes estatísticos foi 0 STATISTICA $^{c}$ e foram considerados significantes os resultados com valor de $p<0,05$.

${ }^{\mathrm{c}}$ Statistica for Windows - Release 6.0 - Copyright StatSoft, Inc. 



$$
\text { 5- } R_{\text {esultados }}
$$





\section{5- RESULTADOS:}

As Tabelas 3 e 4 apresentam os valores dos erros intra e interexaminador, respectivamente, que quantificam a precisão da metodologia empregada.

As Tabelas 5 a 11 apresentam os resultados dos testes da compatibilidade entre os grupos quanto às idades dos pacientes, ao tempo de observação, aos gêneros, aos tipos de Classe II, à utilização de contenção ântero-inferior $(3 \times 3)$ no estágio de observação e às características cefalométricas nos três estágios de avaliação.

A Tabela 12 mostra o resultado da comparação intergrupos das alterações ocasionadas pelo tratamento e a Tabela 13 apresenta os resultados da comparação das alterações pós-tratamento.

As Tabelas 14 e 15 também exibem resultados da comparação entre os grupos das alterações pós-tratamento, mas após a compatibilização dos grupos quanto ao tempo de observação e a exclusão dos pacientes Classe II, Divisão 2, respectivamente. Este último teste foi realizado porque, embora a diferença intergrupos entre os números de pacientes com esse tipo de má oclusão fosse estatisticamente insignificante, ela poderia interferir na alteração pós-tratamento da posição dos incisivos superiores

$\mathrm{Na}$ Tabela 16, o resultado do teste de correlação de Pearson demostra o grau de relação existente entre as alterações ocasionadas pelo tratamento e as alterações pós-tratamento das relações dentárias e a Tabela 17 apresenta o resultado do teste de correlação entre a alteração póstratamento da relação de caninos e as alterações pós-tratamento das demais variáveis cefalométricas estudadas. 


\section{Erro intra-examinador:}

TABELA 3 - Médias, desvios-padrão e resultados do teste t pareado (erro sistemático) e da fórmula de Dahlberg (erro casual) para a avaliação do erro intra-examinador.

\begin{tabular}{|c|c|c|c|c|c|c|}
\hline & \multicolumn{2}{|c|}{$1^{\circ}$ traçado } & \multicolumn{2}{|c|}{$2^{\circ}$ traçado } & \multirow[b]{2}{*}{$\mathrm{p}$} & \multirow[b]{2}{*}{ Dahlberg } \\
\hline & Média & $\mathrm{dp}$ & Média & $\mathrm{dp}$ & & \\
\hline \multicolumn{7}{|c|}{ Componente maxilar } \\
\hline SNA & 80,43 & 2,97 & 79,75 & 3,19 & 0,15 & 1,48 \\
\hline Co-A & 88,96 & 4,90 & 88,90 & 5,68 & 0,91 & 2,06 \\
\hline A-Nperp & $-1,09$ & 3,09 & $-1,20$ & 2,86 & 0,70 & 0,92 \\
\hline \multicolumn{7}{|c|}{ Componente mandibular } \\
\hline SNB & 77,16 & 3,15 & 76,89 & 2,92 & 0,44 & 1,05 \\
\hline CoGn & 114,70 & 6,78 & 114,58 & 7,34 & 0,76 & 1,24 \\
\hline \multicolumn{7}{|c|}{ Relação maxilomandibular } \\
\hline ANB & 3,28 & 1,97 & 2,86 & 2,32 & 0,07 & 0,74 \\
\hline Wits & 2,80 & 1,75 & 2,21 & 2,19 & 0,09 & 1,10 \\
\hline \multicolumn{7}{|l|}{ Padrão facial } \\
\hline FMA & 23,84 & 3,85 & 22,96 & 3,65 & 0,01 & 1,17 \\
\hline SN.GoGn & 30,02 & 4,66 & 29,70 & 4,19 & 0,37 & 1,12 \\
\hline AFAI & 67,48 & 5,48 & 67,41 & 5,90 & 0,85 & 1,14 \\
\hline \multicolumn{7}{|c|}{ Componente dentoalveolar superior } \\
\hline 1.PP & 113,39 & 7,15 & 113,31 & 6,94 & 0,90 & 1,89 \\
\hline 1-PP & 27,97 & 2,46 & 28,29 & 2,70 & 0,22 & 0,82 \\
\hline 1-ENAperp & $-3,14$ & 3,52 & $-2,01$ & 3,18 & 0,02 & 1,60 \\
\hline 6-PP & 24,55 & 2,47 & 24,61 & 2,77 & 0,79 & 0,67 \\
\hline 6-ENAperp & $-27,17$ & 3,01 & $-26,11$ & 3,13 & 0,03 & 1,62 \\
\hline \multicolumn{7}{|c|}{ Componente dentoalveolar inferior } \\
\hline IMPA & 95,58 & 6,16 & 98,77 & 5,99 & 0,00 & 2,69 \\
\hline 1-Pogperp & $-9,14$ & 3,39 & $-9,18$ & 3,79 & 0,90 & 0,86 \\
\hline 1-GoMe & 40,84 & 3,33 & 40,50 & 3,58 & 0,10 & 0,65 \\
\hline 6-Pogperp & $-29,57$ & 2,40 & $-29,79$ & 2,39 & 0,35 & 0,72 \\
\hline 6-GoMe & 32,23 & 2,37 & 32,38 & 2,57 & 0,36 & 0,51 \\
\hline \multicolumn{7}{|c|}{ Relações dentárias } \\
\hline Thor & 3,49 & 0,88 & 3,37 & 0,89 & 0,47 & 0,51 \\
\hline T vert & 2,70 & 1,06 & 2,31 & 1,02 & 0,02 & 0,55 \\
\hline Rel mol & 1,88 & 2,86 & 1,68 & 2,53 & 0,17 & 0,45 \\
\hline Rel can & $-0,42$ & 1,30 & $-0,72$ & 1,34 & 0,21 & 0,74 \\
\hline
\end{tabular}




\section{Erro interexaminador:}

TABELA 4 - Médias, desvios-padrão e resultados da análise de variância e do teste de Tukey para a avaliação do erro interexaminador.

\begin{tabular}{|c|c|c|c|c|c|c|c|}
\hline & \multicolumn{2}{|c|}{ Operador $1(\mathrm{MJ})$} & \multicolumn{2}{|c|}{ Operador $2(\mathrm{JA})$} & \multicolumn{2}{|c|}{ Operador 3 (TS) } & \\
\hline & Média & $\mathrm{dp}$ & Média & $\mathrm{dp}$ & Média & $\mathrm{dp}$ & \\
\hline \multicolumn{8}{|c|}{ Componente maxilar } \\
\hline SNA & 79,65 & 3,93 & 81,12 & 4,11 & 81,19 & 3,67 & 0,06 \\
\hline Co-A & $83,11^{a}$ & 4,18 & $83,67^{\text {a,b }}$ & 4,85 & $84,77^{b}$ & 4,48 & 0,02 \\
\hline A-Nperp & $-0,77$ & 3,03 & 0,16 & 3,36 & 0,21 & 2,99 & 0,27 \\
\hline \multicolumn{8}{|c|}{ Componente mandibular } \\
\hline SNB & 73,65 & 3,18 & 74,22 & 3,29 & 74,49 & 3,12 & 0,18 \\
\hline CoGn & $102,52^{\mathrm{a}}$ & 4,48 & $103,02^{\mathrm{a}}$ & 4,17 & $104,90^{\mathrm{b}}$ & 3,19 & 0,01 \\
\hline \multicolumn{8}{|c|}{ Relação maxilomandibular } \\
\hline ANB & 6,01 & 2,11 & 6,93 & 2,63 & 6,70 & 2,88 & 0,08 \\
\hline Wits & 5,63 & 3,57 & 6,10 & 3,98 & 5,41 & 3,88 & 0,75 \\
\hline \multicolumn{8}{|c|}{ Padrão facial } \\
\hline FMA & 30,72 & 4,22 & 30,72 & 5,86 & 30,88 & 5,23 & 0,97 \\
\hline SN.GoGn & 38,21 & 4,94 & 37,37 & 5,23 & 37,77 & 5,05 & 0,35 \\
\hline AFAI & 65,14 & 5,19 & 64,91 & 5,56 & 65,38 & 5,32 & 0,75 \\
\hline \multicolumn{8}{|c|}{ Componente dentoalveolar superior } \\
\hline 1.PP & 116,04 & 7,84 & 115,48 & 5,91 & 116,42 & 7,29 & 0,78 \\
\hline 1-PP & $28,76^{\mathrm{a}}$ & 2,80 & $27,97^{\mathrm{b}}$ & 2,70 & $28,24^{b}$ & 2,75 & 0,00 \\
\hline 1-ENAperp & 0,58 & 3,07 & $-0,01$ & 2,85 & 0,59 & 3,22 & 0,41 \\
\hline 6-PP & 22,98 & 2,17 & 22,43 & 2,64 & 22,47 & 2,52 & 0,54 \\
\hline 6-ENAperp & $-27,34$ & 3,19 & $-28,27$ & 2,86 & $-27,70$ & 3,18 & 0,08 \\
\hline \multicolumn{8}{|c|}{ Componente dentoalveolar inferior } \\
\hline IMPA & $93,03^{a}$ & 7,48 & $95,95^{b}$ & 7,33 & $97,10^{b}$ & 7,04 & 0,00 \\
\hline 1-Pogperp & $-9,88^{a}$ & 3,96 & $-7,46^{b}$ & 3,30 & $-8,02^{b}$ & 3,17 & 0,00 \\
\hline 1-GoMe & 39,80 & 2,22 & 39,42 & 2,58 & 39,57 & 2,56 & 0,44 \\
\hline 6-Pogperp & $-29,50^{a}$ & 2,46 & $-28,77^{b}$ & 2,12 & $-28,97^{a}$ & 1,97 & 0,03 \\
\hline 6-GoMe & 28,47 & 1,92 & 28,11 & 2,01 & 28,35 & 2,09 & 0,25 \\
\hline \multicolumn{8}{|c|}{ Relações dentárias } \\
\hline T hor & 8,46 & 2,95 & 7,57 & 2,71 & 8,10 & 2,88 & 0,36 \\
\hline T vert & $4,65^{\mathrm{a}}$ & 1,93 & $3,76^{b}$ & 1,79 & $4,02^{b}$ & 2,11 & 0,03 \\
\hline Rel mol & $3,87^{\text {a,b }}$ & 0,62 & $3,48^{\mathrm{a}}$ & 1,50 & $4,20^{b}$ & 0,84 & 0,04 \\
\hline Rel can & $3,18^{a}$ & 0,93 & $3,81^{a}$ & 2,54 & $4,53^{b}$ & 1,44 & 0,04 \\
\hline
\end{tabular}




\section{Compatibilidade entre os grupos:}

TABELA 5 - Médias, desvios-padrão e resultado do teste t para a avaliação da compatibilidade entre as idades nos estágios pré-tratamento, pós-tratamento e de observação e do tempo de observação.

\begin{tabular}{|c|c|c|c|c|c|}
\hline \multirow[t]{2}{*}{ Variável } & \multicolumn{2}{|c|}{$\begin{array}{c}\text { Grupo } 1 \text { (Sem Xp) } \\
(n=30)\end{array}$} & \multicolumn{2}{|c|}{$\begin{array}{c}\text { Grupo } 2(\mathrm{Xp} \text { de } 2 \text { PM }) \\
(\mathrm{n}=30)\end{array}$} & \multirow[b]{2}{*}{$\mathrm{p}$} \\
\hline & Média & $\mathrm{dp}$ & Média & $\mathrm{dp}$ & \\
\hline Idade pré-tratamento & 12,14 & 1,36 & 12,87 & 1,49 & 0,05 \\
\hline Idade pós-tratamento & 14,82 & 1,55 & 15,40 & 1,71 & 0,17 \\
\hline Idade observação & 21,98 & 3,38 & 24,65 & 4,05 & 0,01 \\
\hline Tempo de observação & 7,15 & 3,26 & 9,25 & 3,52 & 0,02 \\
\hline
\end{tabular}

TABELA 6 - Resultado do teste Qui-quadrado para avaliar a compatibilidade entre os grupos quanto à proporção dos gêneros.

\begin{tabular}{|l|r|r|r|}
\hline & \multicolumn{1}{|c|}{ Masculino } & Feminino & \multicolumn{1}{c|}{ Total } \\
\hline Grupo 1 (Sem extração) & 14 & 16 & 30 \\
\hline Grupo 2 (Extrações 2PM) & 13 & 17 & 30 \\
\hline Total & 27 & 23 & 60 \\
\hline$X^{2}=0,07$ & $\mathrm{df}=1$ & $\mathrm{p}=0,80$ & \\
\hline
\end{tabular}

TABELA 7 - Resultado do teste Qui-quadrado para avaliar a compatibilidade entre os grupos quanto à proporção dos tipos de Classe II.

\begin{tabular}{|l|r|r|r|}
\hline & Classe II/1 & Classe II/2 & \multicolumn{1}{|c|}{ Total } \\
\hline Grupo 1 (Sem extração) & 25 & 5 & 30 \\
\hline Grupo 2 (Extrações 2PM) & 23 & 7 & 30 \\
\hline Total & 48 & 12 & 60 \\
\hline$X^{2}=0,42$ & $\mathrm{df}=1$ & $\mathrm{p}=0,52$ & \\
\hline
\end{tabular}

TABELA 8 - Resultados do teste Qui-quadrado para avaliar a compatibilidade entre os grupos quanto à proporção de pacientes que utilizavam contenção ântero-inferior $(3 \times 3)$ no estágio de observação.

\begin{tabular}{|l|r|r|r|}
\hline & \multicolumn{1}{|c|}{ Com 3x3 } & \multicolumn{1}{|c|}{ Sem 3x3 } & \multicolumn{1}{c|}{ Total } \\
\hline Grupo 1 (Sem extração) & 14 & 16 & 30 \\
\hline Grupo 2 (Extrações 2PM) & 13 & 17 & 30 \\
\hline Total & 27 & 23 & 60 \\
\hline$X^{2}=0,07$ & $\mathrm{df}=1$ & $\mathrm{p}=0,80$ & \\
\hline
\end{tabular}


TABELA 9 - Médias, desvios-padrão e resultado do teste t para a avaliação da compatibilidade entre os grupos no estágio pré-tratamento (T1).

\begin{tabular}{|c|c|c|c|c|c|c|}
\hline \multirow[t]{2}{*}{ Variáveis } & \multicolumn{2}{|c|}{$\begin{array}{l}\text { Grupo } 1 \text { (Sem Xp) } \\
\qquad(\mathrm{n}=30)\end{array}$} & \multicolumn{2}{|c|}{$\begin{array}{c}\text { Grupo } 2(\mathrm{Xp} 2 \mathrm{PM}) \\
(\mathrm{n}=30)\end{array}$} & \multirow[b]{2}{*}{ G.L } & \multirow[b]{2}{*}{$\mathrm{p}$} \\
\hline & Média & $\mathrm{dp}$ & Média & $\mathrm{dp}$ & & \\
\hline \multicolumn{7}{|c|}{ Componente maxilar } \\
\hline SNA & 81,53 & 3,31 & 81,21 & 3,54 & 58 & 0,72 \\
\hline Co-A & 85,54 & 4,65 & 86,52 & 5,07 & 58 & 0,44 \\
\hline A-Nperp & $-0,91$ & 2,92 & $-0,03$ & 3,80 & 58 & 0,32 \\
\hline \multicolumn{7}{|c|}{ Componente mandibular } \\
\hline SNB & 75,62 & 2,87 & 76,20 & 2,51 & 58 & 0,41 \\
\hline $\mathrm{CoGn}$ & 104,28 & 6,70 & 107,73 & 6,34 & 58 & 0,05 \\
\hline \multicolumn{7}{|c|}{ Relação maxilomandibular } \\
\hline ANB & 5,92 & 2,39 & 5,00 & 2,53 & 58 & 0,15 \\
\hline Wits & 5,40 & 2,72 & 4,91 & 2,24 & 58 & 0,45 \\
\hline \multicolumn{7}{|c|}{ Padrão facial } \\
\hline FMA & 26,89 & 5,33 & 26,03 & 4,77 & 58 & 0,52 \\
\hline SN.GoGn & 32,31 & 5,70 & 32,80 & 5,17 & 58 & 0,73 \\
\hline AFAI & 60,40 & 5,04 & 64,14 & 4,70 & 58 & 0,00 \\
\hline \multicolumn{7}{|c|}{ Componente dentoalveolar superior } \\
\hline 1.PP & 116,17 & 9,63 & 112,01 & 7,64 & 58 & 0,07 \\
\hline 1-PP & 26,09 & 2,46 & 28,47 & 2,53 & 58 & 0,00 \\
\hline 1-ENAperp & 0,56 & 3,27 & $-0,70$ & 2,93 & 58 & 0,12 \\
\hline 6-PP & 21,07 & 2,12 & 23,23 & 2,62 & 58 & 0,00 \\
\hline 6-ENAperp & $-28,50$ & 2,19 & $-28,24$ & 2,25 & 58 & 0,64 \\
\hline \multicolumn{7}{|c|}{ Componente dentoalveolar inferior } \\
\hline IMPA & 94,73 & 7,15 & 94,49 & 6,47 & 58 & 0,89 \\
\hline 1-Pogperp & $-8,51$ & 3,11 & $-9,85$ & 3,11 & 58 & 0,10 \\
\hline 1-GoMe & 37,69 & 3,11 & 38,92 & 2,60 & 58 & 0,10 \\
\hline 6-Pogperp & $-30,24$ & 2,54 & $-30,74$ & 2,36 & 58 & 0,43 \\
\hline 6-GoMe & 27,18 & 2,68 & 28,19 & 1,98 & 58 & 0,10 \\
\hline \multicolumn{7}{|c|}{ Relações dentárias } \\
\hline Thor & 8,15 & 2,93 & 7,51 & 2,39 & 58 & 0,36 \\
\hline T vert & 5,19 & 1,92 & 4,58 & 2,65 & 58 & 0,31 \\
\hline Rel mol & 3,56 & 0,81 & 3,73 & 0,64 & 58 & 0,38 \\
\hline Rel can & 3,41 & 1,29 & 4,02 & 1,46 & 58 & 0,09 \\
\hline
\end{tabular}


TABELA 10 - Médias, desvios-padrão e resultado do teste t para a comparação intergrupos dos valores das variáveis no estágio pós-tratamento (T2).

\begin{tabular}{|c|c|c|c|c|c|c|}
\hline \multirow[t]{2}{*}{ Variáveis } & \multicolumn{2}{|c|}{$\begin{array}{c}\text { Grupo } 1 \text { (Sem Xp) } \\
(\mathrm{n}=30)\end{array}$} & \multicolumn{2}{|c|}{$\begin{array}{c}\text { Grupo } 2 \text { (Xp } 2 \text { PM) } \\
(\mathrm{n}=30)\end{array}$} & \multirow[b]{2}{*}{ G.L } & \multirow[b]{2}{*}{$\mathrm{P}$} \\
\hline & Média & $\mathrm{dp}$ & Média & $\mathrm{dp}$ & & \\
\hline \multicolumn{7}{|c|}{ Componente maxilar } \\
\hline SNA & 80,11 & 2,97 & 79,39 & 3,36 & 58 & 0,38 \\
\hline $\mathrm{Co}-\mathrm{A}$ & 86,71 & 4,15 & 86,27 & 5,42 & 58 & 0,73 \\
\hline A-Nperp & $-1,86$ & 2,98 & $-2,54$ & 3,85 & 58 & 0,45 \\
\hline \multicolumn{7}{|c|}{ Componente mandibular } \\
\hline SNB & 76,36 & 2,88 & 76,55 & 2,76 & 58 & 0,79 \\
\hline CoGn & 110,54 & 6,31 & 111,94 & 6,39 & 58 & 0,40 \\
\hline \multicolumn{7}{|c|}{ Relação maxilomandibular } \\
\hline ANB & 3,77 & 2,44 & 2,85 & 2,19 & 58 & 0,13 \\
\hline Wits & 1,89 & 1,67 & 2,87 & 2,03 & 58 & 0,05 \\
\hline \multicolumn{7}{|c|}{ Padrão facial } \\
\hline FMA & 26,59 & 6,18 & 26,62 & 5,54 & 58 & 0,98 \\
\hline SN.GoGn & 31,88 & 6,36 & 32,59 & 6,06 & 58 & 0,66 \\
\hline AFAI & 65,24 & 5,97 & 67,13 & 4,54 & 58 & 0,17 \\
\hline \multicolumn{7}{|c|}{ Componente dentoalveolar superior } \\
\hline 1.PP & 111,50 & 6,98 & 112,96 & 7,11 & 58 & 0,43 \\
\hline 1-PP & 27,54 & 2,87 & 27,67 & 3,11 & 58 & 0,87 \\
\hline 1-ENAperp & $-3,03$ & 2,88 & $-2,62$ & 2,22 & 58 & 0,54 \\
\hline 6-PP & 23,00 & 2,47 & 24,71 & 2,07 & 58 & 0,01 \\
\hline 6-ENAperp & $-30,20$ & 2,15 & $-25,41$ & 2,23 & 58 & 0,00 \\
\hline \multicolumn{7}{|c|}{ Componente dentoalveolar inferior } \\
\hline IMPA & 96,87 & 7,62 & 95,37 & 7,69 & 58 & 0,45 \\
\hline 1-Pogperp & $-8,56$ & 3,76 & $-9,95$ & 3,06 & 58 & 0,12 \\
\hline 1-GoMe & 38,69 & 3,77 & 40,29 & 2,57 & 58 & 0,06 \\
\hline 6-Pogperp & $-29,63$ & 3,07 & $-31,03$ & 2,71 & 58 & 0,07 \\
\hline 6-GoMe & 30,28 & 3,57 & 30,78 & 2,27 & 58 & 0,52 \\
\hline \multicolumn{7}{|c|}{ Relações dentárias } \\
\hline Thor & 3,14 & 0,80 & 3,18 & 0,80 & 58 & 0,85 \\
\hline T vert & 2,27 & 1,15 & 1,85 & 0,94 & 58 & 0,13 \\
\hline Rel mol & $-0,87$ & 1,03 & 4,17 & 0,63 & 58 & 0,00 \\
\hline Rel can & $-0,39$ & 0,87 & $-2,00$ & 0,94 & 58 & 0,00 \\
\hline
\end{tabular}


TABELA 11 - Médias, desvios-padrão e resultado do teste t para a comparação intergrupos dos valores das variáveis no estágio de observação (T3).

\begin{tabular}{|c|c|c|c|c|c|c|}
\hline \multirow[t]{2}{*}{ Variáveis } & \multicolumn{2}{|c|}{$\begin{array}{c}\text { Grupo } 1 \text { (Sem Xp) } \\
(n=30)\end{array}$} & \multicolumn{2}{|c|}{$\begin{array}{c}\text { Grupo } 2 \text { (Xp 2PM) } \\
\qquad(\mathrm{n}=30)\end{array}$} & \multirow[b]{2}{*}{ G.L. } & \multirow[b]{2}{*}{ p } \\
\hline & Média & $\mathrm{dp}$ & Média & $\mathrm{dp}$ & & \\
\hline \multicolumn{7}{|c|}{ Componente maxilar } \\
\hline SNA & 80,54 & 3,25 & 81,29 & 3,34 & 58 & 0,38 \\
\hline $\mathrm{CoA}$ & 88,40 & 4,31 & 88,28 & 4,95 & 58 & 0,92 \\
\hline A-Nperp & $-2,21$ & 2,94 & $-0,14$ & 3,05 & 58 & 0,01 \\
\hline \multicolumn{7}{|c|}{ Componente mandibular } \\
\hline SNB & 76,93 & 3,60 & 77,36 & 3,39 & 58 & 0,63 \\
\hline $\mathrm{CoGn}$ & 113,22 & 5,96 & 114,15 & 6,74 & 58 & 0,57 \\
\hline \multicolumn{7}{|c|}{ Relação maxilomandibular } \\
\hline ANB & 3,61 & 2,18 & 3,93 & 1,82 & 58 & 0,54 \\
\hline Wits & 2,12 & 1,36 & 3,64 & 1,37 & 58 & 0,00 \\
\hline \multicolumn{7}{|c|}{ Padrão facial } \\
\hline FMA & 25,81 & 6,57 & 24,23 & 5,40 & 58 & 0,31 \\
\hline SN.GoGn & 30,45 & 7,15 & 30,45 & 6,78 & 58 & 1,00 \\
\hline AFAI & 66,21 & 6,29 & 67,66 & 5,46 & 58 & 0,34 \\
\hline \multicolumn{7}{|c|}{ Componente dentoalveolar superior } \\
\hline 1.PP & 110,30 & 7,61 & 113,37 & 7,14 & 58 & 0,11 \\
\hline 1-PP & 28,13 & 2,61 & 28,26 & 3,13 & 58 & 0,86 \\
\hline 1-ENAPerp & $-2,24$ & 3,45 & $-3,20$ & 2,93 & 58 & 0,25 \\
\hline 6-PP & 23,57 & 2,48 & 24,85 & 2,32 & 58 & 0,04 \\
\hline 6-ENAPerp & $-28,82$ & 2,54 & $-24,60$ & 2,31 & 58 & 0,00 \\
\hline \multicolumn{7}{|c|}{ Componente dentoalveolar inferior } \\
\hline IMPA & 97,47 & 6,34 & 95,71 & 7,01 & 58 & 0,31 \\
\hline 1-pogperp & $-9,01$ & 3,53 & $-9,09$ & 3,44 & 58 & 0,93 \\
\hline 1-GoMe & 40,16 & 4,07 & 41,02 & 3,09 & 58 & 0,36 \\
\hline 6-pogperp & $-29,35$ & 3,30 & $-29,00$ & 2,76 & 58 & 0,66 \\
\hline 6-GoMe & 31,75 & 4,01 & 32,04 & 2,35 & 58 & 0,73 \\
\hline \multicolumn{7}{|c|}{ Relações dentárias } \\
\hline Thor & 3,33 & 0,89 & 3,73 & 0,98 & 58 & 0,11 \\
\hline T vert & 3,25 & 1,37 & 2,89 & 1,28 & 58 & 0,31 \\
\hline Rel mol & $-0,71$ & 0,93 & 4,28 & 0,95 & 58 & 0,00 \\
\hline Rel can & $-0,20$ & 1,47 & $-0,76$ & 1,29 & 58 & 0,12 \\
\hline
\end{tabular}




\section{Alterações ocasionadas pelo tratamento:}

TABELA 12 - Médias, desvios-padrão e resultado do teste t para a comparação intergrupos das alterações do tratamento.

\begin{tabular}{|c|c|c|c|c|c|c|}
\hline \multirow[t]{2}{*}{ Variáveis } & \multicolumn{2}{|c|}{$\begin{array}{c}\text { Grupo } 1(\text { Sem Xp) } \\
(n=30)\end{array}$} & \multicolumn{2}{|c|}{$\begin{array}{c}\text { Grupo } 2 \text { (Xp } 2 \text { PM) } \\
(\mathrm{n}=26)\end{array}$} & \multirow[b]{2}{*}{ G.L } & \multirow[b]{2}{*}{$\mathrm{p}$} \\
\hline & Média & $\mathrm{dp}$ & Média & $\mathrm{dp}$ & & \\
\hline \multicolumn{7}{|c|}{ Componente maxilar } \\
\hline SNA & $-1,41$ & 1,95 & $-1,81$ & 1,86 & 58 & 0,42 \\
\hline CoA & 1,16 & 2,35 & $-0,25$ & 2,37 & 58 & 0,02 \\
\hline A-Nperp & $-0,95$ & 1,96 & $-2,51$ & 2,34 & 58 & 0,01 \\
\hline \multicolumn{7}{|c|}{ Componente mandibular } \\
\hline SNB & 0,73 & 1,76 & 0,34 & 1,02 & 58 & 0,30 \\
\hline CoGn & 6,26 & 4,34 & 4,22 & 3,62 & 58 & 0,05 \\
\hline \multicolumn{7}{|c|}{ Relação maxilomandibular } \\
\hline ANB & $-2,15$ & 2,13 & $-2,16$ & 1,64 & 58 & 0,99 \\
\hline Wits & $-3,51$ & 2,79 & $-2,04$ & 2,29 & 58 & 0,03 \\
\hline \multicolumn{7}{|c|}{ Padrão facial } \\
\hline FMA & $-0,30$ & 2,44 & 0,59 & 2,33 & 58 & 0,16 \\
\hline SN.GoGn & $-0,43$ & 2,30 & $-0,21$ & 2,26 & 58 & 0,71 \\
\hline AFAI & 4,84 & 2,90 & 2,99 & 2,61 & 58 & 0,01 \\
\hline \multicolumn{7}{|c|}{ Componente dentoalveolar superior } \\
\hline 1.PP & $-4,67$ & 10,56 & 0,95 & 9,37 & 58 & 0,03 \\
\hline 1-PP & 1,45 & 1,45 & $-0,80$ & 1,59 & 58 & 0,00 \\
\hline 1-ENAperp & $-3,59$ & 3,73 & $-1,92$ & 2,96 & 58 & 0,06 \\
\hline 6-PP & 1,93 & 1,58 & 1,48 & 1,43 & 58 & 0,25 \\
\hline 6-ENAperp & $-1,70$ & 2,30 & 2,83 & 1,83 & 58 & 0,00 \\
\hline \multicolumn{7}{|c|}{ Componente dentoalveolar inferior } \\
\hline IMPA & 2,14 & 5,24 & 0,87 & 5,67 & 58 & 0,37 \\
\hline 1-Pogperp & $-0,05$ & 2,16 & $-0,10$ & 1,81 & 58 & 0,92 \\
\hline 1-GoMe & 1,00 & 2,30 & 1,37 & 2,27 & 58 & 0,53 \\
\hline 6-Pogperp & 0,61 & 2,35 & $-0,28$ & 1,53 & 58 & 0,09 \\
\hline 6-GoMe & 3,11 & 2,03 & 2,59 & 1,41 & 58 & 0,25 \\
\hline \multicolumn{7}{|c|}{ Relações dentárias } \\
\hline Thor & $-5,01$ & 2,85 & $-4,33$ & 2,47 & 58 & 0,33 \\
\hline T vert & $-2,92$ & 1,50 & $-2,73$ & 2,53 & 58 & 0,73 \\
\hline Rel mol & $-4,44$ & 1,20 & 0,44 & 0,69 & 58 & 0,00 \\
\hline Rel can & $-3,80$ & 1,48 & $-6,02$ & 1,56 & 58 & 0,00 \\
\hline
\end{tabular}




\section{Alterações pós-tratamento:}

TABELA 13 - Médias, desvios-padrão e resultado do teste t para a comparação intergrupos das alterações ocorridas no período pós-tratamento (T3-T2).

\begin{tabular}{|c|c|c|c|c|c|c|}
\hline \multirow[t]{2}{*}{ Variáveis } & \multicolumn{2}{|c|}{$\begin{array}{c}\text { Grupo } 1 \text { (Sem Xp) } \\
(\mathrm{n}=30)\end{array}$} & \multicolumn{2}{|c|}{$\begin{array}{c}\text { Grupo } 2 \text { (Xp } 2 \text { PM) } \\
(\mathrm{n}=30)\end{array}$} & \multirow[b]{2}{*}{ G.L } & \multirow[b]{2}{*}{$\mathrm{p}$} \\
\hline & Média & $\mathrm{dp}$ & Média & $\mathrm{dp}$ & & \\
\hline \multicolumn{7}{|c|}{ Componente maxilar } \\
\hline SNA & 0,43 & 1,56 & 1,90 & 1,84 & 58 & 0,00 \\
\hline $\mathrm{Co}-\mathrm{A}$ & 1,69 & 2,08 & 2,02 & 2,60 & 58 & 0,60 \\
\hline A-Nperp & $-0,35$ & 2,05 & 2,40 & 2,82 & 58 & 0,00 \\
\hline \multicolumn{7}{|c|}{ Componente mandibular } \\
\hline SNB & 0,57 & 1,58 & 0,82 & 51,47 & 58 & 0,54 \\
\hline CoGn & 2,68 & 3,24 & 2,21 & 3,35 & 58 & 0,58 \\
\hline \multicolumn{7}{|c|}{ Relação maxilomandibular } \\
\hline ANB & $-0,16$ & 1,11 & 1,08 & 1,76 & 58 & 0,00 \\
\hline Wits & 0,23 & 1,09 & 0,77 & 2,57 & 58 & 0,29 \\
\hline \multicolumn{7}{|c|}{ Padrão facial } \\
\hline FMA & $-0,78$ & 2,61 & $-2,39$ & 2,99 & 58 & 0,03 \\
\hline SN.GoGn & $-1,42$ & 2,47 & $-2,14$ & 2,92 & 58 & 0,31 \\
\hline AFAI & 0,97 & 1,91 & 0,53 & 1,92 & 58 & 0,38 \\
\hline \multicolumn{7}{|c|}{ Componente dentoalveolar superior } \\
\hline 1.PP & $-1,20$ & 5,49 & 0,41 & 3,73 & 58 & 0,19 \\
\hline 1-PP & 0,59 & 1,11 & 0,59 & 1,33 & 58 & 0,99 \\
\hline 1-ENAperp & 0,79 & 2,30 & $-0,58$ & 2,10 & 58 & 0,02 \\
\hline 6-PP & 0,57 & 1,17 & 0,15 & 1,50 & 58 & 0,23 \\
\hline 6-ENAperp & 1,38 & 1,99 & 0,81 & 2,06 & 58 & 0,28 \\
\hline \multicolumn{7}{|c|}{ Componente dentoalveolar inferior } \\
\hline IMPA & 0,60 & 4,76 & 0,34 & 3,86 & 58 & 0,82 \\
\hline 1-Pogperp & $-0,46$ & 1,33 & 0,86 & 1,71 & 58 & 0,00 \\
\hline 1-GoMe & 1,47 & 1,50 & 0,73 & 1,17 & 58 & 0,04 \\
\hline 6-Pogperp & 0,28 & 1,50 & 2,02 & 1,82 & 58 & 0,00 \\
\hline 6-GoMe & 1,46 & 1,52 & 1,26 & 1,39 & 58 & 0,59 \\
\hline \multicolumn{7}{|c|}{ Relações dentárias } \\
\hline Thor & 0,19 & 0,97 & 0,55 & 1,19 & 58 & 0,21 \\
\hline T vert & 0,98 & 1,07 & 1,04 & 1,26 & 58 & 0,83 \\
\hline Rel mol & 0,16 & 0,77 & 0,11 & 0,96 & 58 & 0,82 \\
\hline Rel can & 0,19 & 1,35 & 1,23 & 1,51 & 58 & 0,00 \\
\hline
\end{tabular}


TABELA 14 - Médias, desvios-padrão e resultado do teste t para a comparação intergrupos das alterações ocorridas no período pós-tratamento (T3-T2), após a compatibilização do tempo de observação.

\begin{tabular}{|c|c|c|c|c|c|c|}
\hline Variáveis & \multicolumn{2}{|c|}{$\begin{array}{c}\text { Grupo } 1 \text { (Sem Xp) } \\
(n=30)\end{array}$} & \multicolumn{2}{|c|}{$\begin{array}{c}\text { Grupo } 2(\mathrm{Xp} 2 \mathrm{PM}) \\
(\mathrm{n}=26)\end{array}$} & \multirow[b]{2}{*}{ G.L } & \multirow[b]{2}{*}{$\mathrm{p}$} \\
\hline & Média & $\mathrm{dp}$ & Média & $\mathrm{dp}$ & & \\
\hline $\begin{array}{l}\text { Tempo de } \\
\text { observação }\end{array}$ & 7,15 & 3,26 & 8,54 & 3,14 & 54 & 0,11 \\
\hline \multicolumn{7}{|c|}{ Componente maxilar } \\
\hline SNA & 0,43 & 1,56 & 1,89 & 1,89 & 54 & 0,00 \\
\hline Co-A & 1,69 & 2,08 & 1,87 & 2,56 & 54 & 0,77 \\
\hline A-Nperp & $-0,35$ & 2,05 & 2,33 & 2,91 & 54 & 0,00 \\
\hline \multicolumn{7}{|c|}{ Componente mandibular } \\
\hline SNB & 0,57 & 1,58 & 0,78 & 1,50 & 54 & 0,62 \\
\hline CoGn & 2,68 & 3,24 & 1,99 & 3,34 & 54 & 0,43 \\
\hline \multicolumn{7}{|c|}{ Relação maxilomandibular } \\
\hline ANB & $-0,16$ & 1,11 & 1,12 & 1,82 & 54 & 0,00 \\
\hline Wits & 0,23 & 1,09 & 0,76 & 2,66 & 54 & 0,32 \\
\hline \multicolumn{7}{|c|}{ Padrão facial } \\
\hline FMA & $-0,78$ & 2,61 & $-2,29$ & 3,00 & 54 & 0,05 \\
\hline SN.GoGn & $-1,42$ & 2,47 & $-2,14$ & 3,01 & 54 & 0,33 \\
\hline AFAI & 0,97 & 1,91 & 0,51 & 1,78 & 54 & 0,35 \\
\hline \multicolumn{7}{|c|}{ Componente dentoalveolar superior } \\
\hline 1.PP & $-1,20$ & 5,49 & 0,44 & 3,59 & 54 & 0,19 \\
\hline 1-PP & 0,59 & 1,11 & 0,60 & 1,27 & 54 & 0,98 \\
\hline 1-ENAperp & 0,79 & 2,30 & $-0,58$ & 2,05 & 54 & 0,02 \\
\hline 6-PP & 0,57 & 1,17 & 0,06 & 1,47 & 54 & 0,15 \\
\hline 6-ENAperp & 1,38 & 1,99 & 0,64 & 1,94 & 54 & 0,15 \\
\hline \multicolumn{7}{|c|}{ Componente dentoalveolar inferior } \\
\hline IMPA & 0,60 & 4,76 & 0,20 & 3,96 & 54 & 0,73 \\
\hline 1-Pogperp & $-0,46$ & 1,33 & 0,88 & 1,73 & 54 & 0,00 \\
\hline 1-GoMe & 1,47 & 1,50 & 0,66 & 1,17 & 54 & 0,03 \\
\hline 6-Pogperp & 0,28 & 1,50 & 1,92 & 1,81 & 54 & 0,00 \\
\hline 6-GoMe & 1,46 & 1,52 & 1,20 & 1,36 & 54 & 0,48 \\
\hline \multicolumn{7}{|c|}{ Relações dentárias } \\
\hline Thor & 0,19 & 0,97 & 0,58 & 1,23 & 54 & 0,19 \\
\hline T vert & 0,98 & 1,07 & 0,99 & 1,27 & 54 & 0,96 \\
\hline Rel mol & 0,16 & 0,77 & 0,06 & 0,97 & 54 & 0,67 \\
\hline Rel can & 0,19 & 1,35 & 1,17 & 1,54 & 54 & 0,01 \\
\hline
\end{tabular}


TABELA 15 - Médias, desvios-padrão e resultado do teste t para a comparação intergrupos das alterações ocorridas no período pós-tratamento (T3-T2), após a exclusão dos pacientes com Classe II, Divisão 2.

\begin{tabular}{|c|c|c|c|c|c|c|}
\hline \multirow[t]{2}{*}{ Variáveis } & \multicolumn{2}{|c|}{$\begin{array}{c}\text { Grupo } 1(\text { Sem XP) } \\
(n=25)\end{array}$} & \multicolumn{2}{|c|}{$\begin{array}{c}\text { Grupo } 2(\mathrm{Xp} 2 \mathrm{PM}) \\
(\mathrm{n}=23)\end{array}$} & \multirow[b]{2}{*}{ G.L. } & \multirow[b]{2}{*}{$\mathrm{p}$} \\
\hline & Média & $\mathrm{dp}$ & Média & $\mathrm{dp}$ & & \\
\hline \multicolumn{7}{|c|}{ Componente maxilar } \\
\hline SNA & 0,66 & 1,32 & 1,76 & 1,91 & 46 & 0,02 \\
\hline $\mathrm{CoA}$ & 1,71 & 2,17 & 2,01 & 2,71 & 46 & 0,67 \\
\hline A-Nperp & $-0,14$ & 1,98 & 2,54 & 2,80 & 46 & 0,00 \\
\hline \multicolumn{7}{|c|}{ Componente mandibular } \\
\hline SNB & 0,69 & 1,46 & 0,65 & 1,54 & 46 & 0,92 \\
\hline CoGn & 2,77 & 3,40 & 2,37 & 3,39 & 46 & 0,68 \\
\hline \multicolumn{7}{|c|}{ Relação maxilomandibular } \\
\hline ANB & $-0,05$ & 1,16 & 1,11 & 1,79 & 46 & 0,01 \\
\hline Wits & 0,28 & 1,14 & 1,01 & 2,51 & 46 & 0,19 \\
\hline \multicolumn{7}{|c|}{ Padrão facial } \\
\hline FMA & $-1,11$ & 2,60 & $-2,50$ & 3,11 & 46 & 0,10 \\
\hline SN.GoGn & $-1,73$ & 2,30 & $-1,96$ & 3,20 & 46 & 0,77 \\
\hline AFAI & 0,80 & 1,99 & 0,44 & 1,87 & 46 & 0,52 \\
\hline \multicolumn{7}{|c|}{ Componente dentoaleolar superior } \\
\hline 1.PP & $-0,58$ & 5,16 & 0,55 & 3,90 & 46 & 0,40 \\
\hline 1-PP & 0,56 & 1,11 & 0,62 & 1,32 & 46 & 0,87 \\
\hline 1-ENAPerp & 1,10 & 2,14 & $-0,52$ & 2,18 & 46 & 0,01 \\
\hline 6-PP & 0,49 & 1,22 & 0,25 & 1,49 & 46 & 0,54 \\
\hline 6-ENAPerp & 1,39 & 1,90 & 1,01 & 2,05 & 46 & 0,51 \\
\hline \multicolumn{7}{|c|}{ Componente dentoalveolar inferior } \\
\hline IMPA & 0,78 & 4,99 & 0,15 & 3,92 & 46 & 0,63 \\
\hline 1-Pogperp & $-0,58$ & 1,43 & 0,93 & 1,67 & 46 & 0,00 \\
\hline 1-GoMe & 1,53 & 1,56 & 0,73 & 1,19 & 46 & 0,05 \\
\hline 6-Pogperp & 0,07 & 1,52 & 2,35 & 1,72 & 46 & 0,00 \\
\hline 6-GoMe & 1,56 & 1,60 & 1,10 & 1,43 & 46 & 0,31 \\
\hline \multicolumn{7}{|c|}{ Relações dentárias } \\
\hline Thor & 0,38 & 0,89 & 0,67 & 1,22 & 46 & 0,34 \\
\hline T vert & 1,16 & 0,99 & 1,13 & 1,30 & 46 & 0,94 \\
\hline Rel mol & 0,17 & 0,84 & 0,14 & 1,00 & 46 & 0,90 \\
\hline Rel can & 0,22 & 1,43 & 1,44 & 1,44 & 46 & 0,01 \\
\hline
\end{tabular}




\section{Correlações:}

TABELA 16 - Médias, desvios-padrão e resultado da análise de correlação entre as alterações das relações dentárias ocorridas durante o tratamento (T2-T1) e no período pós-tratamento (T3-T2).

\begin{tabular}{|c|c|c|c|c|c|c|}
\hline \multirow[t]{2}{*}{ Relações dentárias } & \multicolumn{2}{|c|}{$\begin{array}{c}\text { Alterações do } \\
\text { tratamento } \\
\text { (T2-T1) }\end{array}$} & \multicolumn{2}{|c|}{$\begin{array}{l}\text { Alterações pós- } \\
\text { tratamento } \\
\text { (T3-T2) }\end{array}$} & \multirow[b]{2}{*}{$\mathrm{r}$} & \multirow[b]{2}{*}{$\mathrm{p}$} \\
\hline & Média & $\mathrm{dp}$ & Média & $\mathrm{dp}$ & & \\
\hline T hor & $-4,67$ & 2,67 & 0,37 & 1,1 & $-0,41$ & 0,00 \\
\hline $\mathrm{T}$ vert & $-2,82$ & 2,07 & 1,01 & 1,16 & $-0,40$ & 0,00 \\
\hline Rel can & $-4,91$ & 1,88 & 0,71 & 0,51 & $-0,44$ & 0,00 \\
\hline$*$ & Média & $\mathrm{dp}$ & Média & $d p$ & $\mathrm{r}$ & $\mathrm{p}$ \\
\hline Rel mol - grupo 1 & $-4,44$ & 1,20 & 0,16 & 0,77 & $-0,39$ & 0,03 \\
\hline Rel mol - grupo 2 & 0,44 & 0,69 & 0,11 & 0,96 & $-0,03$ & 0,86 \\
\hline
\end{tabular}

* A correlação da relação molar foi separada por grupos devido à diferença de alteração dessa relação pelo tratamento.

TABELA 17 - Análise da correlação entre a alteração pós-tratamento da relação de caninos (Rel can T3 - Rel can T2) e as alterações pós-tratamento das demais variáveis cefalométricas estudadas.

\begin{tabular}{|l|l|r|r|}
\hline \multicolumn{2}{|c|}{ Variáveis T3 - T2 } & r & p \\
\hline \multirow{8}{*}{ Rel can } & SNA & 0,05 & 0,72 \\
\cline { 2 - 4 } & Co-A & $-0,02$ & 0,87 \\
\cline { 2 - 4 } & A-Nperp & 0,17 & 0,19 \\
\cline { 2 - 4 } & SNB & $-0,12$ & 0,35 \\
\cline { 2 - 4 } & Co-Gn & $-0,11$ & 0,38 \\
\cline { 2 - 4 } & ANB & 0,18 & 0,17 \\
\cline { 2 - 4 } & Wits & 0,08 & 0,55 \\
\cline { 2 - 4 } & FMA & $-0,06$ & 0,64 \\
\cline { 2 - 4 } & SN.GoGn & 0,06 & 0,64 \\
\cline { 2 - 4 } & AFAI & 0,02 & 0,89 \\
\cline { 2 - 4 } & 1.PP & 0,11 & 0,38 \\
\cline { 2 - 4 } & 1-PP & 0,09 & 0,50 \\
\cline { 2 - 4 } & 1-ENAperp & $-0,17$ & 0,19 \\
\cline { 2 - 4 } & 6-PP & 0,01 & 0,92 \\
\cline { 2 - 4 } & 6-ENAperp & $-0,07$ & 0,60 \\
\cline { 2 - 4 } & IMPA & $-0,03$ & 0,82 \\
\cline { 2 - 4 } & 1-Pogperp & $-0,02$ & 0,90 \\
\cline { 2 - 4 } & 1-GoMe & $-0,02$ & 0,89 \\
\cline { 2 - 4 } & 6-Pogperp & 0,02 & 0,12 \\
\cline { 2 - 4 } & 6-GoMe & 0,05 & 0,69 \\
\cline { 2 - 4 } & T hor & $\mathbf{0 , 3 4}$ & $\mathbf{0 , 0 1}$ \\
\cline { 2 - 4 } & T vert & 0,15 & 0,26 \\
\cline { 2 - 4 } & Rel mol & 0,18 & 0,16 \\
\hline
\end{tabular}




$$
\text { 6-Discussão }
$$





\section{6- DISCUSSÃO:}

Inicialmente será realizada a discussão da amostra, da compatibilidade entre os grupos, da metodologia de sua precisão. Em seguida, será discutido o resultado da comparação intergrupos das alterações póstratamento.

As medidas cefalométricas foram agrupadas em sete componentes: componente maxilar, componente mandibular, relação maxilomandibular, padrão facial, componentes dentoalveolares superior e inferior e relações dentárias. O comportamento de cada componente foi avaliado como um todo para que as grandezas fossem avaliadas dentro de um contexto e não isoladamente.

\section{1- Amostra}

As telerradiografias laterais que compuseram essa amostra se encontravam guardadas no arquivo da disciplina de Ortodontia da Faculdade de Odontologia de Bauru/USP. Esse arquivo possui, aproximadamente, quatro mil documentações ortodônticas de pacientes tratados nos cursos de pósgraduação em Ortodontia (lato sensu, strictu sensu e aperfeiçoamento) ministrados nessa faculdade. Esse vasto número de documentações disponíveis permitiu que se constituísse uma amostra satisfatoriamente padronizada.

Selecionaram-se, dessa forma, as documentações dos pacientes com Classe II completa e bilateral, no estágio pré-tratamento, e que foram tratados sem extração ou com a extração de dois pré-molares superiores. A disponibilidade desse tipo específico de paciente era a seguinte: 43 tratados sem extração e 69 tratados com extração de dois pré-molares superiores.

Essa diferença entre o número de pacientes tratados com os protocolos estudados pode ser conseqüente à dificuldade inerente ao tratamento da Classe II sem extração, pois este protocolo requer mais colaboração dos pacientes para o uso do aparelho extrabucal, aparelhos ortopédicos e/ou elásticos intermaxilares e a ocorrência de colaboração 
insuficiente acarreta a substituição do plano de tratamento inicialmente sem extração, por um que inclua a realização de extrações ${ }^{15,16,116,117,128,223}$.

Nas 112 documentações dos pacientes que apresentavam os prérequisitos para integrar a amostra, checou-se a presença das telerradiografias pré-tratamento, pós-tratamento e de observação tomada, no mínimo, 2,4 anos após o término do tratamento. Constatou-se que a maioria das documentações não apresentava a telerradiografia de observação. Entretanto as documentações que não tinham essa telerradiografia não foram excluídas da amostra a princípio, porque se planejou localizar tais pacientes e convocá-los para a tomada radiográfica faltante. No entanto, posteriormente, alguns pacientes acabaram sendo substituídos por outros, por não terem sido localizados ou não comparecerem à consulta agendada.

Finalmente, a amostra foi constituída de 180 telerradiografias laterais de 60 pacientes e esse número foi considerado suficiente baseado nas amostras de outros estudos, que também avaliaram a estabilidade das correções ortodônticas ${ }^{170,227}$. O tamanho da amostra necessário para a obtenção de resultados confiáveis se baseia no comportamento do parâmetro a ser avaliado, ou seja, quando se almeja estudar um efeito de grande expressão ou que sofre pequena variação é necessária uma amostra menor do que quando se estuda um parâmetro que sofre muita variação, caso em que há a necessidade de um maior número de observações para se verificar o efeito estudado $^{210}$.

Para que suas telerradiografias integrassem a amostra, os pacientes deveriam apresentar ainda a ausência de anormalidades dentárias, como perdas dentárias precoces, anomalias de forma (macrodentes, microdentes entre outras) e de número (ausência congênita ou presença de supranumerários), pois a presença dessas alterações poderia requerer a realização de procedimentos diferenciados durante o tratamento, ocasionar a obtenção de uma finalização insatisfatória ou alterar a estabilidade.

A amostra também foi padronizada quanto ao tipo da má oclusão inicial, pois se almejava estudar especificamente a estabilidade das correções da má oclusão de Classe $\mathbb{I}^{210}$. Além disso, esse fator permitiu a obtenção de uma amostra mais homogênea quanto às características esqueléticas, ao 
padrão de crescimento e à necessidade de compensações dentárias, o que torna esse critério de inclusão de elementos na amostra, superior à seleção por tipo de tratamento (com ou sem extrações) ${ }^{10,210}$. Todavia, nesse estudo, esses dois critérios foram empregados, pois se buscou eliminar ao máximo as variáveis capazes de influenciar os resultados, visto que a literatura é controversa a respeito do assunto abordado 27,217 . Enquanto há autores que afirmam que a estabilidade é diferente para as más oclusões de Classe I e Classe II corrigidas ${ }^{217}$ outros afirmam que, embora magnitudes e tipos de má oclusão diferentes requeiram o emprego de protocolos de tratamento distintos, a recidiva, geralmente, apresenta-se da mesma maneira, independentemente do tipo de má oclusão inicial ${ }^{27}$. Da mesma maneira, a presença de uma Classe II bilateral também foi indispensável para que os pacientes integrassem a amostra, já que os protocolos de tratamento estudados não são rotineiramente empregados no tratamento de más oclusões assimétricas.

A padronização da amostra quanto ao tipo de tratamento instituído foi indispensável durante a composição da amostra, haja vista que o objetivo do tratamento era exatamente comparar a estabilidade das correções decorrentes do tratamento sem extração e com a extração de dois pré-molares superiores. Os estudos que comparam a estabilidade das correções instituídas pelo tratamento sem extração àquela obtida com o tratamento com a extração de quatro pré-molares ${ }^{10,30,75}$ ou com extração de dois e de quatro pré-molares simultaneamente ${ }^{162,227}$ concluem que a estabilidade independe do tipo de tratamento empregado. Todavia, a literatura á carente de estudos que comparam a estabilidade dos resultados dos dois protocolos estudados neste trabalho, apesar de alguns autores afirmarem que o tratamento com a extração de dois pré-molares não apresenta estabilidade satisfatória ${ }^{91,144,147,175}$.

Desta forma, apesar de vários estudos mostrarem que a estabilidade independe do tipo de má oclusão, do gênero e da realização ou não de extrações dentárias ${ }^{27,71}$, a padronização da amostra quanto a estes fatores elimina possíveis questionamentos provenientes daqueles autores que afirmam o contrário ${ }^{125,192}$ e por isso foi realizada.

Considerando-se que o sucesso da correção da Classe II pode variar de acordo com a severidade da má oclusão inicial ${ }^{108,223}$, pois estudos 
comprovaram que, quanto maior a magnitude da má oclusão de Classe II, menor a taxa de sucesso de seu tratamento sem extração ${ }^{219}$ e que, no tratamento de pacientes com discrepância anteroposterior entre as bases ósseas mais acentuada e com sobressaliência e protrusão dos incisivos superiores de grande magnitude, melhores resultados são alcançados quando são realizadas as extrações dos dois pré-molares superiores ${ }^{115}$, julgou-se necessário realizar a padronização da amostra quanto à magnitude dá má oclusão inicial, selecionado-se apenas pacientes com Classe II completa.

Em trabalho anterior, BARROS ${ }^{16}$ (2004) utilizou essa mesma amostra para comparar o grau de eficiência dos protocolos de tratamento e, para isso, calculou os valores do índice IPT (índice de prioridade do tratamento). Esse índice quantifica as características da oclusão como a sobressaliência, a sobremordida, o apinhamento, a presença de mordida cruzada, pois gera um escore representativo da oclusão avaliada. O escore zero representa a normalidade e quanto maior o valor do índice, maior o desvio da oclusão em relação à normalidade ${ }^{95}$.

No presente estudo, para a padronização da condição oclusal presente ao término do tratamento, realizou-se a compatibilização dos grupos quanto aos valores de IPT medidos nesse estágio por BARROS ${ }^{16}$ (2004). Os pacientes que apresentavam valores de IPT altos e, discrepantes em relação à média, ou seja, que apresentavam resultados oclusais inferiores aos da maioria da amostra, foram eliminados.

Esta padronização foi realizada, pois há autores que afirmam haver relação diretamente proporcional entre a estabilidade do tratamento ortodôntico e a condição oclusal presente no final do tratamento ${ }^{7,10,27,73}$. Além disso, esse procedimento permitiu discernir a recidiva das más relações dentárias oriundas de tratamento mal finalizado ${ }^{71}$.

Apesar de haver comprovações que negam a existência da relação estabilidade/resultado oclusal final ${ }^{141,165}$, a manutenção deste fator poderia gerar questionamentos sobre a confiabilidade dos resultados deste trabalho por aqueles que afirmam o contrário ${ }^{7,10,27,73}$. De acordo com SADOWSKY; SAKOLS $^{183}$ (1982), apesar de se buscar sempre uma oclusão ideal no final do tratamento, a ocorrência de alterações no período pós-tratamento é inevitável e 
é classificada como recidiva dependendo de sua magnitude e da exigência do observador.

Como dito anteriormente, as telerradiografias de observação foram tomadas há, no mínimo, 2,4 anos, pois as alterações pós-tratamento parecem ser mais expressivas nos dois primeiros anos após o término do tratamento ${ }^{26}$. De acordo com a literatura, os tempos mínimos necessários para uma avaliação confiável da recidiva são de $2 \operatorname{anos}^{100,105,201,230}, 5 \operatorname{anos}^{184}, 7$ anos $^{165}$ entre outros.

Quanto ao tipo de aparelho utilizado para a correção da Classe II sem extração, dos 30 pacientes cujas telerradiografias integraram o grupo 1, apenas três tiveram a correção da relação molar feita exclusivamente pela distalização dos molares superiores com o uso do aparelho extrabucal, pois os outros 12 pacientes que utilizaram o aparelho extrabucal precisaram ter a correção complementada pela utilização de elásticos intermaxilares de Classe II.

Existem autores que afirmam que a distalização máxima dos molares superiores pela utilização do aparelho extrabucal varia de 2 a 2,5mm e que, quando a distalização é insuficiente para corrigir a discrepância anteroposterior, torna-se necessário utilizar também uma mecânica que promova a mesialização dos molares inferiores ${ }^{15}$. Nesse estudo, verificou-se que na maioria dos pacientes que utilizaram o $A E B$, realmente foi necessária a utilização de elásticos de Classe II como terapia complementar, provavelmente, devido à necessidade de mesialização dos molares inferiores ou ainda devido à diminuição da colaboração do paciente que pode ocorrer com o passar do tempo e com o prolongamento do tratamento.

Os demais pacientes utilizaram os aparelhos ortopédicos Bionator de Balters (sete pacientes), Ativador (seis pacientes), Splint maxilar (um paciente) ou Cantilever Bite Jumper - CBJ® (um paciente), porém associados à utilização de aparelho extrabucal e à complementação da mecânica de Classe II com elásticos em 14 dos 15 pacientes, ou seja, somente um paciente utilizou exclusivamente o Bionator. Sabe-se que os efeitos desses aparelhos ortopédicos são semelhantes como restrição do desenvolvimento maxilar, protrusão mandibular, melhora na relação maxilomandibular, verticalização e 
retrusão dos incisivos superiores, vestibularização dos incisivos inferiores, entre outros ${ }^{4,112}$.

O fato de o grupo 1 apresentar heterogeneidade dos procedimentos utilizados para correção da Classe II não interferiu negativamente nos resultados obtidos, já que os efeitos proporcionados pela utilização dos aparelhos extrabucais são semelhantes aos obtidos com a utilização dos aparelhos ortopédicos ${ }^{84,98,127}$ e com a utilização dos elásticos intermaxilares de Classe $1{ }^{229}$ e a estabilidade das correções parece ser semelhante ${ }^{154,194}$.

\section{2- Compatibilidade entre os grupos:}

Considerando-se que diversos fatores podem, supostamente, interferir na estabilidade das correções ortodônticas como o crescimento, o tempo de observação pós-tratamento, o gênero, o tipo de má oclusão tratada, a utilização de contenção entre outros, para a comparação da estabilidade de dois tipos de tratamento diferentes, quanto maior o número de fatores semelhantes entre os grupos comparados, maior a precisão dos resultados.

O crescimento que ocorre após a remoção dos aparelhos pode interferir negativamente na estabilidade das correções ortodônticas se alterar de maneira indesejada as posições dentárias e a oclusão. Dessa maneira, é importante que se conheçam as alterações normais decorrentes do crescimento para diferenciá-las da recidiva ${ }^{58,72,100,105}$.

Quando se verifica a presença de compatibilidade entre as idades dos pacientes que compõem os grupos comparados, supõe-se que a quantidade de crescimento a ser observada neles é semelhante.

Neste estudo, houve compatibilidade intergrupos das idades nos estágios pré-tratamento e pós-tratamento e incompatibilidade no estágio de observação e, conseqüentemente, do tempo de observação pós-tratamento (Tabela 5).

A compatibilidade entre as idades no estágio pré-tratamento possibilitou que se considerassem semelhantes as alterações do crescimento durante o tratamento, além de eliminar a influência da idade no grau de dificuldade da correção da Classe II, já que ele é maior quanto maior a idade 
do paciente ${ }^{69,99,170,218}$. A compatibilidade no estágio pós-tratamento permitiu que se admitisse que a quantidade de crescimento remanescente a ser observada após a remoção dos aparelhos era semelhante.

No estágio de observação, seria ideal que as idades também fossem compatíveis, pois isso demonstraria semelhança nos tempos de observação pós-tratamento, já que os pacientes apresentavam idades compatíveis em T2. Entretanto, ocorreu diferença estatisticamente significante entre as idades dos pacientes nesse estágio decorrente da diferença observada no tempo de observação pós-tratamento (Tabela 5).

Considerando-se que a recidiva pode ocorrer imediatamente após a remoção dos aparelhos ou após alguns meses ou anos e que, na literatura, há autores que afirmam que quanto mais tempo decorrer do término do tratamento para avaliação da estabilidade, maior é a chance de se observar a recidiva ${ }^{82,183,230}$, os grupos foram compatibilizados quanto ao tempo de observação e se realizou um novo teste de comparação intergrupos das alterações pós-tratamento. Os resultados do novo teste mostraram que o tempo de observação não interferiu na estabilidade das correções, pois esta foi semelhante àquela obtida quando se compararam os grupos com tempos de observação incompatíveis (Tabelas 13 e 14, respectivamente).

Outro fator que pode interferir na estabilidade dos resultados é a diferença intergrupos das proporções dos gêneros, haja vista que 0 crescimento é mais adiantado no gênero feminino ${ }^{78,148,165,199,200}$. Apesar de haver estudos que comprovem a inexistência de relação entre gênero e recidiva $^{71}$, a compatibilidade entre os gêneros foi testada e a sua ocorrência permitiu a eliminação desse fator e a possibilidade de sua interferência nos resultados (Tabela 6).

Os tipos de Classe II apresentam caracterísiticas cefalométricas e dentárias específicas e isso pode interferir no tipo de recidiva ${ }^{13,171}$. Todavia, a ocorrência de compatibilidade intergrupos entre as proporções de Classe II, Divisão 1 e 2, observada neste estudo, elimina este fator (Tabela 7). Mesmo assim, para verificação da interferência desse fator sobre os resultados, realizou-se a eliminação dos pacientes com Classe II, Divisão 2, de ambos os grupos, e um novo teste para a comparação das alterações ocorridas no 
período pós-tratamento foi realizado. Não se constatou diferença na estabilidade quando se avaliou a amostra composta por pacientes com os dois tipos de Classe II (Tabela 13) ou apenas com Classe II, Divisão 1 (Tabela 16).

Durante a avaliação das telerradiografias do estágio de observação, constatou-se que alguns pacientes de ambos os grupos ainda apresentavam a contenção ântero-inferior de canino a canino (3×3). É importante ressaltar que a utilização desse tipo de contenção, por um longo período, favorece significantemente a estabilidade da correção do apinhamento ${ }^{10,140,159,166}$, mas essa contenção pode também influenciar, ainda que em menor grau, a estabilidade dos incisivos inferiores no sentido vestibulolingual $e$, conseqüentemente, a estabilidade da sobressaliência e da sobremordida ${ }^{139}$. Todavia, a proporção desses pacientes, nos dois grupos, era estatisticamente semelhante, conforme demonstrado na Tabela 8 , o que implica em semelhança da influência desse fator nos grupos.

Apesar de a amostra ter sido rigorosamente selecionada, a compatibilidade intergrupos das medidas cefalométricas no estágio prétratamento foi testada (Tabela 9).

Os dois grupos apresentavam semelhança do componente maxilar, do mandibular e, conseqüentemente, da relação maxilomandibular. Entretanto, a altura facial ântero-inferior (AFAl) e o desenvolvimento vertical dos molares superiores (6-PP) eram maiores no grupo 2, ou seja, nos pacientes que foram tratados com a extração de dois pré-molares. Essa diferença aponta uma suave tendência de crescimento vertical nesses pacientes que pode ter influenciado a escolha do protocolo de tratamento com extrações dentárias $^{121,130,197}$, apesar de haver relatos na literatura de que a realização de extrações dentárias não influencia significantemente a alteração da dimensão vertical $^{204}$. Ainda quanto ao componente dentoalveolar superior, os incisivos superiores apresentavam um maior desenvolvimento vertical no grupo 1.

O componente dentoalveolar inferior apresentou-se semelhante, assim como as relações dentárias e esta ocorrência foi importante para garantir que os pacientes apresentassem o mesmo tipo e magnitude de má oclusão a ser tratada. 
Da mesma forma que foram avaliadas as características cefalométricas intergrupos no estágio pré-tratamento, verificou-se também se essas características eram semelhantes ou diferentes no estágio póstratamento (Tabela 10) e foi constatada semelhança dos componentes maxilar e mandibular, da relação maxilomandibular, do padrão facial e do componente dentoalveolar inferior.

A medida 6-PP se manteve maior no grupo 2, o que demontra que a suave tendência de crecimento vertical desse grupo se manteve inalterada, apesar do tratamento ${ }^{46}$.

Outra medida que apresentou diferença entre os grupos foi a 6ENAperp e isso já era esperado porque, no grupo 1, os molares foram distalizados, durante o tratamento, até que se obtivesse uma relação de Classe I e, no grupo 2, esses dentes foram mantidos numa relação de Classe II. Adicionalmente a isso, observou-se diferença intergrupos da relação molar, que também já era esperada.

Quanto à relação de caninos, o tratamento com a extração de dois pré-molares superiores propiciou uma melhor correção dessa relação, ou seja, obteve-se uma relação de caninos mais próxima de uma relação de Classe I, corroborando a literatura ${ }^{110,121}$. É importante ressaltar que os grupos já haviam sido compatibilizados quanto ao valor do IPT calculado ao final do tratamento, porém, quando se avaliou mais detalhadamente, ou seja, cefalometricamente, a relação oclusal nesse estágio, constatou-se essa diferença na relação de caninos. A eliminação de pacientes com a finalidade de padronizar esse fator, diminuiria ainda mais o número da amostra e por isso não foi realizada.

\section{3- Metodologia}

Ao se utilizarem as telerradiografias laterais como material de investigação científica, depara-se com vantagens e desvantagens como quando da utilização de qualquer material. A avaliação das características de um paciente apenas por meio de telerradiografias priva o pesquisador das análises clínica e de modelos, que poderiam acrescentar mais riqueza de detalhes à investigação. Nesse estudo, porém, a análise clínica dos pacientes 
cujas telerradiografias compõem a amostra, nos três estágios de avaliação, seria difícil de ser realizada, já que seria necessário acompanhar e avaliar o paciente por um período demasiadamente longo.

Contudo, as telerradiografias laterais são vantajosas por permitirem a avaliação das características esqueléticas, alteração do perfil facial, padrão de crescimento craniofacial entre outras informações relevantes que não são possíveis de serem obtidas pela análise de modelos ou clínica ${ }^{71,114,167,170}$. Apesar de o estudo dos modelos apresentar superioridade para avaliação da manutenção do alinhamento dentário, esta avaliação não foi escopo deste estudo, o que diminuiu a necessidade da utilização deste material ${ }^{10,27,166}$, além de que para o exame da estabilidade das relações dentárias, a avaliação cefalométrica é tão satisfatória quanto a avaliação de modelos ${ }^{75}$ e apresenta a vantagem adicional de permitir a investigação da influência das demais variáveis cefalométricas sobre a estabilidade.

Apesar de os estudos retrospectivos sofrerem críticas por utilizarem em sua amostra apenas os registros de pacientes que responderam satisfatoriamente ao tratamento e eliminar aqueles que não colaboraram ou que tiveram crescimento craniofacial desfavorável, a maioria dos estudos sobre estabilidade é realizado retrospectivamente devido ao longo período de observação envolvido neste tipo de avaliação ${ }^{210}$.

Neste estudo, devido ao seu caráter retrospectivo, o acompanhamento das tomadas de todas as telerradiografias que compuseram esta amostra não foi possível, sendo acompanhadas apenas as telerradiografias de observação realizadas recentemente. Entretanto, as telerradiografias que apresentavam qualidade inadequada, por terem sido tomadas sem supervisão ou devido ao processamento ou armazenamento insatisfatórios por um longo período de tempo, foram excluídas da amostra, uma vez que este fator poderia aumentar a chance de ocorrerem erros durante os traçados ${ }^{71}$. Desta forma, nesse estudo foram utilizadas apenas as telerradiografias que apresentavam qualidade satisfatória para serem traçadas com precisão.

O traçado cefalométrico confeccionado manualmente em sala escurecida foi conferido por um examinador antes da demarcação dos pontos a 
serem utilizados para a sua digitalização ${ }^{165,184}$. A medição digital das grandezas cefalométricas otimizou esse trabalho, pois permitiu que se trabalhasse com um maior número de dados em um menor período de tempo, além de diminuir a probabilidade de ocorrerem erros durante a obtenção dos valores $22,176,190$.

O programa utilizado neste estudo, o Dentofacial Planner, é amplamente utilizado e apresenta grande confiabilidade, pois realiza as medições com precisão de décimos de milímetros ou de graus, o que seria inviável de se obter com a medição manual ${ }^{29,42,119,170}$. Além disso, permite que se realize a correção dos valores de magnificação das telerradiografias, possibilitando que telerradiografias tomadas em diferentes aparelhos de raios $X$ possam ser precisamente comparadas ${ }^{106}$.

Durante a seleção das estruturas que compuseram o traçado anatômico e a seleção das medidas que foram realizadas, considerou-se sua importância para a avaliação da estabilidade ${ }^{112,121}$. Quando necessário, os traçados das telerradiografias de um mesmo paciente foram realizados em seqüência para minimizar a imprecisão na determinação das estruturas anatômicas, pois se realizou a comparação de imagens, de difícil visualização em uma das radiografias, com as demais ${ }^{106}$.

Desta forma, esta metodologia cumpriu perfeitamente a proposta desse estudo e é por isso que se observa na literatura sua ampla utilização para a avaliação da estabilidade das correções ortodônticas ${ }^{30,73,75,88}$.

\section{4- Precisão da metodologia}

Erro intra-examinador: (Tabela 3)

Os erros em medidas cefalométricas sempre ocorrem, entretanto, deve-se minimizá-los a fim de assegurar a precisão da metodologia e evitar confusão entre alterações reais e erros de medição ${ }^{142}$. Isso torna a verificação do erro do método particularmente importante nas investigações radiográficas, pois as radiografias apresentam vários fatores potencialmente capazes de interferir na obtenção fiel do traçado e das medidas cefalométricas ${ }^{106}$. Considerando-se que, quanto mais precisa a metodologia mais fiéis são as 
conclusões inferidas, um trabalho que não quantifica o erro do método deve ser avaliado com suspeita.

Para a verificação do erro intra-examinador, o traçado, a digitalização e a medição de 20 telerradiografias selecionadas aleatoriamente foram realizados exatamente nas mesmas condições e seguindo rigorosamente os mesmos critérios utilizados para o traçado e a digitalização de todas as telerradiografias que compuseram a amostra.

O erro sistemático, calculado pelo teste t pareado com valor de $p<0,05$, decorre da sub ou superestimação de um parâmetro, ou seja, da tentativa inconsciente do operador de sub ou superestimar os valores de suas medições, direcionando os resultados de acordo com suas expectativas. Neste estudo, obteve-se erro sistemático estatisticamente significante para 5 medidas dentre as 24 realizadas, o que indica oportuna precisão da metodologia, com $80 \%$ de precisão. A medida cefalométrica IMPA, por exemplo, que utiliza o ponto localizado no ápice do incisivo inferior, apresentou erro significante e isso pode ter decorrido da dificuldade de localização desse ponto devido à sobreposição de imagens que ocorre nessa área da mandíbula ${ }^{21,189}$ e de seu elevado grau de subjetividade.

O erro casual, calculado pela fórmula proposta por DAHLBERG ${ }^{62}$ (1940), quantifica a imprecisão do operador durante a demarcação dos pontos cefalométricos. Quando se avaliou a ocorrência de erro casual, constatou-se satisfatória precisão da metodologia com apenas 2 medidas (Co-A e IMPA), dentre as 24 , apresentando valores de erro maiores do que $2 \mathrm{~mm}$.

Desta forma, pode-se considerar que a metodologia empregada apresentou satisfatória precisão, o que dá confiabilidade aos resultados deste trabalho.

Erro interexaminador: (Tabela 4)

A verificação do erro interexaminador, que quantifica o grau de calibração dos operadores ${ }^{106}$, foi realizada nesse estudo, pois três operadores participaram da obtenção dos dados. Observou-se a ocorrência de erro em 9 das 24 medidas realizadas, o que indica uma precisão de 62,5\%. Esse valor é 
considerado satisfatório quando comparado aos relatos na literatura, em que a porcentagem de precisão entre dois operadores varia de 60 a $77 \%{ }^{135}$.

Para a avaliação desse erro, é importante considerar que a precisão na demarcação dos pontos cefalométricos repetidas vezes por um mesmo operador sempre é maior do que a demarcação de um mesmo ponto por vários operadores, o que demonstra que a quantidade de erro interexaminador tende a ser maior do que a de erro intra-examinador ${ }^{203,209}$.

Além disso, das 9 medidas que apresentaram erro, apenas 2 (6Pogperp e Rel mol) apresentaram erro entre a autora desse trabalho e os demais operadores, ou seja, 7 medidas apresentaram erro entre os outros dois operadores. A significância dessa ocorrência aumenta se for considerado o fato de que a metade das telerradiografias do estágio pós-tratamento e todas as telerradiografias do estágio de observação foram traçadas pela autora deste trabalho (operadora J.A.), e que estas eram as telerradiografias mais importantes para a comparação da estabilidade.

\section{5- Resultados}

Nesse tópico foi priorizada a discussão das alterações ocorridas no período pós-tratamento que apresentaram diferenças entre os grupos. As alterações ocorridas durante o tratamento, assim como os valores das medidas nos três estágios de avaliação, foram consideradas quando auxiliavam na explicação das alterações ocorridas no período pós-tratamento.

Quanto às relações dentárias, apesar de apenas a relação de caninos apresentar diferença intergrupos no período pós-tratamento, todas foram discutidas devido à grande importância clínica de sua estabilidade.

\section{- Componente maxilar:}

O comportamento do componente maxilar diferiu entre os grupos no período pós-tratamento e esta diferença pode ser observada pela variação do ângulo SNA e da medida A-Nperp (Tabela 13). 
Embora tenha ocorrido protrusão maxilar em ambos os grupos após o tratamento, quando se observa o ângulo SNA, nota-se a ocorrência de maior protrusão no grupo $2(1,9 \mathrm{~mm})$. Além disso, pode-se considerar que a alteração observada no grupo 1 foi clinicamente insignificante, pois foi uma alteração de 0,43mm ocorrida em 7,2 anos e segundo AELBERS; DERMAUT ${ }^{1}$ (1996), as alterações que não excedem $1^{\circ}$ ou $1 \mathrm{~mm}$ possuem pouca significância clínica.

Similarmente, a medida A-Nperp demonstrou retrusão maxilar no grupo 1 , contudo de valor insignificante clinicamente $(0,35 \mathrm{~mm})$ e protrusão maxilar de 2,4mm, no grupo 2. Diante disso, pode-se supor que a diferença observada na avaliação intergrupos ocorreu devido à pequena alteração maxilar no grupo 1 e protrusão maxilar expressiva no grupo 2 .

A explicação para essas diferenças pode ser encontrada quando se compara as alterações do tratamento nos dois grupos (Tabela 12). No grupo 2 , provavelmente, a maior protrusão maxilar pós-tratamento decorreu da maior retrusão maxilar instituída pelo tratamento (não significante para SNA e significante para A-Nperp e Co-A). Por ter ocorrido maior alteração pelo tratamento, a alteração pós-tratamento também foi maior.

O posicionamento do ponto A pode sofrer influência da alteração da inclinação dos incisivos superiores e no grupo 2, provavelmente o ponto $A$ foi mais retruído durante 0 tratamento porque estes dentes foram menos lingualizados do que no grupo 1. Isso ocorreu porque no tratamento com extrações se realiza a aplicação de torque vestibular resistente ao arco retangular durante o fechamento dos espaços das extrações ${ }^{126}$ e também devido ao nivelamento da curva de Spee ser realizado com arcos contínuos, que promovem intrusão associada à vestibularização dos dentes anteriores.

No tratamento sem extração, grande parte do nivelamento da curva de Spee já é realizada durante a utilização dos aparelhos ortopédicos, que favorecem a extrusão dos dentes posteriores, ou de elásticos intermaxilares de Classe II, que ocasionam extrusão dos molares inferiores, necessitando de menor acentuação da curva.

A protrusão maxilar pós-tratamento observada no grupo 2 concorda com os resultados de outros estudos ${ }^{10,75,170}$, porém a recidiva nesse estudo foi maior do que naqueles. Isto pode ter decorrido de diferenças metodológicas, 
uma vez que os outros avaliaram a estabilidade do tratamento realizado com extrações de quatro pré-molares. No tratamento da Classe II com extrações de quatro pré-molares, a quantidade de retração instituída durante o tratamento pode ser menor do que no tratamento com duas extrações devido ao fato desse protocolo ser corriqueiramente empregado em casos de apinhamento superior e inferior. Sabe-se que quanto maior o apinhamento, menor o espaço da extração a ser fechado pela retração dos dentes anteriores e que quanto maior a alteração pelo tratamento, maior tende a ser a alteração póstratamento $^{10,230}$.

$$
\text { MELSEN }^{153} \text { (1978), GLENN; SINCLAIR; ALEXANDER }{ }^{88}
$$

observaram que ocorre diminuição do SNA durante o tratamento com aparelho extrabucal devido à restrição do deslocamento anterior da maxila. Entretanto, a maxila exibe uma tendência de expressar seu desenvolvimento em sentido anterior no período pós-tratamento.

ELMS et al. ${ }^{73}$ (1996) encontraram resultados concordantes com o desse estudo, visto que não encontraram alterações significantes na posição maxilar, no período pós-tratamento, em pacientes tratados sem extração.

\section{- Componente mandibular}

No período pós-tratamento não ocorreu diferença entre as medidas mandibulares dos grupos (Tabela 13), o que demonstra que o emprego de ambos os protocolos promove estabilidade das posições e dimensões mandibulares presentes ao término do tratamento.

Enquanto alguns autores verificaram que os aparelhos ortopédicos promovem maior aumento do comprimento mandibular durante 0 tratamento $^{64,79}$, outros constataram que eles apenas promovem protrusão mandibular, não interferem em seu comprimento e ocasionam menor crescimento na fase pós-tratamento ${ }^{112,134}$. Comparativamente aos pacientes tratados com extração, verificou-se, nesse estudo, que a utilização de aparelhos ortopédicos, por metade dos pacientes do grupo tratado sem extração não promoveu aumento do comprimento mandibular (Tabela 12). 


\section{- Relação maxilomandibular}

A relação maxilomandibular, quando avaliada pela medida ANB, apresentou alterações pós-tratamento significantemente diferentes entre os grupos. Durante o tratamento, a melhora da relação maxilomandibular foi semelhante nos grupos e ocorreu devido a uma associação de pequenos, porém cumulativos, efeitos dentoalveolares ao crescimento craniofacial ${ }^{5}$. Entretanto, houve maior alteração indesejada dessa relação no grupo 2, no período pós-tratamento, que já era esperada, visto que ocorreu maior protrusão maxilar nesse grupo e não houve diferença intergrupos do componente mandibular (Tabela 13)

Quando se avalia o comportamento da relação maxilomandibular entre os grupos pela medida Wits, observam-se diferenças nas alterações do tratamento e no valor dessa medida no estágio de observação (Tabelas $11 \mathrm{e}$ 12, respectivamente). Essas diferenças podem ter decorrido de alterações no plano oclusal, que é utilizado como referência para essa medição, porém não podem ser explicadas precisamente, devido à necesidade de se realizar uma investigação mais específica. Entretanto, apesar de ocorrer essa diferença, ela não influenciou na estabilidade das correções das relações dentárias.

\section{- Padrão facial}

No período pós-tratamento, a mandíbula tendeu a rotacionar em sentido anterior mais acentuadamente no grupo tratado com extrações, conforme demonstrado pela diminuição do FMA. Entretanto, apenas esta medida dentre as três que ilustram o comportamento horizontal e vertical das bases ósseas apontou essa diferença (Tabela 13), devendo, portanto, ser considerada com cautela.

A tendência de rotação posterior da mandíbula durante o tratamento com extração de dois pré-molares foi encontrada por LUECKE; JOHNSTON ${ }^{145}$ (1992) em 30\% dos pacientes e por MERAL et al. $^{155}$ (2004) em $39 \%$ dos pacientes. Nesse estudo, apesar de essa rotação ocorrer, ela apresentou magnitude clinicamente insignificante. Entretanto, como ocorreu rotação 
posterior da mandíbula durante o tratamento, ela rotacionou anteriormente após a remoção dos aparelhos.

No grupo tratado sem extração, praticamente não ocorreu alteração na posição mandibular durante e após o tratamento.

\section{- Componente dentoalveolar superior}

No período pós-tratamento ocorreu protrusão dos incisivos superiores no grupo 1 e retrusão no grupo 2, conforme ilustrado pela alteração da medida 1-ENAperp.

Embora tenha ocorrido maior alteração no grupo 1 da medida 1ENAperp, a posição dos incisivos no estágio de observação era a mesma em ambos os grupos, o que indica que os incisivos dos pacientes dos dois grupos se encontravam igualmente posicionados (Tabela 11). Além disso, a quantidade de alteração que ocorreu no período pós-tratamento foi clinicamente insignificante devido à sua pequena magnitude $(0,79 \mathrm{~mm}$ de protrusão no grupo 1 em um tempo médio de 7,2 anos e de 0,58mm de retrusão no grupo 2 em 9,3 anos).

De acordo com a literatura, geralmente há uma tendência de ocorrer alteração da posição dos incisivos em sentido anterior no período póstratamento, no tratamento sem extrações ${ }^{10,26,192}$. Entretanto, apesar disso, observa-se que a posição desses dentes, instituída pelo tratamento, apresenta estabilidade satisfatória ${ }^{88,226}$.

A tendência que os dentes apresentam de retornar às suas posições originais no período pós-tratamento decorre da necessidade de acomodação fisiológica em sua nova posição ou da maturação oclusal normal ${ }^{30,31,183}$.

\section{- Componente dentoalveolar inferior}

As medidas do componente dentoalveolar inferior não apresentaram diferenças intergrupos nos estágios T1, T2 e T3 e nem das alterações do tratamento. Contudo, no período pós-tratamento, as medidas 1-Pogperp, 1GoMe e 6-Pogperp apresentaram alterações diferentes nos grupos. 
Quando se considera a medida 1-Pogperp, observa-se que houve, no período pós-tratamento, protrusão dos incisivos inferiores no grupo $1 \mathrm{e}$ retrusão no grupo 2. Entretanto, é importante considerar a magnitude das alterações, pois estas foram pequenas com valores de $-0,46 \mathrm{~mm}$ e $0,86 \mathrm{~mm}$ nos grupos 1 e 2, respectivamente, não apresentando significância clínica ainda mais quando se considera o tempo médio em que ocorreram. A diferença estatística apontada ocorreu provavelmente porque as alterações se deram em sentido contrário. No estágio de observação (T3), os valores de 1-Pogperp não demonstram diferença intergrupos na posição destes dentes ilustrando que, apesar das alterações ocorridas após a remoção dos aparelhos, estes dentes se encontram igualmente bem posicionados em ambos os grupos (Tabela 11).

Quanto ao posicionamento vertical dos incisivos inferiores (1-GoMe), observa-se que durante o tratamento, no grupo 1 , ocorreu menor desenvolvimento vertical (não significante) desses dentes, que exibiram maior extrusão no período pós-tratamento. Pode-se supor que essas alterações decorram da presença do recobrimento em acrílico da superfície incisovestibular destes dentes encontrado em alguns aparelhos ortopédicos e que evitam o seu desenvolvimento vertical e vestibularização, apesar destes aparelhos não terem sido utilizados metade dos pacientes desse grupo ${ }^{120,137}$.

Já no grupo 2, ocorreu desenvolvimento vertical normal e praticamente não se observou alterações no período pós-tratamento (Tabela 13). Os incisivos apresentam uma tendência natural de extruírem, e estas alterações devem ser interpretadas como uma compensação dentoalveolar ao crescimento normal ${ }^{192}$.

Embora as alterações não fossem estatisticamente significantes, os molares inferiores mesializaram durante e após o tratamento no grupo 1, conforme a variação da medida 6-Pogperp. Esta mesialização foi superior à observada no grupo 2 durante o tratamento provavelmente devido à utilização de elásticos intermaxilares para Classe II, que promovem mesialização dos molares inferiores. Pode ter decorrido ainda do desgaste do acrílico oclusal póstero-superior realizado nos aparelhos ortopédicos que deixa os molares inferiores livres para irromperem e este irrompimento se dá em sentido anterior e superior ${ }^{5}$. Além disso, segundo JANSON et al. ${ }^{118}$ (2000), a protrusão dos 
incisivos inferiores conseqüente à utilização de alguns aparelhos ortopédicos pode permitir uma mesialização significante dos molares inferiores.

No grupo 2, ocorreu distalização não significante dos molares inferiores durante o tratamento e maior mesialização destes dentes em relação ao outro grupo no período pós-tratamento. Provavelmente, o nivelamento da curva de Spee com arco contínuo provavelmente promoveu a verticalização dos molares inferiores com movimento radicular para anterior associado à inclinação distal da coroa de mesma magnitude ${ }^{25,186,228}$. A distalização destes dentes ilustrada pela medida 6-Pogperp sofreu influência dessa inclinação, já que o ponto localizado no molar inferior para realização dessa medição é na mesial da coroa desse dente e a coroa inclinou para distal. Na fase póstratamento, esses dentes tenderam a retornar à suas posições presentes no estágio pré-tratamento apresentando mesialização mais acentuada nesse grupo justamente por ele ter sofrido maior alteração pelo tratamento.

Essas alterações decorrentes do nivelamento da curva de Spee pelo arco contínuo foram não significantes no grupo 1, pois a utilização dos aparelhos ortopédicos proporciona esse nivelamento tanto pela restrição do desenvolvimento dos dentes anteriores quanto pelo desenvolvimento dos dentes posteriores, restando pouca correção para ser feita com os arcos contínuos $^{33,40,101}$. Além disso, esse grupo utilizou elásticos de Classe II posteriormente, o que pode ter mascarado esses efeitos.

\section{- Relações dentárias}

A sobressaliência e a sobremordida não apresentaram diferenças intergrupos significantes dos seus valores nos estágios pré-tratamento, póstratamento e de observação e nem das alterações do tratamento e das alterações pós-tratamento. Isso mostra que ambos os protocolos de tratamento ocasionam correções semelhantes dessas relações dentárias com estabilidade similar a longo prazo.

Como mencionado anteriormente, a relação molar era semelhante entre os grupos no estágio pré-tratamento (Tabela 9). Entretanto, quanto aos estágios pós-tratamento e de observação e à alteração pelo tratamento, observou-se uma diferença, que já era esperada, visto que os protocolos de 
tratamento estudados diferiam exatamente quanto à correção dessa relação, pois enquanto o tratamento sem extração visava a estabelecer uma relação molar de Classe I, o com extração de dois pré-molares superiores objetivava a manutenção da relação molar de Classe II (Tabelas 10 a 12).

Embora se pudesse esperar que no grupo 1 ocorresse maior alteração pós-tratamento dessa relação, pois a alteração pelo tratamento foi maior, isso não ocorreu, o que pode ter decorrido de adequada contenção das relações dentárias obtidas ${ }^{134,169}$. Dessa forma, a relação molar de Classe II, que foi mantida, apresentou estabilidade semelhante à relação molar de Classe I estabelecida pelo tratamento (Tabela 13).

Pelo teste de correlação se constatou que, no grupo 1, quanto maior a correção da relação molar durante o tratamento, maior a tendência de ocorrer recidiva, entretanto, no grupo 2 essa correlação não foi encontrada, já que a relação molar não foi significantemente alterada pelo tratamento (Tabela 17). Diante disso, pode-se sugerir que, caso houvesse recidiva das relações dentárias corrigidas nos pacientes tratados com extração, essa recidiva não estaria relacionada à alteração da relação molar.

Quanto à relação de caninos, obteve-se com o tratamento, com extrações de dois pré-molares, uma relação mais próxima de uma Classe I do que com o tratamento sem extração (Tabela 10) e a alteração do tratamento, nesse grupo, também foi significantemente maior (Tabela 12). Devido a isso, ocorreram maiores alterações no período pós-tratamento no grupo 2 (Tabelas 13 e 16), embora, essa relação no estágio de obsevação tenha sido semelhante entre os grupos (Tabela 11).

Pode-se especular que essa diferença intergrupos na alteração póstratamento da relação de caninos tenha sido influenciada pela reabertura dos espaços das extrações, pois pela avaliação dos modelos, observou-se essa ocorrência em $16,66 \%$ dos pacientes ${ }^{51}$. A protrusão dos incisivos superiores, no período pós-tratamento, que também se apresentou maior no grupo tratado com extrações, pode estar relacionada à reabertura dos espaços e à alteração da relação de caninos. Contudo, seria necessária uma investigação mais específica para se avaliar a existência da relação entre a alteração póstratamento da relação de caninos e a reabertura dos espaços das extrações, 
mesmo porque, apesar de ocorrer alteração na relação de caninos, não ocorreu diferença na relação molar, o que pode ser atribuído à maior precisão da visualização dos molares nas telerradiografias do que a dos caninos.

De todas as variáveis cefalométricas estudadas, verificou-se que apenas a estabilidade da sobressaliência apresentou uma correlação fraca, porém estatisticamente significante, com a estabilidade da relação de caninos, o que indica que quanto maior a alteração pós-tratamento da relação de caninos, maior tende a ser a recidiva da correção da sobressaliência e viceversa (Tabela 17).

Para que não houvesse dúvidas de que o melhor posicionamento dos caninos no final do tratamento no grupo 2 teria influenciado na comparação da estabilidade, realizou-se a compatibilização dos grupos quanto ao valor da relação de caninos no estágio pós-tratamento e foi constatado que os valores continuaram semelhantes entre os grupos no estágio pré-tratamento e no de observação (Tabelas 18, 19 e 20, abaixo). As alterações do tratamento continuaram sendo diferentes (Tabela 21) e a alteração pós-tratamento passou a ser semelhante entre eles, o que permite que se afirme que a estabilidade dessa relação foi semelhante entre os grupos (Tabela 22). Além disso, os valores e as alterações das demais relações dentárias também não sofreram alteração, conforme ilustrado nas Tabelas 18 a 22.

TABELA 18 - Médias, desvios-padrão e resultado do teste t para a comparação intergrupos dos valores das variáveis no estágio pré-tratamento (T1), após a compatibilização da relação de caninos no estágio pós-tratamento.

\begin{tabular}{|l|r|r|r|r|r|}
\hline & \multicolumn{2}{|c|}{$\begin{array}{c}\text { Grupo 1 (Sem Xp) } \\
(\mathrm{n}=17)\end{array}$} & \multicolumn{2}{|c|}{$\begin{array}{c}\text { Grupo 2 (Xp2PM) } \\
(\mathrm{n}=16)\end{array}$} & \\
\hline & Média & \multicolumn{1}{c|}{$\mathrm{dp}$} & \multicolumn{1}{c|}{ Média } & \multicolumn{1}{c|}{$\mathrm{dp}$} & \multicolumn{1}{c|}{$\mathrm{p}$} \\
\hline T hor & 8,86 & 2,89 & 7,63 & 2,04 & 0,16 \\
\hline T vert & 5,20 & 2,05 & 5,00 & 2,64 & 0,81 \\
\hline Rel mol & 3,68 & 0,65 & 3,59 & 0,57 & 0,68 \\
\hline Rel can & 3,55 & 1,29 & 4,50 & 1,55 & 0,06 \\
\hline
\end{tabular}


TABELA 19 - Médias, desvios-padrão e resultado do teste t para a comparação intergrupos dos valores das variáveis no estágio pós-tratamento (T2), após a compatibilização da relação de caninos nesse mesmo estágio.

\begin{tabular}{|l|r|r|r|r|r|}
\hline & \multicolumn{2}{|c|}{$\begin{array}{c}\text { Grupo 1 (Sem Xp) } \\
(\mathrm{n}=17)\end{array}$} & \multicolumn{2}{|c|}{$\begin{array}{c}\text { Grupo 2 (Xp2PM) } \\
(\mathrm{n}=16)\end{array}$} & \\
\hline & \multicolumn{1}{|c|}{ Média } & \multicolumn{1}{c|}{$\mathrm{dp}$} & \multicolumn{1}{c|}{ Média } & \multicolumn{1}{c|}{$\mathrm{dp}$} & \multicolumn{1}{c|}{$\mathrm{p}$} \\
\hline T hor & 3,06 & 0,88 & 3,34 & 0,66 & 0,31 \\
\hline T vert & 2,26 & 1,29 & 1,97 & 0,99 & 0,47 \\
\hline Rel mol & $\mathbf{- 1 , 2 4}$ & $\mathbf{0 , 9 8}$ & $\mathbf{4 , 0 4}$ & $\mathbf{0 , 6 5}$ & $\mathbf{0 , 0 0}$ \\
\hline Rel can & $-0,98$ & 0,58 & $-1,50$ & 0,92 & 0,06 \\
\hline
\end{tabular}

TABELA 20 - Médias, desvios-padrão e resultado do teste t para a comparação intergrupos dos valores das variáveis no estágio de observação (T3), após a compatibilização da relação de caninos no estágio pós-tratamento.

\begin{tabular}{|l|r|r|r|r|r|}
\hline & \multicolumn{2}{|c|}{$\begin{array}{c}\text { Grupo 1 (Sem Xp) } \\
(\mathrm{n}=17)\end{array}$} & \multicolumn{2}{|c|}{$\begin{array}{c}\text { Grupo 2 (Xp2PM) } \\
(\mathrm{n}=16)\end{array}$} & \\
\hline & \multicolumn{1}{|c|}{ Média } & \multicolumn{1}{c|}{$\mathrm{dp}$} & \multicolumn{1}{c|}{ Média } & \multicolumn{1}{c|}{$\mathrm{dp}$} & \multicolumn{1}{c|}{$\mathrm{p}$} \\
\hline T hor & 3,33 & 0,85 & 3,83 & 0,80 & 0,09 \\
\hline T vert & 3,32 & 1,34 & 3,21 & 0,73 & 0,76 \\
\hline Rel mol & $\mathbf{- 0 , 9 0}$ & $\mathbf{0 , 8 9}$ & $\mathbf{4 , 4 6}$ & $\mathbf{0 , 8 8}$ & $\mathbf{0 , 0 0}$ \\
\hline Rel can & $-0,77$ & 1,35 & $-0,69$ & 1,21 & 0,85 \\
\hline
\end{tabular}

TABELA 21 - Médias, desvios-padrão e resultado do teste t para a comparação intergrupos das alterações do tratamento, após a compatibilização da relação de caninos no estágio póstratamento.

\begin{tabular}{|l|r|r|r|r|r|}
\hline & \multicolumn{2}{|c|}{$\begin{array}{c}\text { Grupo 1 (Sem Xp) } \\
(\mathrm{n}=17)\end{array}$} & \multicolumn{2}{c|}{$\begin{array}{c}\text { Grupo 2 } \\
(\mathrm{n}=16)\end{array}$} & \\
\hline & \multicolumn{1}{|c|}{ Média } & \multicolumn{1}{c|}{$\mathrm{dp}$} & \multicolumn{1}{c|}{ Média } & \multicolumn{1}{c|}{$\mathrm{dp}$} & \multicolumn{1}{c|}{$\mathrm{p}$} \\
\hline T hor & $-5,80$ & 2,77 & $-4,29$ & 2,02 & 0,08 \\
\hline T vert & $-2,94$ & 1,39 & $-3,03$ & 2,66 & 0,90 \\
\hline Rel mol & $\mathbf{- 4 , 9 2}$ & $\mathbf{1 , 0 5}$ & $\mathbf{0 , 4 5}$ & $\mathbf{0 , 6 1}$ & $\mathbf{0 , 0 0}$ \\
\hline Rel can & $\mathbf{- 4 , 5 2}$ & $\mathbf{1 , 1 2}$ & $\mathbf{- 6 , 0 0}$ & $\mathbf{1 , 8 5}$ & $\mathbf{0 , 0 1}$ \\
\hline
\end{tabular}

TABELA 22 - Médias, desvios-padrão e resultado do teste t para a comparação intergrupos das alterações ocorridas no período pós-tratamento (T3-T2), após a compatibilização da relação de caninos no estágio pós-tratamento.

\begin{tabular}{|l|r|r|r|r|r|}
\hline & \multicolumn{2}{|c|}{$\begin{array}{c}\text { Grupo 1 (Sem Xp) } \\
(\mathrm{n}=17)\end{array}$} & \multicolumn{2}{|c|}{$\begin{array}{c}\text { Grupo 2 (Xp2PM } \\
(\mathrm{n}=16))\end{array}$} & \\
\hline & \multicolumn{1}{|c|}{ Média } & \multicolumn{1}{c|}{$\mathrm{dp}$} & \multicolumn{1}{c|}{ Média } & \multicolumn{1}{c|}{$\mathrm{dp}$} & $\mathrm{p}$ \\
\hline T hor & 0,26 & 0,80 & 0,49 & 0,93 & 0,46 \\
\hline T vert & 1,06 & 0,92 & 1,24 & 1,07 & 0,61 \\
\hline Rel mol & 0,34 & 0,89 & 0,42 & 0,95 & 0,80 \\
\hline Rel can & 0,21 & 1,41 & 0,81 & 1,39 & 0,22 \\
\hline
\end{tabular}


A estabilidade das relações dentárias dos pacientes dessa amostra também foi avaliada em modelos por CAMARDELLA ${ }^{51}$, e ocorreu semelhança entre os resultados das avaliações oclusal e cefalométrica. Isso mostra que os valores do erro interexaminador, verificados nesse estudo, não interferiram nos resultados obtidos e que a estabilidade das relações dentárias corrigidas é semelhante entre os dois protocolos de tratamento avaliados.

\section{6 - CONSIDERAÇÕES CLÍNICAS}

Cada um dos protocolos para tratamento da Classe II avaliados por este estudo é indicado em situações específicas, que se relacionam diretamente ao sucesso do tratamento.

No tratamento sem extração realizado com a utilização de aparelhos ortopédicos, é indispensável que a utilização do aparelho ocorra durante o pico do crescimento pubertário, a fim de que se maximizem os efeitos esqueléticos em detrimento dos dentários ${ }^{65,112}$. Similarmente, os aparelhos extrabucais, associados ou não aos aparelhos ortopédicos, também apresentam maiores alterações esqueléticas quando empregados nessa fase ${ }^{12,92}$. Todavia, algumas alterações dentárias benéficas podem ser obtidas quando há crescimento reduzido ou nulo. Já o emprego dos elásticos intermaxilares para Classe II permite a correção por meio de movimentações dentárias e, portanto, seus efeitos dependem em menor grau da idade do paciente ${ }^{163,221}$. Entretanto, 0 fator mais importante que se relaciona ao protocolo sem extração é a dependência que existe da colaboração do paciente em utilizar os aparelhos ou elásticos. A não ser que se empreguem os aparelhos ortopédicos mecânicos, os distalizadores intrabucais ou os mini-implantes, que são fixos, a colaboração fulgura como o pré-requisito fundamental para o sucesso da correção sem extração ${ }^{73,88,230}$..

No tratamento com a extração de dois pré-molares superiores, minimiza-se exatamente o fator colaboração do paciente, haja vista que a relação molar não é corrigida e a correção das demais relações dentárias decorre da mecânica realizada pelo ortodontista no aparelho fixo. Essa é 
também a principal vantagem desse protocolo de extrações em relação ao de extrações de quatro pré-molares ${ }^{110,113}$.

Contudo, é fundamental ressaltar que esse tipo de tratamento é indicado apenas para os casos em que a discrepância presente no arco dentário inferior é mínima ou inexistente e, no primeiro caso, apesar de sua pequena magnitude, é necessário que se avalie a viabilidade de corrigi-la eficientemente sem extrações. Dessa forma, torna-se necessária a inclusão, no plano de tratamento, de procedimentos que permitam sua correção, como os desgastes interproximais ou a protrusão dos incisivos inferiores ${ }^{50}$.

Considerando-se que o sucesso do tratamento depende da manutenção permanente das alterações realizadas, a estabilidade proporcionada pelos variados protocolos de tratamento existentes deve ser um fator decisivo durante a indicação de um tratamento em detrimento do outro ${ }^{2,93}$. Esse estudo demonstrou que ambos os protocolos de tratamento avaliados proporcionam estabilidade semelhante das relações dentárias, e isso auxilia o ortodontista durante a opção por um destes protocolos, uma vez que o deixa livre para decidir, considerando outros fatores que não a estabilidade. Diante disso, a decisão pelo plano de tratamento sem extração ou com a extração de dois pré-molares será baseada em fatores como a idade do paciente e o seu grau de motivação com o tratamento, a relação custo/benefício do tratamento, a facilidade técnica e a preferência do profissional.

Havia dogmas a respeito do tratamento com extração de dois prémolares, pois se acreditava que as extrações ocasionavam desde problemas digestivos $^{74}$ até desordens temporomandibulares ${ }^{39,172}$ 40,70,202 e que a relação molar de Classe II mantida era instável ${ }^{91,144,147,175}$. Esse estudo colabora para a eliminação da idéia de que a relação molar mantida é instável, pois mostrou que a estabilidade dessa relação é semelhante à da Classe I obtida pelo tratamento.

A estabilidade das relações dentárias são as mais importantes ${ }^{183}$, pois a recidiva se encontra explícita na avaliação clínica feita pelo cirurgião dentista ou pelos próprios pacientes, provocando a insatisfação desses em relação ao tratamento ortodôntico. Por esse mesmo motivo, a estabilidade das inclinações e angulações dentárias e do alinhamento dos dentes anteriores 
também são importantes. As alterações pós-tratamento das características esqueléticas apresentam importância secundária, já que não são visíveis na avaliação clínica, mas também devem ser almejadas, porque suas alterações podem refletir em alterações nas posições dentárias.

É importante destacar ainda a existência de grande variabilidade individual da estabilidade, uma vez que são inúmeros os fatores independentes do tratamento que se relacionam a ela, como o crescimento craniofacial, a colaboração do paciente durante a utilização da contenção, entre outros ${ }^{141}$.

SUGESTÃO PARA FUTUROS TRABALHOS:

- Comparar a estabilidade oclusal do tratamento da Classe II, com extração de dois e quatro pré-molares. 

7- Conclusões 



\section{7- CONCLUSÕES:}

A hipótese nula de que não há diferença na estabilidade da correção das relações dentárias da má oclusão de Classe II quando o tratamento é realizado sem extração ou com extração de dois pré-molares superiores foi aceita. Concluiu-se também que as alterações das variáveis dentoalveolares e esqueléticas estudadas não influíram na estabilidade das relações dentárias. 

$R_{\text {eferências }}$

Bibliográficas 



\section{REFERÊNCIAS BIBLIOGRÁFICAS}

1. Aelbers CM, Dermaut LR. Orthopedics in orthodontics: Part I, Fiction or reality--a review of the literature. Am $\mathrm{J}$ Orthod Dentofacial Orthop. 1996;110(5):513-9.

2. Alexander RG, Sinclair PM, Goates LJ. Differential diagnosis and treatment planning for the adult nonsurgical orthodontic patient. Am J Orthod. 1986;89(2):95-112.

3. Almeida MR, Freitas MR, Almeida RR, Almeida RR, Henriques JFC. A correção da Classe II de Angle utilizando o aparelho de Jones Jig Apresentação de um caso clínico. J bras ortodon ortop facial. 2000;5(27):920.

4. Almeida MR, Henriques JF, Almeida RR, Almeida-Pedrin RR, Ursi W. Treatment effects produced by the Bionator appliance. Comparison with an untreated Class II sample. Eur J Orthod. 2004;26(1):65-72.

5. Almeida MR, Henriques JF, Ursi W. Comparative study of the Frankel (FR-2) and bionator appliances in the treatment of Class II malocclusion. Am J Orthod Dentofacial Orthop. 2002;121(5):458-66.

6. Andresen V, Häupl K. Funktionskieferorthopädie,. Leipzig: H Meusser; 1936.

7. Andrews LF. The six keys to normal occlusion. Am J Orthod. 1972;62(3):296309.

8. Angle E. Treatment of malocclusion of the teeth. 7 ed. Philadelphia: SSWhite; 1907.

9. Angle EH. Treatment of malocclusion of the teeth. Angle's System. 1907:479$89 ; 502-05 ; 14-17$.

10. Artun J, Garol JD, Little RM. Long-term stability of mandibular incisors following successful treatment of Class II, Division 1, malocclusions. Angle Orthod. 1996;66(3):229-38.

11. Artun J, Kokich VG, Osterberg SK. Long-term effect of root proximity on periodontal health after orthodontic treatment. Am J Orthod Dentofacial Orthop. 1987;91(2):125-30.

12. Arvystas MG. Nonextraction treatment of Class II, Division 1 malocclusions. Am J Orthod. 1985;88(5):380-95.

13. Arvystas MG. Nonextraction treatment of severe Class II, Division 2 malocclusions. Part 1. Am J Orthod Dentofacial Orthop. 1990;97(6):510-21.

14. Arvystas MG. The rationale for early orthodontic treatment. Am J Orthod Dentofacial Orthop. 1998;113(1):15-8. 
15. Atherton GJ, Glenny AM, O'Brien K. Development and use of a taxonomy to carry out a systematic review of the literature on methods described to effect distal movement of maxillary molars. J Orthod. 2002;29(3):211-6; discussion 195-6.

16. Barros S. Avaliação do grau de eficiência do tratamento da Classe II realizado sem extrações e com extrações de dois pré-molares superiores. [mestrado]. Bauru: Universidade de São Paulo; 2004.

17. Barrow G. Developmental changes of the maxillary and mandibular dental arches. Angle Orthod. 1952;22(41-46).

18. Bass NM. Orthopedic coordination of dentofacial development in skeletal Class II malocclusion in conjunction with edgewise therapy. Part II. Am J Orthod. 1983;84(5):466-90.

19. Battagel J. The relationship between hard and soft tissue changes following treatment of Class II division 1 malocclusion using Edgewise and Fränkel appliance techniques. Eur J Orthod. 1990;12:154-65.

20. Baumirind S. The decision to extract: Part II. Analysis of clinician's stated reasons for extraction. Am J Orthod Dentofacial Orthop. 1996;109(4):393402.

21. Baumrind S, Frantz RC. The reliability of head film measurements. 1. Landmark identification. Am J Orthod. 1971;60(2):111-27.

22. Baumrind S, Frantz RC. The reliability of head film measurements. 2. Conventional angular and linear measures. Am J Orthod. 1971;60(5):50517.

23. Beattie JR, Paquette DE, Johnston LE, Jr. The functional impact of extraction and nonextraction treatments: a long-term comparison in patients with "borderline," equally susceptible Class II malocclusions. Am J Orthod Dentofacial Orthop. 1994;105(5):444-9.

24.Bell WH, Jacobs JD, Legan HL. Treatment of Class II deep bite by orthodontic and surgical means. Am J Orthod. 1984;85(1):1-20.

25. Bennett JC, McLaughlin RP. Management of deep overbite with a preadjusted appliance system. J Clin Orthod. 1990;24(11):684-96.

26. Binda SRK, Kuijpers-Jagtman AM, Maertens JKM, Van'thof MA. A long-term cephalometricevaluation of treated Class II division 2 malocclusion. Eur $\mathrm{J}$ Orthod. 1994;16(4):301-08.

27. Birkeland K, Furevik J, Boe OE, Wisth PJ. Evaluation of treatment and posttreatment changes by the PAR Index. Eur J Orthod. 1997;19(3):279-88.

28. Bishara SE, Cummins DM, Jacobsen JR. The morphologic basis for the extraction decision in Class II, division 1 malocclusions: A comparative study. Am J Orthod Dentofacial Orthop. 1995;107(2):129-35. 
29. Bishara SE, Cummins DM, Jorgensen GJ, Jakobsen JR. A computer assisted photogrammetric analysis of soft tissue changes after orthodontic treatment. Part I: Methodology and reliability. Am J Orthod Dentofacial Orthop. 1995;107(6):633-9.

30.Bishara SE, Cummins DM, Zaher AR. Treatment and posttreatment changes in patients with Class II, Division 1 malocclusion after extraction and nonextraction treatment. Am $J$ Orthod Dentofacial Orthop. 1997;111(1):18-27.

31. Bishara SE, Jakobsen JR, Treder JE, Stasi MJ. Changes in the maxillary and mandibular tooth size-arch length relationship from early adolescence to early adulthood. A longitudinal study. Am J Orthod Dentofacial Orthop. $1989 ; 95(1): 46-59$.

32. Bishara SE, Jakobsen JR, Vorhies B. Changes in dentofacial structures in untreated Class II division 1 and normal subjects: a longitudinal study. Angle Orthod. 1997;67(1):55-66.

33. Bishara SE, Ziaja RR. Functional appliances: a review. Am J Orthod Dentofacial Orthop. 1989;95(6):250-58.

34. Bjork A. Prediction of mandibular growth rotation. Am J Orthod. 1969;55(6):585-99.

35. Björk A, Skieller V. Normal and abnormal growth of the mandible: a synthesis of longitudinal cephalometric implant studies over a period of 25 years. Eur J Orthod. 1983;5(1):1-46.

36. Block MS, Hoffman DR. A new device for absolute anchorage for orthodontics. Am J Orthod Dentofacial Orthop. 1995;107(3):251-8.

37. Boley JC, Pontier JP, Smith S, Fulbright M. Facial changes in extraction and nonextraction patients. Angle Orthod. 1998;68(6):539-46.

38. Bolla E, Muratore F, Carano A, Bowman SJ. Evaluation of maxillary molar distalization with the distal jet: a comparison with other contemporary methods. Angle Orthod. 2002;72(5):481-94.

39. Bowbeer GR. Saving the face and the TMJ--Part 2. Funct Orthod. 1986;3(2):9-13, 15, 17 passim.

40. Bowbeer GR. The 6th key to facial beauty and TMJ health. Funct Orthod. 1987;4(4):10-1, 13-5, 18 passim.

41. Bowman SJ. One-stage versus two-stage treatment: are two really necessary? Am J Orthod Dentofacial Orthop. 1998;113(1):111-6.

42. Braun S. Achieving improved visualization of the temporomandibular joint condyle and fossa in the sagittal cephalogram and a pilot study of their relationships in habitual occlusion. Am $\mathrm{J}$ Orthod Dentofacial Orthop. 1996;109(6):635-8. 
43. Braun S, Sjursen RC, Jr., Legan HL. On the management of extraction sites. Am J Orthod Dentofacial Orthop. 1997;112(6):645-55.

44.Bresonis WL, Grewe JM. Treatment and posttreatment changes in orthodontic cases: overbite and overjet. Angle Orthod. 1974;44(4):295-9.

45. Broadbent $\mathrm{BH}$. A new x-ray technique and its application to Orthodontia. Angle Orthod. 1931;1(2):45-66.

46. Brodie A. Facial patterns: a theme on variation. Angle Orthod. 1946;16(3):75-87.

47. Brodie A. The fourth dimension in Orthodontics. Angle Orthod. $1954 ; 24(1): 15-30$.

48. Brodie AG. Does scientific investigation support the extraction of teeth in orthodontic therapy? Am J Orthod Oral Surg. 1944;30(8):444-60.

49. Brusola JAC. Ortodoncia clinica. Barcelona: Salvat Editores, S.A.; 1989.

50.Bryk C, White LW. The geometry of Class II correction with extractions. J Clin Orthod. 2001;35(9):570-79.

51. Camardella L. Comparação da estabilidade oclusal do tratamento da Classe II com e sem extrações de dois pré-molares superiores. [Mestrado]. Bauru: Universidade de São Paulo; 2006.

52. Cançado $\mathrm{RH}$. Estudo comparativo dos resultados oclusais e da eficiência dos protocolos de tratamento em uma e duas fases da má oclusão de Classe II, Divisão 1. [doutorado]. Bauru: Universidade de São Paulo; 2005.

53. Canut JA. Mandibular incisor extraction: indications and long-term evaluation. Eur J Orthod. 1996;18(5):485-9.

54. Carano A, Testa M. The distal jet for upper molar distalization. J Clin Orthod. $1996 ; 30(7): 374-80$.

55. Case SC. The extraction debate of 1911 by Case, Dewey, and Cryer. Discussion of Case: The question of extraction in orthodontia. Am J Orthod. $1964 ; 50(12): 900-12$.

56. Case SC. The question of extraction in orthodontia. Am J Orthod. 1964;50(9):660-91.

57. Celenza F, Hochman MN. Absolute anchorage in orthodontics: direct and indirect implant-assisted modalities. J Clin Orthod. 2000;34(7):397-402.

58. Coben SE. The biology of Class II treatment. Am J Orthod. 1971;59(5):47087.

59. Cole $\mathrm{H}$. Certain results of extraction in the treatment of malocclusion. Angle Orthod. 1948;28(3-4):103-13. 
60. Conley R, Jernigan $\mathrm{C}$. Soft tissue changes after upper premolar extraction in Class II camouflage therapy. Angle Orthod. 2006;46(1):59-65.

61. Cryer MH, Dewey M. The extraction debate of 1911 by Case, Dewey and Cryer. Discussion of Case: The question of extraction in orthodontia. Am J Orthod. 1964;50(10):751-68.

62. Dahlberg G. Statistical methods for medical and biological students. New York: Intercience; 1940.

63. De Vincenzo JP. Changes in mandibular length before, during, and after succesful orthopedic correction of Class II malocclusions, using a functional appliance. Am J Orthod Dentofacial Orthop. 1991;99(3):241-57.

64.Dermaut LR, van den Eynde F, de Pauw G. Skeletal and dento-alveolar changes as a result of headgear activator therapy related to different vertical growth patterns. Eur J Orthod. 1992;14(2):140-6.

65.Derringer K. A cephalometric study to compare the effects of cervical traction and Andresen therapy in the treatment of class II division 1 malocclusion. Part 2--Dentoalveolar changes. Br J Orthod. 1990;17(2):8999.

66. Dibbets JM, van der Weele LT. Extraction, orthodontic treatment, and craniomandibular dysfunction. Am $\mathrm{J}$ Orthod Dentofacial Orthop. $1991 ; 99(3): 210-9$.

67. Dolce C, Schader RE, McGorray SP, Wheeler TT. Centrographic analysis of 1-phase versus 2-phase treatment for Class II malocclusion. Am J Orthod Dentofacial Orthop. 2005;128(2):195-200.

68. Dugoni SA. Comprehensive mixed dentition treatment. Am J Orthod Dentofacial Orthop. 1998;113(1):75-84.

69. Dyer GS, Harris EF, Vaden JL. Age effects on orthodontic treatment: adolescents contrasted with adults. Am J Orthod Dentofacial Orthop. $1991 ; 100(6): 523-30$.

70. Eirew HL. An orthodontic challenge. Br Dent J. 1976;140(3):96-9.

71. El-Mangoury $\mathrm{NH}$. Orthodontic relapse in subjects with varying degrees of anteroposterior and vertical dysplasia. Am J Orthod. 1979;75(5):548-61.

72. Elms TN, Buschang PH, Alexander RG. Long-term stability of Class II, Division 1, nonextraction cervical face-bow therapy: I. Model analysis. Am J Orthod Dentofacial Orthop. 1996;109(3):271-6.

73. Elms TN, Buschang PH, Alexander RG. Long-term stability of Class II, Division 1, nonextraction cervical face-bow therapy: II. Cephalometric analysis. Am J Orthod Dentofacial Orthop. 1996;109(4):386-92. 
74. Ferris HC, Buckley JP, Bowman GF. The extraction debate of 1911 by Case, Dewey, and Cryer. Discussion of Case: The question of extraction in orthodontia. Am J Orthod. 1964;50(11):843-51.

75. Fidler BC, Artun J, Joondeph DR, Little RM. Long-term stability of Angle Class II, division 1 malocclusions with successful occlusal results at end of active treatment. Am J Orthod Dentofacial Orthop. 1995;107(3):276-85.

76. Fisher B. Retention. A discussion of permanency of results in orthodontic practice. Am J Orhtod. 1941;29(1):5-17.

77. Fogle LL, Southard KA, Southard TE, Casko JS. Treatment outcomes of growing Class II Division 1 patients with varying degrees of anteroposterior and vertical dysplasias, Part 1. Cephalometrics. Am J Orthod Dentofacial Orthop. 2004;125(4):450-6.

78. Foley TF, Mamandras AH. Facial growth in female 14 to 20 years of age. Am J Orthod Dentofacial Orthop. 1992;101(3):248-54.

79. Franchi L, Baccetti T, McNamara JA, Jr. Treatment and posttreatment effects of acrylic splint Herbst appliance therapy. Am J Orthod Dentofacial Orthop. 1999;115(4):429-38.

80. Fraser EJ. Principles of extraction therapy. Angle Orthod. 1956;26(4):241-2.

81. Freitas MR, Beltrao RT, Janson G, Henriques JF, Cançado RH. Long-term stability of anterior open bite extraction treatment in the permanent dentition. Am J Orthod Dentofacial Orthop. 2004;125(1):78-87.

82. Gardner RA, Harris EF, Vaden JL. Postorthodontic dental changes: a longitudinal study. Am J Orthod Dentofacial Orthop. 1998;114(5):581-6.

83. Gardner SD, Chaconas SJ. Posttreatment and postretention changes following orthodontic therapy. Angle Orthod. 1976;46(2):151-61.

84. Ghafari J, Shofer FS, Jacobsson-Hunt U, Markowitz DL, Laster LL. Headgear versus function regulator in the early treatment of Class II, division 1 malocclusion: a randomized clinical trial. Am J Orthod Dentofacial Orthop. 1998;113(1):51-61.

85. Gianelly AA. One-phase versus two-phase treatment. Am J Orthod Dentofacial Orthop. 1995;108(5):556-9.

86. Gianelly AA, Bednar J, Dietz VJ. Japanese Ni-Ti coils used to move molars distally. Am J Orthod Dentofacial Orthop. 1991;99(6):564-66.

87. Gianelly AA, Cozzani M, Boffa J. Condylar position and maxillary first premolar extraction. Am J Orthod Dentofacial Orthop. 1991;99(5):473-6.

88. Glenn G, Sinclair PM, Alexander RG. Nonextraction orthodontic therapy: posttreatment dental and skeletal stability. Am J Orthod Dentofacial Orthop. 1987;92(4):321-8. 
89. Gottlieb EL, Nelson AH, Vogels DS. 1990 JCO study of orthodontics diagnosis and treatment procedures. J Clin Orthod. 1991;25(3):145-55.

90. Graber T. New horizons in case analysis - Clinical cephalometrics. Am J Orthod. 1952;38(8):603-24.

91. Graber T, Vanarsdall Jr R. Ortodontia: Princípios e técnicas atuais. $3^{\underline{a}}$ ed. Rio de janeiro: Guanabara koogan; 2000.

92. Graber TM. Extraoral force - facts and fallacies. Am J Orthod. 1955;41:490505.

93. Graber TM. Current orthodontic concepts and techniques. Philadelphia: W. B. Saunders Company; 1969.

94. Graber TM. Maxillary second molar extraction in Class II malocclusion. Am J Orthod. 1969;56(4):331-53.

95. Grainger RM. Orthodontic treatment priority index. Vital Health Stat 2. 1967(25):1-49.

96. Hahn GW. Extraction Panel. Orthodontics: Its objectives, past and present. Am J Orthod Oral Surg. 1944;30(8):401-04.

97. Hanigan TA. Early treatment and evidence-based orthodontics. Timing of treatment. Am J Orthod Dentofacial Orthop. 2001;119(4):19A.

98. Haralabakis NB, Halazonetis DJ, Sifakakis IB. Activator versus cervical headgear: superimpositional cephalometric comparison. Am J Orthod Dentofacial Orthop. 2003;123(3):296-305.

99. Harris EF, Dyer GS, Vaden JL. Age effects on orthodontic treatment: skeletodental assessments from the Johnston analysis. Am J Orthod Dentofacial Orthop. 1991;100(6):531-36.

100. Harris EF, Vaden JL, Dunn KL, Behrents RG. Effects of patient age on postorthodontic stability in Class II, division 1 malocclusions. Am J Orthod Dentofacial Orthop. 1994;105(1):25-34.

101. Harvold EP, Vargervik K. Morphogenetic response to activator treatment. Am J Orthod. 1971;60(5):478-90.

102. Heide M. Class II, Division 2, A Challenge. Angle Orthod. 1957;27(3):15961.

103. Hellekant M, Lagerstrom L, Gleerup A. Overbite and overjet correction in a Class II, division 1 sample treated with Edgewise therapy. Eur J Orthod. 1989;11(2):91-106.

104. Herschcopf SA. Class II, Division 2 malocclusion-Nonextraction. Am J Orthod Dentofacial Orthop. 1990;97(5):374-80. 
105. Herzberg R. A cephalometric study of Class II relapse. Angle Orthod. 1973;43(1):112-18.

106. Houston WJ. The analysis of errors in orthodontic measurements. Am J Orthod. 1983;83(5):382-90.

107. Hubbard GW, Nanda RS, Currier GF. A cephalometric evaluation of nonextraction cervical headgear treatment in Class II malocclusions. Angle Orthod. 1994;64(5):359-70.

108.Jacobs T, Sawaengkit $P$. National institute of Dental and Craniofacial Reserch efficacy trials of bionator Class II tratment: A review. Angle Orthod. 2002;72(6):571-75.

109.Jacobson A. The "Wits" appraisal of jaw disharmony. Am J Orthod. 1975;67(2):125-38.

110.Janson G, Brambilla AC, Henriques JF, De Freitas MR, Neves LS. Class II treatment success rate in 2- and 4-premolar extraction protocols. Am J Orthod Dentofacial Orthop. 2004;125(4):472-9.

111.Janson G, Busato MC, Henriques JF, de Freitas MR, de Freitas LM. Alignment stability in Class II malocclusion treated with 2- and 4-premolar extraction protocols. Am J Orthod Dentofacial Orthop. 2006;130(2):189-95.

112.Janson G, Caffer Dde C, Henriques JF, de Freitas MR, Neves LS. Stability of Class II, division 1 treatment with the headgear-activator combination followed by the edgewise appliance. Angle Orthod. 2004;74(5):594-604.

113.Janson G, Dainesi EA, Henriques JF, de Freitas MR, de Lima KJ. Class II subdivision treatment success rate with symmetric and asymmetric extraction protocols. Am J Orthod Dentofacial Orthop. 2003;124(3):257-64; quiz 339.

114.Janson G, de Souza JE, de Freitas MR, Henriques JF, Cavalcanti CT. Occlusal changes of Class II malocclusion treatment between Frankel and the eruption guidance appliances. Angle Orthod. 2004;74(4):521-5.

115.Janson G, Graciano JT, Henriques JF, de Freitas MR, Pinzan A, PinzanVercelino CR. Occlusal and cephalometric Class II Division 1 malocclusion severity in patients treated with and without extraction of 2 maxillary premolars. Am J Orthod Dentofacial Orthop. 2006;129(6):759-67.

116.Janson G, Janson MR, Cruz KS, Henriques JF, de Freitas MR. Unusual orthodontic retreatment. Am J Orthod Dentofacial Orthop. 2003;123(4):46875.

117.Janson G, Maria FR, Barros SE, Freitas MR, Henriques JF. Orthodontic treatment time in 2- and 4-premolar-extraction protocols. Am J Orthod Dentofacial Orthop. 2006;129(5):666-71. 
118. Janson GR, da Silva CC, Bergersen EO, Henriques JF, Pinzan A. Eruption Guidance Appliance effects in the treatment of Class II, Division 1 malocclusions. Am J Orthod Dentofacial Orthop. 2000;117(2):119-29.

119. Janson GR, Metaxas A, Woodside DG. Variation in maxillary and mandibular molar and incisor vertical dimension in 12-year-old subjects with excess, normal, and short lower anterior face height. Am J Orthod Dentofacial Orthop. 1994;106(4):409-18.

120.Janson I, Noachtar R. Funtional appliance therapy with the bionator. Sem Orthod. 1998;4:33-45.

121.Janson M. Influência das características cefalométricas na proporção de sucesso do tratamento da Classe II com extrações de dois e quatro prémolares [Mestrado]. Bauru: Universidade de São Paulo; 2005.

122.Jarjoura K, Gagnon G, Nieberg L. Caries risk after interproximal enamel reduction. Am J Orthod Dentofacial Orthop. 2006;130(1):26-30.

123.Johnston LE. Answers in search of quetioners. Am J Orthod Dentofacial Orthop. 2002;121(6):552-3.

124.Jones RD, White JM. Rapid Class II molar correction with an open-coil jig. J Clin Orthod. 1992;26(10):661-4.

125. Kahl-Nieke B, Fischbach $\mathrm{H}$, Schwarze CW. Post-retention crowding and incisor irregularity: a long-term follow-up evaluation of stability and relapse. Br J Orthod. 1995;22(3):249-57.

126. Kaley J, Phillips C. Factors related to root resorption in edgewise practice. Angle Orthod. 1991;61(2):125-32.

127.Keeling SD, Wheeler TT, King GJ, Garvan CW, Cohen DA, Cabassa S, et al. Anteroposterior skeletal and dental changes after early Class II treatment with bionators and headgear. Am J Orthod Dentofacial Orthop. 1998;113(1):40-50.

128. Kessel SP. The rationale of premolar extraction only in Class II therapy. Am J Orthod. 1963;49(4):276-93.

129.King GJ, McGorray SP, Wheeler TT, Dolce C, Taylor M. Comparison of peer assessment ratings (PAR) from 1-phase and 2-phase treatment protocols for Class II malocclusions. Am J Orthod Dentofacial Orthop. 2003;123(5):489-96.

130.Klapper L, Navarro SF, Bowman D, Pawlowski B. The influence of extraction and nonextraction orthodontic treatment on brachyfacial and dolichofacial growth patterns. Am J Orthod Dentofacial Orthop. 1992;101(5):425-30. 
131.Kloehn SJ. Guiding alveolar growth and eruption of teeth to reduce treatment time and produce a more balanced denture and face. Angle Orthod. 1947;17(1):10-33.

132. Konik M, Pancherz $\mathrm{H}$, Hansen $\mathrm{K}$. The mechanism of Class II correction in late Herbst treatment. Am J Orthod Dentofacial Orthop. 1997;112(1):87-91.

133. Kremenak C, Kinser D, Harman H, Menard C, Jakobsen J. Orthodontic risk factors for temporomandibular disorders (TMJ). I: Premolar extractions. Am J Orthod Dentofacial Orthop. 1992;101:13-20.

134.Lagerstrom LO, Nielsen IL, Lee R, Isaacson RJ. Dental and skeletal contributions to occlusal correction in patients treated with the high-pull headgear-activator combination. Am $\mathrm{J}$ Orthod Dentofacial Orthop. 1990;97(6):495-504.

135.Lau PY, Cooke MS, Hagg U. Effect of training and experience on cephalometric measurement errors on surgical patients. Int $\mathrm{J}$ Adult Orthodon Orthognath Surg. 1997;12(3):204-13.

136. Lautrou A, Salvadori A. Growth and choices in orthopedic or orthodontic therapy. Orthod Fr. 2000;71(4):325-34.

137.Levin RI. Activator headgear therapy. Am J Orthod. 1985;87(2):91-109.

138. Litt RA. Class II div 2 malocclusion. To extract or not extract? Angle Orthod. 1984;54(2):123-38.

139. Little RM. The irregularity index: a quantitative score of mandibular anterior alignment. Am J Orthod. 1975;68(5):554-63.

140.Little RM. Stability and relapse of dental arch alignment. $\mathrm{Br} \mathrm{J}$ Orthod. 1990;17(3):235-41.

141.Little RM, Wallen TR, Riedel RA. Stability and relapse of mandibular anterior alignment-first premolar extraction cases treated by traditional edgewise orthodontics. Am J Orthod. 1981;80(4):349-65.

142. Liu Y, Gravely J. The reliability of the 'Ortho Grid' in cephalometric assessment. Br J Orthod. 1991;18(1):21-7.

143. Livieratos FA, Johnston LE, Jr. A comparison of one-stage and two-stage nonextraction alternatives in matched Class II samples. Am J Orthod Dentofacial Orthop. 1995;108(2):118-31.

144.Loughlin F. Aims, aids and auxiliaries. Am J Orthod. 1952;38(5):315-34.

145. Luecke PE, 3rd, Johnston LE, Jr. The effect of maxillary first premolar extraction and incisor retraction on mandibular position: testing the central dogma of "functional orthodontics". Am J Orthod Dentofacial Orthop. 1992;101(1):4-12. 
146. Luppanapornlarp S, Johnston Jr LE. The effects of premolar-extraction: A long-term comparison of outcomes in "clear-cut" extraction and nonextraction Class II patients. Angle Orthod. 1993;63(4):257-72.

147. Mailankody J. Enigma of Class II molar finishing - Reader's forum. Am J Orthod Dentofacial Orthop. 2004;126(6):15A-16A.

148. Martins D, Janson G, Almeida R, Pinzan A, Henriques J, Freitas M. Atlas de crescimento craniofacial. 1 ed. São Paulo: Santos; 1998.

149. McCauley D. The cuspid and its function in retention. Am J Orthod. 1944;30:196-205.

150.McCullough S. Angle Class II, division 1 malocclusion treated without premolar extraction. Am J Orthod Dentofacial Orthop. 1994;106(3):317-21.

151. McNamara J, Brudon W. Orthodontic and orthopedic treatment in the mixed dentition. 5 ed. Ann Arbor: Needham Press; 1995.

152. McNamara JA, Jr. A method of cephalometric evaluation. Am J Orthod. 1984;86(6):449-69.

153. Melsen B. Effects of cervical anchorage during and after treatment: an implant study. Am J Orthod. 1978;73(5):526-40.

154. Melsen B, Dalstra M. Distal molar movement with Kloehn headgear: is it stable? Am J Orthod Dentofacial Orthop. 2003;123(4):374-8.

155. Meral O, Iscan HN, Okay C, Gursoy Y. Effects of bilateral upper first premolar extraction on the mandible. Eur J Orthod. 2004;26(2):223-31.

156. Merrifield LL, Cross JJ. Directional forces. Am J Orthod. 1970;57(5):43564.

157. Mihalik CA, Proffit WR, Phillips C. Long-term follow-up of Class II adults treated with orthodontic camouflage: a comparison with orthognathic surgery outcomes. Am J Orthod Dentofacial Orthop. 2003;123(3):266-78.

158. Mills CM, Holman RG, Graber TM. Heavy intermittent cervical traction in class II treatment: a longitudinal cephalometric assessment. Am J Orthod. 1978;74(4):361-79.

159. Miyazaki $\mathrm{H}$. Occlusal stability after extraction orthodontic therapy in adult and adolescent patients. Am $J$ Orthod Dentofacial Orthop. 1998;114(5):530-37.

160. Moorrees CF. Thoughts on the early treatment of Class II malocclusion. Clin Orthod Res. 1998;1(2):97-101.

161. Nangia A, Darendeliler MA. Finishing occlusion in Class II or Class III molar relation: therapeutic Class II and III. Aust Orthod J. 2001;17(2):89-94. 
162. Nashed RR, Reynolds IR. A cephalometric investigation of overjet changes in fifty severe Class II division I malocclusions. Br J Orthod. 1989;16(1):317.

163. Nelson B, Hansen K, Hägg U. Overjet reduction and molar correction in fixed apliance treatment of Class II, Division 1, malocclusion: Sagittal and vertical components. Am J Orthod Dentofacial Orthop. 1999;115(1):13-23.

164.O'Reilly MT, Rinchuse DJ, Close J. Class II elastics and extractions and temporomandibular disorders: a longitudinal prospective study. Am J Orthod Dentofacial Orthop. 1993;103(5):459-63.

165. Ormiston JP, Huang GJ, Little RM, Decker JD, Seuk GD. Retrospective analysis of long-term stable and unstable orthodontic treatment outcomes. Am J Orthod Dentofacial Orthop. 2005;128(5):568-74; quiz 669.

166. Owman G, Bjerklin K, Kurol J. Mandibular incisor stability after orthodontic treatment in the upper arch. Eur J Orthod. 1989;11(4):341-50.

167.Pae EK, McKenna GA, Sheehan TJ, Garcia R, Kuhlberg A, Nanda R. Role of lateral cephalograms in assessing severity and difficulty of orthodontic cases. Am J Orthod Dentofacial Orthop. 2001;120(3):254-62.

168. Pancherz $\mathrm{H}$. The Herbst appliance--its biologic effects and clinical use. Am J Orthod. 1985;87(1):1-20.

169.Pancherz H, Hansen K. Occlusal changes during and after Herbst treatment: a cephalometric investigation. Eur J Orthod. 1986;8(4):215-28.

170.Paquette DE, Beattie JR, Johnston LE, Jr. A long-term comparison of nonextraction and premolar extraction edgewise therapy in "borderline" Class II patients. Am J Orthod Dentofacial Orthop. 1992;102(1):1-14.

171.Peck S, Peck L, Kataja M. Class II Division 2 malocclusion: a heritable pattern of small teeth in well-developed jaws. Angle Orthod. 1998;68(1):920.

172.Perry HT, Jr. Adolescent temporomandibular dysfunction. Am J Orthod. 1973;63(5):517-25.

173.Poulton DR. The influence of extraoral traction. Am J Orthod. 1967;53(1):818.

174. Proffit WR. Forty-year review of extraction frequencies at a university orthodontic clinic. Angle Orthod. 1994;64(6):407-14.

175. Reitan K. Experiments of rotation of teeth and their subsequent retention. Trans Eur Soc. 1958;34:124.

176. Richardson A. A comparison of traditional and computerized methods of cephalometric analysis. Eur J Orthod. 1981;3(1):15-20. 
177. Ricketts RM. Dr. Robert M. Ricketts on early treatment (part 1). J Clin Orthod. 1979;13(1):23-38.

178. Riedel RA. A review of the retention problem. Angle Orthod. 1960;30(4):179-99.

179. Riolo ML. An atlas of craniofacial growth: cephalometric standards from the University School Growth Study,. The University of Michigan, Ann Arbor, Center for Human Growth and Development. 1974:1-8.

180. Roberts WE, Marshall KJ, Mozsary PG. Rigid endosseous implant utilized as anchorage to protract molars and close an atrophic extraction site. Angle Orthod. 1990;60(2):135-52.

181.Rogers A. Making facial muscles our allies in treatment and retention. Dental Cosmos. 1922;64:711-30.

182. Runge ME, Sadowsky C. Class II, Division 1 vertical pattern. Am J Orthod Dentofacial Orthop. 1988;94(4):271-77.

183.Sadowsky C, Sakols El. Long-term assessment of orthodontic relapse. Am J Orthod. 1982;82(6):456-63.

184.Sadowsky C, Schneider BJ, BeGole EA, Tahir E. Long-term stability after orthodontic treatment: nonextraction with prolonged retention. Am J Orthod Dentofacial Orthop. 1994;106(3):243-9.

185.Sage J. The pros and cons of the extraction procedure in orthodontics. Am J Orthod Oral Surg. 1947;33(10):642-73.

186. Sakima M, Raveli D, Martins L, Mendes A, Sakima P. Avaliação cefalométrica comparativa de dois métodos de correção da sobremordida. Estudo com implantes metálicos. Parte II. Rev dent press ortodon ortopedi facial. 2000;5:47-57.

187.Salzmann JA. An evaluation of retention and relapse following orthodontic therapy. Am J Orthod. 1965;51(10):779-81.

188.Salzmann JA. Practice of orthodontics. Philadelphia: J.B. Lippincott Company; 1966.

189. Sandler PJ. Reproducibility of cephalometric measurements. Br J Orthod. 1988;15(2):105-10.

190.Savara BS, Takeuchi Y. Anatomical location of cephalometric landmarks on the sphenoid and temporal bones. Angle Orthod. 1979;49(2):141-9.

191. Schudy FF. The control of vertical overbite in clinical orthodontics. Angle Orthod. 1968;38(1):19-39.

192.Schudy GF. Posttreatment craniofacial growth: its implications in orthodontic treatment. Am J Orthod. 1974;65(1):39-57. 
193.Schütz-Fransson U, Bjerklin K, Kurol J. Mandibular incisor stability after bimaxillary orthodontictreatment with premolar extraction in the upper arch. J Orofac Orthoped. 1998;59(1):47-58.

194.Schutz-Fransson U, Bjerklin K, Lindsten R. Long-term follow-up of orthodontically treated deep bite patients. Eur J Orthod. 2006;28(5):503-12.

195.Sheridan JJ. Air-rotor stripping update. J Clin Orthod. 1987;21(11):781-8.

196. Shields TM, Little RM, Chapko MK. Stability and relapse of mandibular anterior alignment-a cephalometric appraisal of first premolar extraction cases treated by traditional Edgewise orthodontics. Am $\mathrm{J}$ Orthod. 1985;87(1):27-38.

197.Simão T. Influência das características cefalométricas na proporção de sucesso do tratamento da Classe II sem extrações e com extrações de dois pré-molares superiores [Mestrado]. Bauru: Universidade de São Paulo; 2006.

198.Simons ME, Joondeph DR. Change in overbite: a ten-year postretention study. Am J Orthod. 1973;64(4):349-67.

199. Sinclair PM, Little RM. Maturation of untreated normal occlusions. Am J Orthod. 1983;83(2):114-23.

200.Sinclair PM, Little RM. Dentofacial maturation of untreated normals. Am J Orthod. 1985;88(2):146-56.

201.Sondhi A, Cleall JF, BeGole EA. Dimensional changes in the dental arches of orthodontically treated cases. Am J Orthod. 1980;77(1):60-74.

202.Spahl T, WItzig J. The clinical management of basic maxillofacial orthopedic appliances. Littleton: PSG Publishing; 1987.

203.Stabrun AE, Danielsen K. Precision in cephalometric landmark identification. Eur J Orthod. 1982;4(3):185-96.

204.Staggers JA. Vertical changes following first premolar extractions. Am J Orthod Dentofacial Orthop. 1994;105(1):19-24.

205.Strang RHW. Tratado de ortodoncia. Buenos Aires: Editorial Bibliográfica Argentina; 1957.

206.Swain BF. Borderline extraction cases. J Clin Orthod. 1971;5(10):539-647.

207.Terry HK. The labiolingual appliance. Am J Orthod. 1969;55(6):714-33.

208. Thurow RC. Cephalometric methods in research and private practice. Angle Orthod. 1951;21(2):104-16. 
209.Trpkova B, Major P, Prasad N, Nebbe B. Cephalometric landmarks identification and reproducibility: a meta analysis. Am J Orthod Dentofacial Orthop. 1997;112(2):165-70.

210.Tulloch JF, Medland W, Tuncay OC. Methods used to evaluate growth modification in Class II malocclusion. Am J Orthod Dentofacial Orthop. 1990;98(4):340-7.

211.Tulloch JF, Phillips C, Proffit WR. Benefit of early Class II treatment: progress report of a two-phase randomized clinical trial. Am J Orthod Dentofacial Orthop. 1998;113(1):62-72, quiz 73-4.

212.Tulloch JF, Proffit WR, Phillips C. Outcomes in a 2-phase randomized clinical trial of early Class II treatment. Am J Orthod Dentofacial Orthop. 2004;125(6):657-67.

213. Tweed $\mathrm{CH}$. The application of the principles of the edgewise arch in the treatment of Class II, division 1 malocclusion: part 2. Angle Orthod. $1936 ; 6(4): 255-57$.

214. Tweed $\mathrm{CH}$. The application of the principles of the edgewise arch in the treatment of Class II, Division 1 malocclusion: part. 1. Angle Orthod. 1936;7:109-208.

215. Tweed $\mathrm{CH}$. Indication for the extraction of teeth in orthodontic procedures. Am J Orthod. 1944;30:405-28.

216. Tweed $\mathrm{CH}$. The Frankfort-mandibular incisor angle (FMIA) in orthodontic diagnosis, treatment planning and prognosis. Angle Orthod. 1954;24(3):121-69.

217. Unde MD, Sadowsky C, BeGole EA. Long-term stability of dental relationships after orthodontic treatment. Angle Orthod. 1983;53(3):240-52.

218. Vaden JL, Harris EF, Behrents RG. Adult versus adolescent Class II correction: a comparison- Case report. Am J Orthod Dentofacial Orthop. 1995;107(6):651-61.

219. Valarelli F. Relação entre o grau de severidade e o sucesso do tratamento sem extração da má oclusão de Classe II. [Doutorado]. Bauru: Universidade de São Paulo; 2006.

220. Viazis AD. Efficient orthodontic treatment timing. Am J Orthod Dentofacial Orthop. 1995;108(5):560-1.

221. Weber FN. Clinical investigations related to use of the Begg technique at the University of Tennessee. Am J Orthod. 1971;59(1):24-36.

222. Weiland FJ, Droschl H. Treatment of a Class II, Division 1 malocclusion with the Jasper Jumper: a case report. Am J Orthod Dentofacial Orthop. 1996;109(1):1-7. 
223. Wheeler TT, McGorray SP, Dolce C, Taylor MG, King GJ. Effectiveness of early treatment of Class II malocclusion. Am J Orthod Dentofacial Orthop. 2002;121(1):9-17.

224. Wieslander L. Long-term effect of treatment with the headgear-Herbst appliance in the early mixed dentition. Stability or relapse? Am J Orthod Dentofacial Orthop. 1993;104(4):319-29.

225. Wieslander L, Buck DL. Physiologic recovery after cervical traction therapy. Am J Orthod. 1974;66(3):294-301.

226. Wieslander L, Lagerstrom L. The effect of activator treatment on Class II malocclusion. Am J Orthod. 1979;75(1):20-26.

227. Wood CM. The effect of retention on the relapse of Class II Division 1 cases. Br J Orthod. 1983;10(4):198-202.

228. Woods M. A reassessment of space requirements for lower arch leveling. $J$ Clin Orthod. 1986;20(11):770-8.

229. Yamaguchi K, Nanda RS. The effects of extraction and nonextraction treatment on the mandibular position. Am J Orthod Dentofacial Orthop. 1991;100(5):443-52.

230. Yavari J, Shrout MK, Russell CM, Haas AJ, Hamilton EH. Relapse in Angle Class II Division 1 Malocclusion treated by tandem mechanics without extraction of permanent teeth: A retrospective analysis. Am J Orthod Dentofacial Orthop. 2000;118(1):34-42. 
Abstract 



\section{ABSTRACT}

Class II malocclusion treatment stability of nonextraction and twomaxillary premolar extraction protocols

The purpose of this study was to compare the dental relationships stability of Class II malocclusion treatment with and without two-maxillary premolar extractions and the influence of dentoalveolar and skeletal cephalometric variables on the stability. Two groups consisting of 30 patients each with matching characteristics were compared. Lateral cephalograms were evaluated at the pretreatment, posttreatment and observation stages. The average posttreatment period was 8.2 years. Student's $t$ test was used to compare the posttreatment period changes between the groups and the findings indicated that both groups presented similar changes of the overjet, overbite and molar relationship at the posttreatment period. Only the canine relationship showed greater posttreatment changes in the extraction group however, there were no intergroup significant differences in these variables at the observation stage. The cephalometric variables evaluated did not influence dental relationships stability.

Keywords: Malocclusion, Angle Class II. Tooth Extraction. Cephalometry. 



$$
\text { Apêndice }
$$



As Tabelas A-1 a A-10 apresentam os valores individuais de cada variável para cada paciente, do grupo 1.

As variáveis com o sufixo "c-f "se referem às alterações pós-tratamento, pois c é de controle e f de final de tratamento e as variáveis com o sufixo "f-i" se referem às alterações do tratamento, pois fé de final de tratamento e i de início do tratamento.

TABELA A-1

\begin{tabular}{|c|c|c|c|c|c|c|c|c|c|c|c|c|c|c|}
\hline & Nome & Grupo & Gênero & Classe II & SNA i & Co-A i & A-Nper i & SNB i & Co-Gn i & ANB i & Wits i & FMA i & $\begin{array}{c}\text { SN.GoGn } \\
\mathrm{i}\end{array}$ & AFAl i \\
\hline 1 & A.S.S. & 1 & $F$ & 1 & 80,5 & 79,6 & $-1,8$ & 76 & 99,1 & 4,5 & 5,5 & 27,3 & 33,2 & 53,5 \\
\hline 2 & A.C.I. & 1 & $\mathrm{~F}$ & 1 & 81,5 & 92,8 & 1,3 & 75,5 & 112,5 & 6,1 & 4,2 & 34,4 & 42,1 & 69,9 \\
\hline 3 & A.L.G & 1 & $F$ & 1 & 84,1 & 87,5 & $-0,3$ & 77,4 & 99 & 6,7 & 5,7 & 23,3 & 26,7 & 51 \\
\hline 4 & B.S & 1 & $\mathrm{~F}$ & 2 & 80,7 & 82,4 & $-1,4$ & 76,3 & 105,8 & 4,3 & 2,2 & 22,5 & 29,1 & 58,3 \\
\hline 5 & C.B & 1 & $\mathrm{~F}$ & 1 & 83,3 & 81,4 & $-3,3$ & 77,9 & 96,9 & 5,5 & 4,1 & 24,1 & 25 & 50,8 \\
\hline 6 & C.P & 1 & $M$ & 1 & 83,2 & 85,2 & $-2,3$ & 75,4 & 102,5 & 7,8 & 5,7 & 37,2 & 37,6 & 62,2 \\
\hline 7 & C.U & 1 & $M$ & 1 & 77,7 & 85,4 & $-2,3$ & 75,5 & 109,5 & 2,2 & 3 & 21 & 28,7 & 65,2 \\
\hline 8 & C.G.A & 1 & $M$ & 1 & 78,1 & 85,2 & $-2,4$ & 70,8 & 99,7 & 7,3 & 6,5 & 31,8 & 38,9 & 63,2 \\
\hline 9 & C.S. & 1 & $\mathrm{~F}$ & 1 & 79,6 & 84 & $-3,7$ & 74,2 & 99,9 & 5,4 & 6 & 23,1 & 27,3 & 55,9 \\
\hline 10 & D.M.O & 1 & $\mathrm{~F}$ & 1 & 78,1 & 80,7 & $-5,2$ & 75,7 & 103,3 & 2,4 & 2,8 & 29,2 & 33,5 & 61,8 \\
\hline 11 & D.M. & 1 & $M$ & 1 & 80,3 & 88,7 & $-2,6$ & 72,4 & 100,4 & 8 & 11,3 & 18,1 & 23,6 & 53,7 \\
\hline 12 & E.A.S. & 1 & $F$ & 2 & 78,7 & 79 & $-1,8$ & 71,8 & 93,3 & 7 & 7,9 & 29,9 & 37,3 & 56,8 \\
\hline 13 & E.M. & 1 & $F$ & 1 & 81,6 & 84,8 & 3,5 & 74,4 & 109,2 & 7,2 & 8,2 & 29,8 & 39,9 & 66,9 \\
\hline 14 & E.S. & 1 & $M$ & 1 & 78,2 & 86,9 & $-2,2$ & 71,1 & 109,5 & 7,2 & 6,9 & 32,9 & 40,8 & 67,3 \\
\hline 15 & F.A. & 1 & $M$ & 1 & 89,9 & 91,3 & $-3,6$ & 81,6 & 105,6 & 8,3 & 9,5 & 31,2 & 24,9 & 61,7 \\
\hline 16 & G.G. & 1 & $M$ & 1 & 75 & 78,4 & $-5,1$ & 73,2 & 95,8 & 1,8 & 1,1 & 29,1 & 36,2 & 59,9 \\
\hline 17 & H.C. & 1 & $M$ & 2 & 81,2 & 81,9 & -4 & 76,4 & 102,8 & 4,8 & 3,3 & 29,6 & 31,9 & 67,5 \\
\hline 18 & J.A.C. & 1 & $M$ & 2 & 82,2 & 95,4 & 0,1 & 79,4 & 122,5 & 2,8 & 0 & 21,1 & 27,3 & 61,8 \\
\hline 18 & J.D.A. & 1 & $\mathrm{~F}$ & 1 & 87,8 & 89,6 & 4,8 & 79,4 & 107,5 & 8,4 & 7,9 & 27,3 & 32,1 & 60,6 \\
\hline 20 & L.B.P. & 1 & $F$ & 1 & 81,6 & 83 & $-2,6$ & 75,9 & 99,8 & 5,7 & 5,7 & 24 & 28,3 & 52,8 \\
\hline 21 & L.G.B. & 1 & $M$ & 1 & 81,9 & 84,7 & 0,2 & 75,1 & 100,4 & 6,8 & 5,5 & 23 & 29,9 & 54,8 \\
\hline 22 & M.M.L. & 1 & $M$ & 1 & 85,5 & 91,7 & 4,7 & 77 & 107,6 & 8,4 & 7,4 & 24,3 & 31,3 & 62,8 \\
\hline 23 & M.A.C. & 1 & $M$ & 1 & 80,4 & 82,8 & $-1,1$ & 79,4 & 111,4 & 1 & $-0,5$ & 26,5 & 33,1 & 62,5 \\
\hline 24 & M.L.C. & 1 & $\mathrm{~F}$ & 1 & 79,4 & 90,7 & $-1,1$ & 71,1 & 109 & 8,4 & 5,4 & 33,8 & 41,3 & 64,1 \\
\hline 25 & N.C. & 1 & $\mathrm{~F}$ & 1 & 85,9 & 83 & 1,3 & 77,2 & 99,7 & 8,8 & 7,2 & 26,9 & 30,2 & 59,7 \\
\hline 26 & N.G. & 1 & $\mathrm{~F}$ & 1 & 85,2 & 81,7 & 0,3 & 79,1 & 101,1 & 6,1 & 5 & 25,8 & 29,3 & 57,7 \\
\hline 27 & P.G. & 1 & $\mathrm{~F}$ & 2 & 77,6 & 84,1 & $-3,6$ & 70,1 & 99,3 & 7,5 & 7,8 & 38,1 & 44,4 & 61,1 \\
\hline 28 & P.C. & 1 & $F$ & 1 & 84,1 & 80,9 & 1,1 & 76,5 & 98,8 & 7,6 & 6,6 & 23,6 & 27,9 & 59,6 \\
\hline 29 & V.V & 1 & $\mathrm{~F}$ & 1 & 78,8 & 94,4 & $-0,8$ & 77,6 & 119,5 & 1,2 & 2,8 & 18,3 & 27,2 & 63,8 \\
\hline 30 & W.L. & 1 & $M$ & 1 & 83,7 & 89,1 & 6,6 & 75,3 & 107 & 8,4 & 7,4 & 19,4 & 30,2 & 65,2 \\
\hline
\end{tabular}


TABELA A-2

\begin{tabular}{|c|c|c|c|c|c|c|c|c|c|c|c|c|c|c|}
\hline & 1.PP i & $\begin{array}{c}1- \\
\text { ENAper i }\end{array}$ & 1-PP i & 6-PP i & $\begin{array}{c}6- \\
\text { ENAper i }\end{array}$ & IMPA i & $\begin{array}{c}\text { 1-Pogper } \\
\mathrm{i}\end{array}$ & 1-GoMe i & $\begin{array}{c}\text { 6-Pogper } \\
\mathrm{i}\end{array}$ & 6-GoMe i & Thor i & T vert i & Rel mol i & Rel can i \\
\hline 1 & 128,7 & 3,6 & 20,6 & 18,6 & $-25,8$ & 87,4 & $-11,4$ & 34,2 & $-30,4$ & 23,2 & 10,3 & 4,1 & 4,1 & 3,4 \\
\hline 2 & 116,3 & 1,8 & 28,2 & 24,8 & $-27,6$ & 93,8 & -10 & 44,9 & $-31,5$ & 31,3 & 6,3 & 3,7 & 3,2 & 1,2 \\
\hline 3 & 126,9 & 2,9 & 21,7 & 19,1 & $-26,2$ & 103,3 & $-5,1$ & 33,6 & $-26,9$ & 25 & 8,8 & 6,1 & 3,9 & 5 \\
\hline 4 & 106 & $-2,9$ & 25,4 & 21,2 & $-26,8$ & 94,2 & $-8,2$ & 35,9 & $-28,6$ & 28,4 & 5,2 & 5 & 2,9 & 3,2 \\
\hline 5 & 113,6 & $-0,4$ & 22,3 & 16,2 & $-28,3$ & 104,2 & $-8,3$ & 32,9 & $-32,1$ & 24,8 & 6,8 & 5,9 & 4,3 & 2,9 \\
\hline 6 & 133,4 & 3,4 & 24,4 & 18,9 & -30 & 94,4 & $-8,3$ & 40 & $-30,4$ & 28,3 & 10,5 & 4,7 & 2,8 & 2,7 \\
\hline 7 & 121,6 & 2,2 & 26,1 & 23 & $-25,8$ & 97,9 & $-6,3$ & 42 & $-30,6$ & 32,5 & 5,7 & 3,2 & 4,1 & 3 \\
\hline 8 & 110,9 & 0,4 & 30,3 & 20 & $-28,4$ & 91,2 & $-7,5$ & 39,8 & $-26,8$ & 28,4 & 10,8 & 8,6 & 4,6 & 6,6 \\
\hline 9 & 124 & 1,9 & 23,2 & 20,8 & $-27,6$ & 108,1 & $-4,2$ & 36,4 & $-25,9$ & 27,7 & 8,1 & 5,3 & 3,3 & 2,7 \\
\hline 10 & 118,5 & 2 & 26,9 & 22,1 & $-27,8$ & 82,8 & $-12,4$ & 35,5 & $-30,7$ & 25,4 & 9,9 & 3,6 & 1,7 & 2,4 \\
\hline 11 & 121,4 & 8,8 & 24,5 & 18,9 & $-25,3$ & 100 & $-6,4$ & 35,4 & $-27,5$ & 25,4 & 14,9 & 9,3 & 3,9 & 6,1 \\
\hline 12 & 93,9 & $-4,3$ & 26,2 & 22,3 & $-28,7$ & 92,5 & -7 & 35,8 & $-28,5$ & 22,3 & 3,5 & 6,5 & 3,8 & 3 \\
\hline 13 & 117,6 & 0,5 & 28,5 & 24,5 & $-30,7$ & 87,7 & $-11,1$ & 40,2 & $-31,3$ & 27,4 & 11,1 & 4,5 & 4 & 3,5 \\
\hline 14 & 107,8 & $-0,8$ & 28,8 & 22 & $-29,1$ & 90,3 & $-13,1$ & 42,6 & $-33,9$ & 29,8 & 7,1 & 6,6 & 3,4 & 4,5 \\
\hline 15 & 130 & 7,2 & 24,2 & 23,1 & $-25,1$ & 100,4 & $-5,4$ & 42,5 & $-28,3$ & 30,2 & 9,8 & 6,7 & 5 & 3,1 \\
\hline 16 & 115 & 0,8 & 27,8 & 20,6 & $-26,8$ & 100,3 & $-5,4$ & 36,8 & $-28,1$ & 25,9 & 5,1 & 3,5 & 2,8 & 0,9 \\
\hline 17 & 102,2 & -3 & 30,4 & 23 & $-26,5$ & 93,4 & $-7,8$ & 39,5 & $-29,6$ & 30,4 & 4,6 & 3,3 & 4,2 & 4,6 \\
\hline 18 & 101,1 & $-3,7$ & 27,8 & 22,5 & $-29,2$ & 85,6 & $-14,6$ & 38,4 & -35 & 29,3 & 5,2 & 7,1 & 1,7 & 4,4 \\
\hline 18 & 111,3 & $-1,8$ & 27,1 & 21,5 & $-30,5$ & 85,5 & -14 & 36,1 & $-31,6$ & 24,3 & 10,8 & 6,1 & 3,3 & 3,9 \\
\hline 20 & 120,6 & 0 & 25 & 18,4 & $-27,6$ & 100,3 & $-7,3$ & 31,9 & $-27,4$ & 22,8 & 9,6 & 5,9 & 3,9 & 2,9 \\
\hline 21 & 124,3 & 0,5 & 23 & 18,5 & $-33,7$ & 104,2 & $-5,1$ & 35,9 & $-32,3$ & 26,3 & 8,5 & 6 & 3,6 & 3,2 \\
\hline 22 & 125,9 & 5,7 & 27,4 & 22,6 & $-30,2$ & 100,3 & $-5,5$ & 38,2 & $-31,4$ & 26,6 & 11,1 & 3,6 & 4 & 4 \\
\hline 23 & 117,3 & $-0,4$ & 27,7 & 23,3 & $-28,6$ & 84,4 & $-12,9$ & 34,6 & $-34,6$ & 24,3 & 6,4 & 2 & 1,9 & 1,7 \\
\hline 24 & 112,8 & $-2,8$ & 26,4 & 20,6 & $-31,1$ & 100,2 & $-8,2$ & 37,7 & -30 & 28,8 & 6,4 & 2,5 & 3,5 & 2 \\
\hline 25 & 111,1 & $-1,3$ & 25,9 & 20,9 & $-28,6$ & 104 & $-4,1$ & 38,4 & $-27,7$ & 28,2 & 5,5 & 5,6 & 4,4 & 3,4 \\
\hline 26 & 109,9 & $-5,2$ & 23,9 & 18,1 & $-32,2$ & 91,6 & -9 & 35,4 & -33 & 25,1 & 4,6 & 3,8 & 3,1 & 2 \\
\hline 27 & 99,4 & $-2,2$ & 27,4 & 21,4 & $-25,6$ & 82,8 & $-12,6$ & 38,9 & $-29,1$ & 25,2 & 6,4 & 7,9 & 4,3 & 3,1 \\
\hline 28 & 120,5 & 2,2 & 26,1 & 19,2 & $-29,7$ & 92,7 & $-7,1$ & 38,1 & $-29,1$ & 28,5 & 12,1 & 6,7 & 3,7 & 4,5 \\
\hline 29 & 117,3 & $-1,1$ & 26,2 & 24 & $-29,7$ & 89,1 & $-11,3$ & 37,5 & $-35,6$ & 28 & 5,8 & 1,3 & 3,4 & 3,7 \\
\hline 30 & 125,8 & 2,7 & 29,4 & 21,9 & $-31,9$ & 99,4 & $-5,6$ & 41,7 & $-29,3$ & 31,5 & 13,6 & 6,5 & 4,1 & 4,8 \\
\hline
\end{tabular}


TABELA A-3

\begin{tabular}{|c|c|c|c|c|c|c|c|c|c|c|c|c|c|c|}
\hline & SNA f & Co-A f & A-Nper f & SNB f & Co-Gn f & ANB f & Wits $f$ & FMA f & $\begin{array}{c}\text { SN.GoGn } \\
f\end{array}$ & AFAl f & 1.PP f & $\begin{array}{c}1- \\
\text { ENAper } \mathrm{f}\end{array}$ & 1-PP f & 6-PP f \\
\hline 1 & 77,1 & 81,1 & $-3,2$ & 76,1 & 104,9 & 1,1 & 0 & 27,4 & 34,3 & 55,2 & 118,2 & $-1,6$ & 21,5 & 21 \\
\hline 2 & 80 & 90,5 & $-0,3$ & 75,1 & 114 & 4,9 & 4,6 & 35,9 & 42,1 & 71 & 123,6 & 2,4 & 26,4 & 25,3 \\
\hline 3 & 83,9 & 89,1 & $\begin{array}{l}-2,2 \\
\end{array}$ & 79,7 & 106 & 4,2 & 0,3 & 24,7 & 26 & 55,2 & 117 & $-0,9$ & 23 & 18,6 \\
\hline 4 & 82,1 & 84,5 & 1,4 & 74,6 & 107,3 & 7,5 & 3,5 & 24,7 & 32,1 & 64,1 & 106,3 & $-3,6$ & 27,1 & 22,5 \\
\hline 5 & 81,4 & 84,2 & $-4,2$ & 79,3 & 107,3 & 2,1 & 2,3 & 22 & 24,6 & 55 & 121,9 & $-0,3$ & 23 & 20,3 \\
\hline 6 & 78,9 & 82,5 & $-5,8$ & 73,2 & 102,3 & 5,8 & 2,4 & 39,4 & 40,8 & 67,3 & 102,4 & $-5,3$ & 27,9 & 20,4 \\
\hline 7 & 78 & 86,2 & $-1,5$ & 77,1 & 115,3 & 0,8 & $-0,4$ & 19 & 26,4 & 72,3 & 119,4 & 1,9 & 30,3 & 25,9 \\
\hline 8 & 81,3 & 90,6 & $-3,1$ & 75,7 & 114,8 & 5,7 & 1,6 & 36,4 & 38 & 79,1 & 96,5 & $-7,3$ & 34,4 & 25 \\
\hline 9 & 79,8 & 82,9 & $-3,2$ & 75,3 & 104,2 & 4,6 & 4,6 & 23,2 & 26,3 & 62 & 116,3 & -1 & 25,6 & 24,4 \\
\hline 10 & 77 & 82,1 & $-5,9$ & 75,4 & 108,6 & 1,7 & $-0,3$ & 29,4 & 33,4 & 68,4 & 105,2 & $-6,8$ & 30,1 & 23,7 \\
\hline 11 & 75,6 & 89,4 & $-6,1$ & 75,4 & 114,7 & 0,1 & 0,7 & 14,8 & 20 & 59,7 & 114,6 & $-4,2$ & 25,4 & 20,2 \\
\hline 12 & 79,3 & 80,8 & $-3,4$ & 75,4 & 101 & 3,9 & 2,8 & 28,8 & 33,8 & 58,9 & 109,6 & $-2,2$ & 25,7 & 23,2 \\
\hline 13 & 78,8 & 84,2 & $-0,1$ & 73,7 & 111,6 & 5,1 & 1,2 & 30,7 & 39,3 & 68 & 98,6 & $-4,7$ & 31,5 & 25 \\
\hline 14 & 76 & 87,7 & 0,7 & 71 & 114,8 & 5 & 5,2 & 26,1 & 37,8 & 70,8 & 107,3 & $-9,7$ & 28,4 & 24 \\
\hline 15 & 85,9 & 89,1 & $-7,2$ & 83,6 & 111,8 & 2,4 & 1,2 & 26,8 & 20,4 & 63,7 & 119,7 & 1,1 & 26 & 22,9 \\
\hline 16 & 76,8 & 81,8 & $-5,1$ & 73 & 99,9 & 3,8 & 1,1 & 29,7 & 35 & 63,4 & 106,7 & $-4,3$ & 29,3 & 19,4 \\
\hline 17 & 80,7 & 86,7 & $-2,9$ & 78,1 & 114,6 & 2,6 & 2,9 & 28,7 & 31,2 & 76,4 & 113 & $-1,6$ & 31,6 & 26,8 \\
\hline 18 & 80 & 93,8 & 0,1 & 77,2 & 122,6 & 2,7 & 0,2 & 19,8 & 28,4 & 65,8 & 112,9 & $-4,4$ & 27,6 & 25,1 \\
\hline 18 & 86,2 & 89,4 & 3,9 & 79,1 & 109,5 & 7,1 & 4,9 & 27,6 & 32,4 & 62,9 & 105 & $-4,9$ & 29 & 22,6 \\
\hline 20 & 77,8 & 81,4 & $-4,7$ & 76 & 105,3 & 1,8 & 0,1 & 24,4 & 29,5 & 57,7 & 109,2 & $-4,2$ & 26,9 & 20,4 \\
\hline 21 & 82,1 & 90,7 & $-0,8$ & 76,5 & 108,3 & 5,6 & 2,5 & 23 & 27,9 & 60,6 & 115,9 & $-0,7$ & 25,6 & 20,8 \\
\hline 22 & 82,9 & 94,6 & 2,8 & 77,4 & 117 & 5,6 & 0,5 & 26,3 & 34,3 & 69,1 & 109,1 & $-2,9$ & 29,7 & 24,2 \\
\hline 23 & 75,9 & 84,7 & $-2,7$ & 78,2 & 120,4 & $-2,3$ & $-0,1$ & 25,1 & 33,9 & 68,1 & 125,7 & $-0,2$ & 27,2 & 29 \\
\hline 24 & 77,9 & 90,1 & $-1,4$ & 70 & 109,6 & 7,9 & 2,6 & 35,9 & 44,5 & 68,8 & 107,1 & $-6,7$ & 28,8 & 21,8 \\
\hline 25 & 84,9 & 84,3 & 3 & 77,4 & 102,3 & 7,5 & 3,8 & 24,4 & 29,8 & 62,1 & 108 & $-4,8$ & 25,7 & 20,8 \\
\hline 26 & 83,1 & 86,4 & $-1,1$ & 81 & 113,5 & 2,1 & 1,4 & 21,1 & 24,6 & 60,9 & 110,4 & $-6,7$ & 23,3 & 20 \\
\hline 27 & 77,1 & 83 & $-5,6$ & 72,8 & 104,6 & 4,3 & 3,1 & 39 & 42,8 & 67,3 & 109,3 & $-0,5$ & 28,9 & 23,4 \\
\hline 28 & 81,4 & 83,5 & $-0,1$ & 76,2 & 108 & 5,2 & 2,7 & 26,5 & 31,7 & 66,8 & 109 & $-3,1$ & 27,4 & 22,9 \\
\hline 29 & 79,2 & 93,8 & 1,6 & 78,5 & 121,6 & 0,7 & 0,3 & 17 & 27,6 & 65,9 & 115,1 & $-2,5$ & 27,9 & 25,5 \\
\hline 30 & 82,3 & 92,1 & 1,2 & 78,7 & 120,5 & 3,6 & 1,1 & 19,9 & 27,4 & 70,7 & 112 & $-1,3$ & 31,1 & 24,8 \\
\hline
\end{tabular}


TABELA A-4

\begin{tabular}{|c|c|c|c|c|c|c|c|c|c|c|}
\hline & $\begin{array}{c}6- \\
\text { ENAper } f\end{array}$ & IMPA f & $\begin{array}{c}\text { 1-Pogper } \\
\mathrm{f}\end{array}$ & $\begin{array}{c}\text { 1-GoMe } \\
\mathrm{f}\end{array}$ & $\begin{array}{c}\text { 6-Pogper } \\
\mathrm{f}\end{array}$ & $\begin{array}{c}\text { 6-GoMe } \\
f\end{array}$ & Thorf & T vert $f$ & Rel mol f & Rel can f \\
\hline 1 & $-26,9$ & 85,1 & $-11,3$ & 32,8 & $-30,7$ & 24,1 & 2,3 & 0,9 & $-0,5$ & 0,5 \\
\hline 2 & $-27,9$ & 93,7 & -8 & 45,4 & $-30,3$ & 30,9 & 2,8 & 0,6 & $-0,2$ & $-2,4$ \\
\hline 3 & $-28,1$ & 108,7 & -3 & 34,3 & $-25,2$ & 28,8 & 3 & 2,6 & $-0,4$ & $-0,4$ \\
\hline 4 & $-31,1$ & 97,1 & $-8,6$ & 38,4 & $-30,4$ & 32,2 & 3,7 & 3,1 & $-0,4$ & 0,6 \\
\hline 5 & $-27,9$ & 99,9 & $-9,1$ & 34 & $-30,1$ & 26 & 3,7 & 3,2 & $-1,3$ & $-1,1$ \\
\hline 6 & $-30,1$ & 85 & $-11,1$ & 40,4 & $-29,4$ & 30,2 & 3,8 & 3,7 & 0,2 & 0 \\
\hline 7 & -26 & 99,7 & $-9,6$ & 43,5 & $-31,4$ & 36,9 & 4 & 1,4 & $-1,1$ & 0,1 \\
\hline 8 & $-29,8$ & 95,5 & $-8,7$ & 48 & $-27,5$ & 38,4 & 3,2 & 3,7 & 1,1 & 0,6 \\
\hline 9 & $-29,9$ & 107 & $-3,2$ & 38,2 & $-26,4$ & 30,6 & 2,4 & 2,2 & $-1,1$ & $-0,9$ \\
\hline 10 & -31 & 86,1 & $-15,9$ & 37,1 & $-34,8$ & 29,4 & 3,6 & 2 & $-0,3$ & 1,6 \\
\hline 11 & $-31,4$ & 103,4 & $-7,2$ & 37,1 & $-28,4$ & 31,6 & 4,2 & 4,2 & $-1,7$ & $-0,3$ \\
\hline 12 & $-30,7$ & 95,6 & $-7,3$ & 35,3 & $-28,2$ & 25,4 & 3,4 & 3,5 & $-1,1$ & $-0,3$ \\
\hline 13 & $-31,8$ & 88,5 & $-10,8$ & 37,2 & $-30,9$ & 28,2 & 3 & 3 & $-1,5$ & $-0,8$ \\
\hline 14 & $-33,7$ & 86,6 & $-13,9$ & 41,4 & $-32,2$ & 32 & 2,8 & 3 & $-0,6$ & $-0,4$ \\
\hline 15 & $-29,7$ & 106,2 & $-3,9$ & 40,5 & $-28,8$ & 32,3 & 2,7 & 2,6 & $-1,1$ & $-0,7$ \\
\hline 16 & $-31,7$ & 105,8 & $-3,5$ & 36,7 & $-26,6$ & 28 & 2,8 & 2,6 & 0,1 & $-0,1$ \\
\hline 17 & $-32,4$ & 91,1 & $-11,8$ & 46,4 & $-33,6$ & 34,3 & 3,7 & 2,9 & $-2,2$ & $-0,6$ \\
\hline 18 & $-30,2$ & 96,4 & $-14,7$ & 37,4 & $-34,6$ & 32,4 & 3,1 & 1,6 & $-1,5$ & 0,4 \\
\hline 18 & $-31,9$ & 94,7 & $-9,5$ & 35,8 & $-30,9$ & 25,5 & 3,1 & 3,2 & $-0,2$ & $-1,1$ \\
\hline 20 & $-29,4$ & 93,5 & $-9,4$ & 32,9 & -29 & 25,8 & 4,7 & 3,7 & 0,2 & $-1,7$ \\
\hline 21 & $-32,7$ & 114,3 & $-4,4$ & 36,1 & $-26,5$ & 30 & 4,1 & 1,6 & $-3,1$ & $-1,9$ \\
\hline 22 & -34 & 95,9 & $-6,3$ & 40,2 & $-30,3$ & 32,5 & 4,1 & 2,1 & $-0,8$ & 0,4 \\
\hline 23 & -31 & 89,4 & $-14,1$ & 37,6 & $-37,2$ & 24 & 0,9 & $-0,9$ & -3 & $-0,7$ \\
\hline 24 & -32 & 99,3 & -5 & 39,5 & $-25,1$ & 32,1 & 2,7 & 1,4 & $-0,1$ & $-0,4$ \\
\hline 25 & $-30,2$ & 106,4 & $-2,6$ & 36,5 & $-23,8$ & 30,3 & 2,1 & 0,8 & $-0,8$ & $-0,2$ \\
\hline 26 & $-32,2$ & 89,4 & $-12,5$ & 36,8 & $-32,6$ & 29,2 & 2,1 & 1,7 & $-1,5$ & 0,8 \\
\hline 27 & $-25,6$ & 94,9 & -10 & 40,3 & $-28,9$ & 28,3 & 3,9 & 2,6 & 1,5 & 0,5 \\
\hline 28 & -31 & 100,7 & $-4,1$ & 40,4 & -27 & 32,2 & 2,3 & 1,8 & $-1,5$ & $-0,7$ \\
\hline 29 & $-28,5$ & 93,3 & $-10,5$ & 37,9 & $-30,4$ & 30,9 & 2,6 & 0,6 & $-2,1$ & $-1,2$ \\
\hline 30 & $-27,3$ & 103 & $-6,7$ & 42,7 & $-27,8$ & 36 & 3,4 & 2,7 & $-1,2$ & $-1,3$ \\
\hline
\end{tabular}


TABELA A-5

\begin{tabular}{|c|c|c|c|c|c|c|c|c|c|c|c|c|c|c|}
\hline & SNA c & Co-A c & A-Nper C & SNB C & Co-Gn c & ANB c & Wits c & FMA C & $\begin{array}{c}\text { SN.GoGn } \\
\text { c }\end{array}$ & AFAI c & 1.PP C & $\begin{array}{c}1- \\
\text { ENAper } \\
C\end{array}$ & 1-PP c & 6-PP c \\
\hline 1 & 79 & 88,1 & $\begin{array}{ll}-1,8 \\
\end{array}$ & 77,6 & 114,4 & 1,4 & 0,7 & 23,3 & 31 & 57,1 & 115,2 & 0,6 & 24,4 & 22,1 \\
\hline 2 & 81,3 & 91,8 & 0,9 & 75,6 & 114,9 & 5,6 & 4,7 & 36,4 & 42,5 & 73 & 116,9 & 2 & 29,7 & 26,2 \\
\hline 3 & 86,6 & 89,9 & $-0,4$ & 82,8 & 108,8 & 3,8 & 0,9 & 19 & 19,7 & 55,3 & 111,9 & $-0,2$ & 23,9 & 19,1 \\
\hline 4 & 78 & 84,7 & $-1,9$ & 71,8 & 108,1 & 6,2 & 2,9 & 27,7 & 35,8 & 67,2 & 100,3 & $-4,2$ & 27,8 & 22,6 \\
\hline 5 & 81,9 & 86,4 & $-2,9$ & 78,9 & 108,3 & 3 & 4 & 19,6 & 22,9 & 54,4 & 113,8 & $-2,6$ & 22,7 & 20,1 \\
\hline 6 & 79 & 88,6 & $-4,7$ & 72,7 & 112,6 & 6,3 & 3,8 & 37,4 & 40,6 & 74,2 & 104,5 & -1 & 29,9 & 23,5 \\
\hline 7 & 79,1 & 88 & 0,4 & 77,5 & 119,1 & 1,6 & 0,2 & 17,7 & 27,1 & 75 & 121,8 & 1,6 & 29,8 & 27 \\
\hline 8 & 81,5 & 92,2 & $-2,1$ & 75,9 & 114,6 & 5,6 & 1,6 & 31,5 & 33,1 & 77,8 & 103,6 & $-3,8$ & 33,7 & 24,6 \\
\hline 9 & 78,1 & 84,5 & -4 & 74,3 & 107,9 & 3,9 & 4,1 & 23,7 & 28,4 & 62,6 & 116 & 1,1 & 26,5 & 24,7 \\
\hline 10 & 79,5 & 83,5 & $-4,2$ & 77,2 & 111,6 & 2,3 & 2,7 & 27,9 & 31,2 & 68,7 & 104,4 & -3 & 30,2 & 24,4 \\
\hline 11 & 75,7 & 92,3 & $-5,8$ & 73,3 & 116,7 & 2,4 & 2,6 & 12,1 & 18,4 & 60,3 & 105,5 & $-7,7$ & 25,6 & 19,7 \\
\hline 12 & 79,5 & 84,1 & $-1,4$ & 75,3 & 106,1 & 4,2 & 3,9 & 26,4 & 32,7 & 60,8 & 98 & $-4,9$ & 27,1 & 24 \\
\hline 13 & 79,7 & 86,2 & 0,3 & 74,2 & 115,4 & 5,5 & 1,3 & 30,7 & 39,4 & 68,5 & 106,1 & $-3,6$ & 32 & 24,9 \\
\hline 14 & 75,1 & 87,6 & $-0,5$ & 71,1 & 114,6 & 4 & 4,2 & 25,9 & 37,7 & 71,2 & 102,5 & $-10,2$ & 29,4 & 24,8 \\
\hline 15 & 87 & 88,6 & $-10,4$ & 85,6 & 112,2 & 1,4 & 1 & 29,1 & 17,3 & 66,2 & 121,9 & 4 & 27,1 & 23,6 \\
\hline 16 & 79,5 & 86,3 & $-4,5$ & 77,4 & 112,5 & 2,1 & 1,6 & 26,3 & 30,1 & 67,7 & 114,2 & $-0,2$ & 28,7 & 23,7 \\
\hline 17 & 82,8 & 88,6 & $-6,6$ & 81,4 & 118,7 & 1,5 & 2,9 & 29,3 & 27,7 & 76 & 118,3 & 1,8 & 30,2 & 29,2 \\
\hline 18 & 79 & 97 & -1 & 77,4 & 124,9 & 1,6 & 0,6 & 20 & 27 & 68,5 & 112 & $-4,6$ & 29,5 & 26,2 \\
\hline 18 & 85,5 & 89,1 & $-0,3$ & 79,4 & 112,3 & 6,1 & 2,7 & 32,8 & 33,8 & 64,6 & 101,1 & $-5,3$ & 28,6 & 21,4 \\
\hline 20 & 79,4 & 83,8 & $-3,2$ & 76,3 & 107,1 & 3,1 & 1,8 & 21,5 & 26,6 & 57,5 & 108 & $-2,7$ & 27,5 & 20,3 \\
\hline 21 & 81,5 & 90,4 & $-1,2$ & 78,3 & 111,2 & 3,2 & 1,6 & 20,4 & 26 & 57,4 & 127,6 & 1 & 23,6 & 21,4 \\
\hline 22 & 85,7 & 95,2 & 2,8 & 81 & 119,5 & 4,7 & 0,5 & 22,2 & 27 & 70 & 111,3 & $-4,7$ & 30,5 & 25,3 \\
\hline 23 & 76,7 & 86,3 & $-4,1$ & 78,2 & 123,5 & $-1,6$ & $-0,5$ & 25 & 32,1 & 68,4 & 124,2 & 3,9 & 27,7 & 27,8 \\
\hline 24 & 77,4 & 93,6 & $-1,9$ & 70 & 111,9 & 7,4 & 3,3 & 34,7 & 43,3 & 69,3 & 103,1 & $-6,1$ & 29,3 & 21,8 \\
\hline 25 & 84,8 & 82,7 & 0,3 & 78,1 & 100,7 & 6,7 & 3 & 26,1 & 28,2 & 60,3 & 110,7 & $-2,5$ & 26,3 & 20,3 \\
\hline 26 & 82,5 & 84,6 & $-1,8$ & 81,9 & 112,8 & 0,6 & 0,6 & 20,3 & 24 & 61,4 & 106,9 & -6 & 24,6 & 21,6 \\
\hline 27 & 76,2 & 82,5 & $-6,4$ & 72,1 & 103,4 & 4,1 & 2,1 & 41,8 & 45,6 & 68,9 & 101 & $-4,1$ & 29,9 & 23,8 \\
\hline 28 & 80,8 & 83 & 0 & 75,9 & 107,7 & 4,9 & 1,8 & 24,3 & 31,2 & 66,2 & 106,5 & $-3,5$ & 27,6 & 23 \\
\hline 29 & 78,6 & 96,3 & $-3,7$ & 77,9 & 123,4 & 0,8 & 1,5 & 20,4 & 26 & 67,4 & 112 & $-3,8$ & 28,9 & 25,9 \\
\hline 30 & 84,8 & 96,1 & 3,8 & 78,8 & 121,8 & 6 & 1,6 & 20,7 & 27,2 & 70,3 & 109,7 & 1,4 & 31,3 & 24 \\
\hline
\end{tabular}


TABELA A-6

\begin{tabular}{|c|c|c|c|c|c|c|c|c|c|c|}
\hline & $\begin{array}{c}6- \\
\text { ENAper } \\
\text { C }\end{array}$ & IMPA C & $\begin{array}{c}\text { 1-Pogper } \\
\text { c }\end{array}$ & $\begin{array}{c}\text { 1-GoMe } \\
\text { c }\end{array}$ & $\begin{array}{c}6 \text {-Pogper } \\
\text { c }\end{array}$ & $\begin{array}{c}\text { 6-GoMe } \\
\text { c }\end{array}$ & Thor c & T vert c & $\begin{array}{c}\text { Rel mol } \\
\text { C }\end{array}$ & $\begin{array}{l}\text { Rel can } \\
\quad \text { c }\end{array}$ \\
\hline 1 & $-26,8$ & 98,1 & $-11,3$ & 35,1 & -32 & 25,5 & 3,5 & 3,9 & $-0,4$ & 0,6 \\
\hline 2 & $-26,6$ & 92,8 & $-10,5$ & 47,4 & -31 & 32,6 & 3,4 & 3,6 & 0,7 & $-2,7$ \\
\hline 3 & $-25,5$ & 109,5 & $-3,7$ & 35,4 & $-23,2$ & 30,2 & 2,6 & 4,1 & $-1,8$ & $-1,3$ \\
\hline 4 & $-28,8$ & 97,5 & $-8,2$ & 41,2 & $-27,7$ & 34,6 & 3,5 & 3,3 & $-0,3$ & 2 \\
\hline 5 & $-28,8$ & 92 & -11 & 34,5 & $-29,9$ & 26,5 & 5 & 4,7 & $-0,8$ & 1,8 \\
\hline 6 & $-27,6$ & 96,8 & $-13,4$ & 47,1 & $-30,2$ & 36,5 & 4,1 & 5 & 0,5 & 1,6 \\
\hline 7 & $-25,6$ & 102,1 & $-7,7$ & 45,4 & $-30,2$ & 39,4 & 2,3 & 0 & $-1,5$ & $-0,9$ \\
\hline 8 & -28 & 94,8 & $-7,3$ & 49,1 & $-24,8$ & 40,6 & 5,8 & 5,6 & 1,1 & 3,4 \\
\hline 9 & -28 & 104,6 & $-4,6$ & 39,3 & $-25,9$ & 31,1 & 3,8 & 3,5 & $-0,8$ & $-1,7$ \\
\hline 10 & $-26,7$ & 91,4 & $-13,5$ & 39,7 & $-31,1$ & 30,2 & 3,7 & 3,4 & $-0,3$ & 0 \\
\hline 11 & $-32,7$ & 103,5 & $-8,4$ & 37,6 & -29 & 33,9 & 3,7 & 4,7 & $-0,8$ & $-1,5$ \\
\hline 12 & -30 & 92 & $-7,6$ & 36,1 & $-27,1$ & 26,3 & 2 & 3,8 & -1 & -1 \\
\hline 13 & $-30,5$ & 89,7 & $-11,2$ & 39,1 & $-31,5$ & 29,3 & 3,5 & 4,3 & $-0,7$ & 0,6 \\
\hline 14 & $-32,7$ & 85,9 & $-15,7$ & 41,6 & $-32,3$ & 32,3 & 2,8 & 4 & $-0,5$ & 0,1 \\
\hline 15 & $-25,6$ & 101,8 & $-5,9$ & 43,7 & $-27,4$ & 35,5 & 4,2 & 4,3 & $-1,1$ & 0,7 \\
\hline 16 & $-28,1$ & 104,1 & $-4,8$ & 41,4 & $-26,2$ & 32,6 & 3 & 1,5 & $-1,5$ & 0,1 \\
\hline 17 & $-26,9$ & 96,4 & $-11,3$ & 46,5 & $-32,3$ & 35,7 & 2,4 & 1,5 & $-2,2$ & $-1,4$ \\
\hline 18 & $-30,6$ & 92,9 & -15 & 39,5 & $-34,4$ & 32,5 & 3,8 & 3,2 & $-1,1$ & 0,9 \\
\hline 18 & -34 & 93,2 & $-11,4$ & 37,3 & $-34,9$ & 25,6 & 2,9 & 3,4 & 0,7 & $-1,5$ \\
\hline 20 & $-28,5$ & 102,4 & $-8,4$ & 33,8 & $-29,2$ & 27 & 4 & 4,6 & $-0,2$ & 0,9 \\
\hline 21 & $-29,1$ & 107,6 & $-4,6$ & 36 & $-28,5$ & 29,3 & 4 & 2,7 & $-0,2$ & $-1,1$ \\
\hline 22 & $-34,3$ & 96,1 & $-6,2$ & 42,1 & $-30,2$ & 34,4 & 3,5 & 3,9 & $-0,9$ & $-1,5$ \\
\hline 23 & $-26,2$ & 92 & $-14,5$ & 39 & $-37,3$ & 27,6 & 1,9 & 0,2 & $-2,4$ & $-3,2$ \\
\hline 24 & $-31,5$ & 95,4 & $-6,3$ & 41,2 & -26 & 33,8 & 3,2 & 3,3 & $-0,6$ & 0,2 \\
\hline 25 & $-27,5$ & 106,3 & $-3,3$ & 36,3 & $-23,3$ & 30,1 & 2,9 & 2,4 & $-0,5$ & 0,8 \\
\hline 26 & $-30,9$ & 86,5 & $-13,6$ & 37 & $-32,5$ & 29 & 2,8 & 2,8 & $-1,6$ & 0,8 \\
\hline 27 & $-26,9$ & 94,9 & $-9,6$ & 40,2 & $-27,5$ & 28,4 & 2,5 & 2,2 & 1,4 & 0,3 \\
\hline 28 & -30 & 102,1 & $-5,9$ & 40,2 & $-27,4$ & 33,4 & 2,4 & 2,1 & $-1,7$ & -1 \\
\hline 29 & $-30,7$ & 94,8 & $-8,1$ & 38,6 & $-29,2$ & 30,8 & 2,4 & 1,2 & $-1,7$ & $-1,9$ \\
\hline 30 & $-25,5$ & 107 & $-7,4$ & 43,4 & $-28,4$ & 37,7 & 4,4 & 4,2 & $-1,2$ & $-0,1$ \\
\hline
\end{tabular}


TABELA A-7

\begin{tabular}{|c|c|c|c|c|c|c|c|c|c|c|c|c|c|c|}
\hline & SNA c-f & Co-A c-f & $\begin{array}{c}\text { A-Nper } \\
\text { C-f }\end{array}$ & SNB c-f & $\underset{f}{\text { Co-Gn c- }}$ & ANB c-f & Wits c-f & FMA c-f & $\begin{array}{c}\text { SN.GoGn } \\
c-f\end{array}$ & AFAl c-f & 1-PP c-f & $\begin{array}{c}1- \\
\text { ENAper } \\
c-f\end{array}$ & 1-PP c-f & 6-PP c-f \\
\hline 1 & 1,9 & 7 & 1,4 & 1,5 & 9,5 & 0,3 & 0,7 & $-4,1$ & $-3,3$ & 1,9 & -3 & 2,2 & 2,9 & 1,1 \\
\hline 2 & 1,3 & 1,3 & 1,2 & 0,5 & 0,9 & 0,7 & 0,1 & 0,5 & 0,4 & 2 & $-6,7$ & $-0,4$ & 3,3 & 0,9 \\
\hline 3 & 2,7 & 0,8 & 1,8 & 3,1 & 2,8 & $-0,4$ & 0,6 & $-5,7$ & $-6,3$ & 0,1 & $-5,1$ & 0,7 & 0,9 & 0,5 \\
\hline 4 & $-4,1$ & 0,2 & $-3,3$ & $-2,8$ & 0,8 & $-1,3$ & $-0,6$ & 3 & 3,7 & 3,1 & -6 & $-0,6$ & 0,7 & 0,1 \\
\hline 5 & 0,5 & 2,2 & 1,3 & $-0,4$ & 1 & 0,9 & 1,7 & $-2,4$ & $-1,7$ & $-0,6$ & $-8,1$ & $-2,3$ & $-0,3$ & $-0,2$ \\
\hline 6 & 0,1 & 6,1 & 1,1 & $-0,5$ & 10,3 & 0,5 & 1,4 & -2 & $-0,2$ & 6,9 & 2,1 & 4,3 & 2 & 3,1 \\
\hline 7 & 1,1 & 1,8 & 1,9 & 0,4 & 3,8 & 0,8 & 0,6 & $-1,3$ & 0,7 & 2,7 & 2,4 & $-0,3$ & $-0,5$ & 1,1 \\
\hline 8 & 0,2 & 1,6 & 1 & 0,2 & $-0,2$ & $-0,1$ & 0 & $-4,9$ & $-4,9$ & $-1,3$ & 7,1 & 3,5 & $-0,7$ & $-0,4$ \\
\hline 9 & $-1,7$ & 1,6 & $-0,8$ & -1 & 3,7 & $-0,7$ & $-0,5$ & 0,5 & 2,1 & 0,6 & $-0,3$ & 2,1 & 0,9 & 0,3 \\
\hline 10 & 2,5 & 1,4 & 1,7 & 1,8 & 3 & 0,6 & 3 & $-1,5$ & $-2,2$ & 0,3 & $-0,8$ & 3,8 & 0,1 & 0,7 \\
\hline 11 & 0,1 & 2,9 & 0,3 & $-2,1$ & 2 & 2,3 & 1,9 & $-2,7$ & $-1,6$ & 0,6 & $-9,1$ & $-3,5$ & 0,2 & $-0,5$ \\
\hline 12 & 0,2 & 3,3 & 2 & $-0,1$ & 5,1 & 0,3 & 1,1 & $-2,4$ & $-1,1$ & 1,9 & $-11,6$ & $-2,7$ & 1,4 & 0,8 \\
\hline 13 & 0,9 & 2 & 0,4 & 0,5 & 3,8 & 0,4 & 0,1 & 0 & 0,1 & 0,5 & 7,5 & 1,1 & 0,5 & $-0,1$ \\
\hline 14 & $-0,9$ & $-0,1$ & $-1,2$ & 0,1 & $-0,2$ & -1 & -1 & $-0,2$ & $-0,1$ & 0,4 & $-4,8$ & $-0,5$ & 1 & 0,8 \\
\hline 15 & 1,1 & $-0,5$ & $-3,2$ & 2 & 0,4 & -1 & $-0,2$ & 2,3 & $-3,1$ & 2,5 & 2,2 & 2,9 & 1,1 & 0,7 \\
\hline 16 & 2,7 & 4,5 & 0,6 & 4,4 & 12,6 & $-1,7$ & 0,5 & $-3,4$ & $-4,9$ & 4,3 & 7,5 & 4,1 & $-0,6$ & 4,3 \\
\hline 17 & 2,1 & 1,9 & $-3,7$ & 3,3 & 4,1 & $-1,1$ & 0 & 0,6 & $-3,5$ & $-0,4$ & 5,3 & 3,4 & $-1,4$ & 2,4 \\
\hline 18 & -1 & 3,2 & $-1,1$ & 0,2 & 2,3 & $-1,1$ & 0,4 & 0,2 & $-1,4$ & 2,7 & $-0,9$ & $-0,2$ & 1,9 & 1,1 \\
\hline 18 & $-0,7$ & $-0,3$ & $-4,2$ & 0,3 & 2,8 & -1 & $-2,2$ & 5,2 & 1,4 & 1,7 & $-3,9$ & $-0,4$ & $-0,4$ & $-1,2$ \\
\hline 20 & 1,6 & 2,4 & 1,5 & 0,3 & 1,8 & 1,3 & 1,7 & $-2,9$ & $-2,9$ & $-0,2$ & $-1,2$ & 1,5 & 0,6 & $-0,1$ \\
\hline 21 & $-0,6$ & $-0,3$ & $-0,4$ & 1,8 & 2,9 & $-2,4$ & $-0,9$ & $-2,6$ & $-1,9$ & $-3,2$ & 11,7 & 1,7 & -2 & 0,6 \\
\hline 22 & 2,8 & 0,6 & 0 & 3,6 & 2,5 & $-0,9$ & 0 & $-4,1$ & $-7,3$ & 0,9 & 2,2 & $-1,8$ & 0,8 & 1,1 \\
\hline 23 & 0,8 & 1,6 & $-1,4$ & 0 & 3,1 & 0,7 & $-0,4$ & $-0,1$ & $-1,8$ & 0,3 & $-1,5$ & 4,1 & 0,5 & $-1,2$ \\
\hline 24 & $-0,5$ & 3,5 & $-0,5$ & 0 & 2,3 & $-0,5$ & 0,7 & $-1,2$ & $-1,2$ & 0,5 & -4 & 0,6 & 0,5 & 0 \\
\hline 25 & $-0,1$ & $-1,6$ & $-2,7$ & 0,7 & $-1,6$ & $-0,8$ & $-0,8$ & 1,7 & $-1,6$ & $-1,8$ & 2,7 & 2,3 & 0,6 & $-0,5$ \\
\hline 26 & $-0,6$ & $-1,8$ & $-0,7$ & 0,9 & $-0,7$ & $-1,5$ & $-0,8$ & $-0,8$ & $-0,6$ & 0,5 & $-3,5$ & 0,7 & 1,3 & 1,6 \\
\hline 27 & $-0,9$ & $-0,5$ & $-0,8$ & $-0,7$ & $-1,2$ & $-0,2$ & -1 & 2,8 & 2,8 & 1,6 & $-8,3$ & $-3,6$ & 1 & 0,4 \\
\hline 28 & $-0,6$ & $-0,5$ & 0,1 & $-0,3$ & $-0,3$ & $-0,3$ & $-0,9$ & $-2,2$ & $-0,5$ & $-0,6$ & $-2,5$ & $-0,4$ & 0,2 & 0,1 \\
\hline 29 & $-0,6$ & 2,5 & $-5,3$ & $-0,6$ & 1,8 & 0,1 & 1,2 & 3,4 & $-1,6$ & 1,5 & $-3,1$ & $-1,3$ & 1 & 0,4 \\
\hline 30 & 2,5 & 4 & 2,6 & 0,1 & 1,3 & 2,4 & 0,5 & 0,8 & $-0,2$ & $-0,4$ & $-2,3$ & 2,7 & 0,2 & $-0,8$ \\
\hline
\end{tabular}


TABELA A-8

\begin{tabular}{|c|c|c|c|c|c|c|c|c|c|c|}
\hline & $\begin{array}{c}6- \\
\text { ENAper } \\
c-f\end{array}$ & IMPA c-f & $\begin{array}{c}\text { 1-Pogper } \\
\text { C-f }\end{array}$ & $\begin{array}{c}\text { 1-GoMe } \\
c-f\end{array}$ & $\begin{array}{c}\text { 6-Pogper } \\
\text { C-f }\end{array}$ & $\begin{array}{c}\text { 6-GoMe } \\
c-f\end{array}$ & Thor c-f & T vert c-f & $\begin{array}{c}\text { Rel mol } \\
\text { C-f }\end{array}$ & $\begin{array}{c}\text { Rel can } \\
\text { C-f }\end{array}$ \\
\hline 1 & 0,1 & 13 & 0 & 2,3 & $-1,3$ & 1,4 & 1,2 & 3 & 0,1 & 0,1 \\
\hline 2 & 1,3 & $-0,9$ & $-2,5$ & 2 & $-0,7$ & 1,7 & 0,6 & 3 & 0,9 & $-0,3$ \\
\hline 3 & 2,6 & 0,8 & $-0,7$ & 1,1 & 2 & 1,4 & $-0,4$ & 1,5 & $-1,4$ & $-0,9$ \\
\hline 4 & 2,3 & 0,4 & 0,4 & 2,8 & 2,7 & 2,4 & $-0,2$ & 0,2 & 0,1 & 1,4 \\
\hline 5 & $-0,9$ & $-7,9$ & $-1,9$ & 0,5 & 0,2 & 0,5 & 1,3 & 1,5 & 0,5 & 2,9 \\
\hline 6 & 2,5 & 11,8 & $-2,3$ & 6,7 & $-0,8$ & 6,3 & 0,3 & 1,3 & 0,3 & 1,6 \\
\hline 7 & 0,4 & 2,4 & 1,9 & 1,9 & 1,2 & 2,5 & $-1,7$ & $-1,4$ & $-0,4$ & -1 \\
\hline 8 & 1,8 & $-0,7$ & 1,4 & 1,1 & 2,7 & 2,2 & 2,6 & 1,9 & 0 & 2,8 \\
\hline 9 & 1,9 & $-2,4$ & $\begin{array}{l}-1,4 \\
\end{array}$ & 1,1 & 0,5 & 0,5 & 1,4 & 1,3 & 0,3 & $-0,8$ \\
\hline 10 & 4,3 & 5,3 & 2,4 & 2,6 & 3,7 & 0,8 & 0,1 & 1,4 & 0 & $-1,6$ \\
\hline 11 & $-1,3$ & 0,1 & $-1,2$ & 0,5 & $-0,6$ & 2,3 & $-0,5$ & 0,5 & 0,9 & $-1,2$ \\
\hline 12 & 0,7 & $-3,6$ & $-0,3$ & 0,8 & 1,1 & 0,9 & $-1,4$ & 0,3 & 0,1 & $-0,7$ \\
\hline 13 & 1,3 & 1,2 & $-0,4$ & 1,9 & $-0,6$ & 1,1 & 0,5 & 1,3 & 0,8 & 1,4 \\
\hline 14 & 1 & $-0,7$ & $-1,8$ & 0,2 & $-0,1$ & 0,3 & 0 & 1 & 0,1 & 0,5 \\
\hline 15 & 4,1 & $-4,4$ & -2 & 3,2 & 1,4 & 3,2 & 1,5 & 1,7 & 0 & 1,4 \\
\hline 16 & 3,6 & $-1,7$ & $-1,3$ & 4,7 & 0,4 & 4,6 & 0,2 & $-1,1$ & $-1,6$ & 0,2 \\
\hline 17 & 5,5 & 5,3 & 0,5 & 0,1 & 1,3 & 1,4 & $-1,3$ & $-1,4$ & 0 & $-0,8$ \\
\hline 18 & $-0,4$ & $-3,5$ & $-0,3$ & 2,1 & 0,2 & 0,1 & 0,7 & 1,6 & 0,4 & 0,5 \\
\hline 18 & $-2,1$ & $-1,5$ & $-1,9$ & 1,5 & -4 & 0,1 & $-0,2$ & 0,2 & 0,9 & $-0,4$ \\
\hline 20 & 0,9 & 8,9 & 1 & 0,9 & $-0,2$ & 1,2 & $-0,7$ & 0,9 & $-0,4$ & 2,6 \\
\hline 21 & 3,6 & $-6,7$ & $-0,2$ & $-0,1$ & -2 & $-0,7$ & $-0,1$ & 1,1 & 2,9 & 0,8 \\
\hline 22 & $-0,3$ & 0,2 & 0,1 & 1,9 & 0,1 & 1,9 & $-0,6$ & 1,8 & $-0,1$ & $-1,9$ \\
\hline 23 & 4,8 & 2,6 & $-0,4$ & 1,4 & $-0,1$ & 3,6 & 1 & 1,1 & 0,6 & $-2,5$ \\
\hline 24 & 0,5 & $-3,9$ & $-1,3$ & 1,7 & $-0,9$ & 1,7 & 0,5 & 1,9 & $-0,5$ & 0,6 \\
\hline 25 & 2,7 & $-0,1$ & $-0,7$ & $-0,2$ & 0,5 & $-0,2$ & 0,8 & 1,6 & 0,3 & 1 \\
\hline 26 & 1,3 & $-2,9$ & $-1,1$ & 0,2 & 0,1 & $-0,2$ & 0,7 & 1,1 & $-0,1$ & 0 \\
\hline 27 & $-1,3$ & 0 & 0,4 & $-0,1$ & 1,4 & 0,1 & $-1,4$ & $-0,4$ & $-0,1$ & $-0,2$ \\
\hline 28 & 1 & 1,4 & $-1,8$ & $-0,2$ & $-0,4$ & 1,2 & 0,1 & 0,3 & $-0,2$ & $-0,3$ \\
\hline 29 & $-2,2$ & 1,5 & 2,4 & 0,7 & 1,2 & $-0,1$ & $-0,2$ & 0,6 & 0,4 & $-0,7$ \\
\hline 30 & 1,8 & 4 & $-0,7$ & 0,7 & $-0,6$ & 1,7 & 1 & 1,5 & 0 & 1,2 \\
\hline
\end{tabular}


TABELA A-9

\begin{tabular}{|c|c|c|c|c|c|c|c|c|c|c|c|c|c|c|}
\hline & SNA f-i & Co-A f-i & $\underset{\mathrm{i}}{\mathrm{A}-\mathrm{Nper} \mathrm{f}-}$ & SNB f-i & Co-Gn f-i & ANB f-i & Wits $f-i$ & FMA f-i & $\underset{f-i}{\text { SN.GoGn }}$ & AFAI f-i & 1-PP f-i & $\begin{array}{c}1- \\
\text { ENAper } \\
f-i\end{array}$ & 1-PP f-i & 6-PP f-i \\
\hline 1 & $-3,4$ & 1,5 & $\begin{array}{l}-1,4 \\
\end{array}$ & 0,1 & 5,8 & $-3,4$ & $-5,5$ & 0,1 & 1,1 & 1,7 & $-10,5$ & $-5,2$ & 0,9 & 2,4 \\
\hline 2 & $-1,5$ & $-2,3$ & $-1,6$ & $-0,4$ & 1,5 & $-1,2$ & 0,4 & 1,5 & 0 & 1,1 & 7,3 & 0,6 & $-1,8$ & 0,5 \\
\hline 3 & $-0,2$ & 1,6 & $-1,9$ & 2,3 & 7 & $-2,5$ & $-5,4$ & 1,4 & $-0,7$ & 4,2 & $-9,9$ & $-3,8$ & 1,3 & $-0,5$ \\
\hline 4 & 1,4 & 2,1 & 2,8 & $-1,7$ & 1,5 & 3,2 & 1,3 & 2,2 & 3 & 5,8 & 0,3 & $-0,7$ & 1,7 & 1,3 \\
\hline 5 & $-1,9$ & 2,8 & $-0,9$ & 1,4 & 10,4 & $-3,4$ & $-1,8$ & $-2,1$ & $-0,4$ & 4,2 & 8,3 & 0,1 & 0,7 & 4,1 \\
\hline 6 & $-4,3$ & $-2,7$ & $-3,5$ & $-2,2$ & $-0,2$ & -2 & $-3,3$ & 2,2 & 3,2 & 5,1 & -31 & $-8,7$ & 3,5 & 1,5 \\
\hline 7 & 0,3 & 0,8 & 0,8 & 1,6 & 5,8 & $-1,4$ & $-3,4$ & -2 & $\begin{array}{l}-2,3 \\
\end{array}$ & 7,1 & $-2,2$ & $-0,3$ & 4,2 & 2,9 \\
\hline 8 & 3,2 & 5,4 & $-0,7$ & 4,9 & 15,1 & $-1,6$ & $-4,9$ & 4,6 & $-0,9$ & 15,9 & $-14,4$ & $-7,7$ & 4,1 & 5 \\
\hline 9 & 0,2 & $-1,1$ & 0,5 & 1,1 & 4,3 & $-0,8$ & $-1,4$ & 0,1 & -1 & 6,1 & $-7,7$ & $-2,9$ & 2,4 & 3,6 \\
\hline 10 & $-1,1$ & 1,4 & $-0,7$ & $-0,3$ & 5,3 & $-0,7$ & $-3,1$ & 0,2 & $-0,1$ & 6,6 & $-13,3$ & $-8,8$ & 3,2 & 1,6 \\
\hline 11 & $-4,7$ & 0,7 & $-3,5$ & 3 & 14,3 & $-7,9$ & $-10,6$ & $-3,3$ & $-3,6$ & 6 & $-6,8$ & $\begin{array}{l}-13 \\
\end{array}$ & 0,9 & 1,3 \\
\hline 12 & 0,6 & 1,8 & $-1,6$ & 3,6 & 7,7 & $-3,1$ & $-5,1$ & $-1,1$ & $-3,5$ & 2,1 & 15,7 & 2,1 & $-0,5$ & 0,9 \\
\hline 13 & $-2,8$ & $-0,6$ & $-3,6$ & $-0,7$ & 2,4 & $-2,1$ & -7 & 0,9 & $-0,6$ & 1,1 & -19 & $-5,2$ & 3 & 0,5 \\
\hline 14 & $-2,2$ & 0,8 & 2,9 & $-0,1$ & 5,3 & $-2,2$ & $-1,7$ & $-6,8$ & -3 & 3,5 & $-0,5$ & $-8,9$ & $-0,4$ & 2 \\
\hline 15 & -4 & $-2,2$ & $-3,6$ & 2 & 6,2 & $-5,9$ & $-8,3$ & $-4,4$ & $-4,5$ & 2 & $-10,3$ & $-6,1$ & 1,8 & $-0,2$ \\
\hline 16 & 1,8 & 3,4 & 0 & $-0,2$ & 4,1 & 2 & 0 & 0,6 & $-1,2$ & 3,5 & $-8,3$ & $-5,1$ & 1,5 & $-1,2$ \\
\hline 17 & $-0,5$ & 4,8 & 1,1 & 1,7 & 11,8 & $-2,2$ & $-0,4$ & $-0,9$ & $-0,7$ & 8,9 & 10,8 & 1,4 & 1,2 & 3,8 \\
\hline 18 & $-2,2$ & $-1,6$ & 0 & $-2,2$ & 0,1 & $-0,1$ & 0,2 & $-1,3$ & 1,1 & 4 & 11,8 & $-0,7$ & $-0,2$ & 2,6 \\
\hline 18 & $-1,6$ & $-0,2$ & $-0,9$ & $-0,3$ & 2 & $-1,3$ & -3 & 0,3 & 0,3 & 2,3 & $-6,3$ & $-3,1$ & 1,9 & 1,1 \\
\hline 20 & $-3,8$ & $-1,6$ & $-2,1$ & 0,1 & 5,5 & $-3,9$ & $-5,6$ & 0,4 & 1,2 & 4,9 & $-11,4$ & $-4,2$ & 1,9 & 2 \\
\hline 21 & 0,2 & 6 & -1 & 1,4 & 7,9 & $-1,2$ & -3 & 0 & -2 & 5,8 & $-8,4$ & $-1,2$ & 2,6 & 2,3 \\
\hline 22 & $-2,6$ & 2,9 & $-1,9$ & 0,4 & 9,4 & $-2,8$ & $-6,9$ & 2 & 3 & 6,3 & $-16,8$ & $-8,6$ & 2,3 & 1,6 \\
\hline 23 & $-4,5$ & 1,9 & $-1,6$ & $-1,2$ & 9 & $-3,3$ & 0,4 & $-1,4$ & 0,8 & 5,6 & 8,4 & 0,2 & $-0,5$ & 5,7 \\
\hline 24 & $-1,5$ & $-0,6$ & $-0,3$ & $-1,1$ & 0,6 & $-0,5$ & $-2,8$ & 2,1 & 3,2 & 4,7 & $-5,7$ & $-3,9$ & 2,4 & 1,2 \\
\hline 25 & -1 & 1,3 & 1,7 & 0,2 & 2,6 & $-1,3$ & $-3,4$ & $-2,5$ & $-0,4$ & 2,4 & $-3,1$ & $-3,5$ & $-0,2$ & $-0,1$ \\
\hline 26 & $-2,1$ & 4,7 & $-1,4$ & 1,9 & 12,4 & -4 & $-3,6$ & $-4,7$ & $-4,7$ & 3,2 & 0,5 & $-1,5$ & $-0,6$ & 1,9 \\
\hline 27 & $-0,5$ & $-1,1$ & -2 & 2,7 & 5,3 & $-3,2$ & $-4,7$ & 0,9 & $-1,6$ & 6,2 & 9,9 & 1,7 & 1,5 & 2 \\
\hline 28 & $-2,7$ & 2,6 & $-1,2$ & $-0,3$ & 9,2 & $-2,4$ & $-3,9$ & 2,9 & 3,8 & 7,2 & $-11,5$ & $-5,3$ & 1,3 & 3,7 \\
\hline 29 & 0,4 & $-0,6$ & 2,4 & 0,9 & 2,1 & $-0,5$ & $-2,5$ & $-1,3$ & 0,4 & 2,1 & $-2,2$ & $-1,4$ & 1,7 & 1,5 \\
\hline 30 & $-1,4$ & 3 & $-5,4$ & 3,4 & 13,5 & $-4,8$ & $-6,3$ & 0,5 & $-2,8$ & 5,5 & $-13,8$ & -4 & 1,7 & 2,9 \\
\hline
\end{tabular}


TABELA A-10

\begin{tabular}{|c|c|c|c|c|c|c|c|c|c|c|}
\hline & $\begin{array}{c}6- \\
\text { ENAper } \\
f-i\end{array}$ & IMPA f-i & 1-Pogper & $\underset{f-i}{1-G o M e}$ & 6-Pogper & 6-GoMe & Thor f-i & T vert f-i & $\underset{f-i}{R e l}$ mol & $\begin{array}{c}\text { Rel can } \\
f-i\end{array}$ \\
\hline 1 & $-1,1$ & $-2,3$ & 0,1 & $-1,4$ & $-0,3$ & 0,9 & -8 & $-3,2$ & $-4,6$ & $-2,9$ \\
\hline 2 & $-0,3$ & $-0,1$ & 2 & 0,5 & 1,2 & $-0,4$ & $-3,5$ & $-3,1$ & $-3,4$ & $-3,6$ \\
\hline 3 & $-1,9$ & 5,4 & 2,1 & 0,7 & 1,7 & 3,8 & $-5,8$ & $-3,5$ & $-4,3$ & $-5,4$ \\
\hline 4 & $-4,3$ & 2,9 & $-0,4$ & 2,5 & $-1,8$ & 3,8 & $-1,5$ & $-1,9$ & $-3,3$ & $-2,6$ \\
\hline 5 & 0,4 & $-4,3$ & $-0,8$ & 1,1 & 2 & 1,2 & $-3,1$ & $-2,7$ & $-5,6$ & -4 \\
\hline 6 & $-0,1$ & $-9,4$ & $-2,8$ & 0,4 & 1 & 1,9 & $-6,7$ & -1 & $-2,6$ & $-2,7$ \\
\hline 7 & $-0,2$ & 1,8 & $-3,3$ & 1,5 & $-0,8$ & 4,4 & $-1,7$ & $-1,8$ & $-5,2$ & $-2,9$ \\
\hline 8 & $-1,4$ & 4,3 & $-1,2$ & 8,2 & $-0,7$ & 10 & $-7,6$ & $-4,9$ & $-3,5$ & -6 \\
\hline 9 & $-2,3$ & $-1,1$ & 1 & 1,8 & $-0,5$ & 2,9 & $-5,7$ & $-3,1$ & $-4,4$ & $-3,6$ \\
\hline 10 & $-3,2$ & 3,3 & $-3,5$ & 1,6 & $-4,1$ & 4 & $-6,3$ & $-1,6$ & -2 & $-0,8$ \\
\hline 11 & $-6,1$ & 3,4 & $-0,8$ & 1,7 & $-0,9$ & 6,2 & $-10,7$ & $-5,1$ & $-5,6$ & $-6,4$ \\
\hline 12 & -2 & 3,1 & $-0,3$ & $-0,5$ & 0,3 & 3,1 & $-0,1$ & -3 & $-4,9$ & $-3,3$ \\
\hline 13 & $-1,1$ & 0,8 & 0,3 & -3 & 0,4 & 0,8 & $-8,1$ & $-1,5$ & $-5,5$ & $-4,3$ \\
\hline 14 & $-4,6$ & $-3,7$ & $-0,8$ & $-1,2$ & 1,7 & 2,2 & $-4,3$ & $-3,6$ & -4 & $-4,9$ \\
\hline 15 & $-4,6$ & 5,8 & 1,5 & -2 & $-0,5$ & 2,1 & $-7,1$ & $-4,1$ & $-6,1$ & $-3,8$ \\
\hline 16 & $-4,9$ & 5,5 & 1,9 & $-0,1$ & 1,5 & 2,1 & $-2,3$ & $-0,9$ & $-2,7$ & -1 \\
\hline 17 & $-5,9$ & $-2,3$ & -4 & 6,9 & -4 & 3,9 & $-0,9$ & $-0,4$ & $-6,4$ & $-5,2$ \\
\hline 18 & -1 & 10,8 & $-0,1$ & -1 & 0,4 & 3,1 & $-2,1$ & $-5,5$ & $-3,2$ & -4 \\
\hline 18 & $-1,4$ & 9,2 & 4,5 & $-0,3$ & 0,7 & 1,2 & $-7,7$ & $-2,9$ & $-3,5$ & -5 \\
\hline 20 & $-1,8$ & $-6,8$ & $-2,1$ & 1 & $-1,6$ & 3 & $-4,9$ & $-2,2$ & $-3,7$ & $-4,6$ \\
\hline 21 & 1 & 10,1 & 0,7 & 0,2 & 5,8 & 3,7 & $-4,4$ & $-4,4$ & $-6,7$ & $-5,1$ \\
\hline 22 & $-3,8$ & $-4,4$ & $-0,8$ & 2 & 1,1 & 5,9 & -7 & $-1,5$ & $-4,8$ & $-3,6$ \\
\hline 23 & $-2,4$ & 5 & $-1,2$ & 3 & $-2,6$ & $-0,3$ & $-5,5$ & $-2,9$ & $-4,9$ & $-2,4$ \\
\hline 24 & $-0,9$ & $-0,9$ & 3,2 & 1,8 & 4,9 & 3,3 & $-3,7$ & $-1,1$ & $-3,6$ & $-2,4$ \\
\hline 25 & $-1,6$ & 2,4 & 1,5 & $-1,9$ & 3,9 & 2,1 & $-3,4$ & $-4,8$ & $-5,2$ & $-3,6$ \\
\hline 26 & 0 & $-2,2$ & $-3,5$ & 1,4 & 0,4 & 4,1 & $-2,5$ & $-2,1$ & $-4,6$ & $-1,2$ \\
\hline 27 & 0 & 12,1 & 2,6 & 1,4 & 0,2 & 3,1 & $-2,5$ & $-5,3$ & $-2,8$ & $-2,6$ \\
\hline 28 & $-1,3$ & 8 & 3 & 2,3 & 2,1 & 3,7 & $-9,8$ & $-4,9$ & $-5,2$ & $-5,2$ \\
\hline 29 & 1,2 & 4,2 & 0,8 & 0,4 & 5,2 & 2,9 & $-3,2$ & $-0,7$ & $-5,5$ & $-4,9$ \\
\hline 30 & 4,6 & 3,6 & $-1,1$ & 1 & 1,5 & 4,5 & $-10,2$ & $-3,8$ & $-5,3$ & $-6,1$ \\
\hline
\end{tabular}


As Tabelas B-1 a B-10 apresentam os valores individuais de cada variável para cada paciente, do grupo 2.

As variáveis com o sufixo "c-f "se referem às alterações pós-tratamento, pois c é de controle e f de final de tratamento e as variáveis com o sufixo "f-i" se referem às alterações do tratamento, pois fé de final de tratamento e i de início do tratamento.

TABELA

B-1

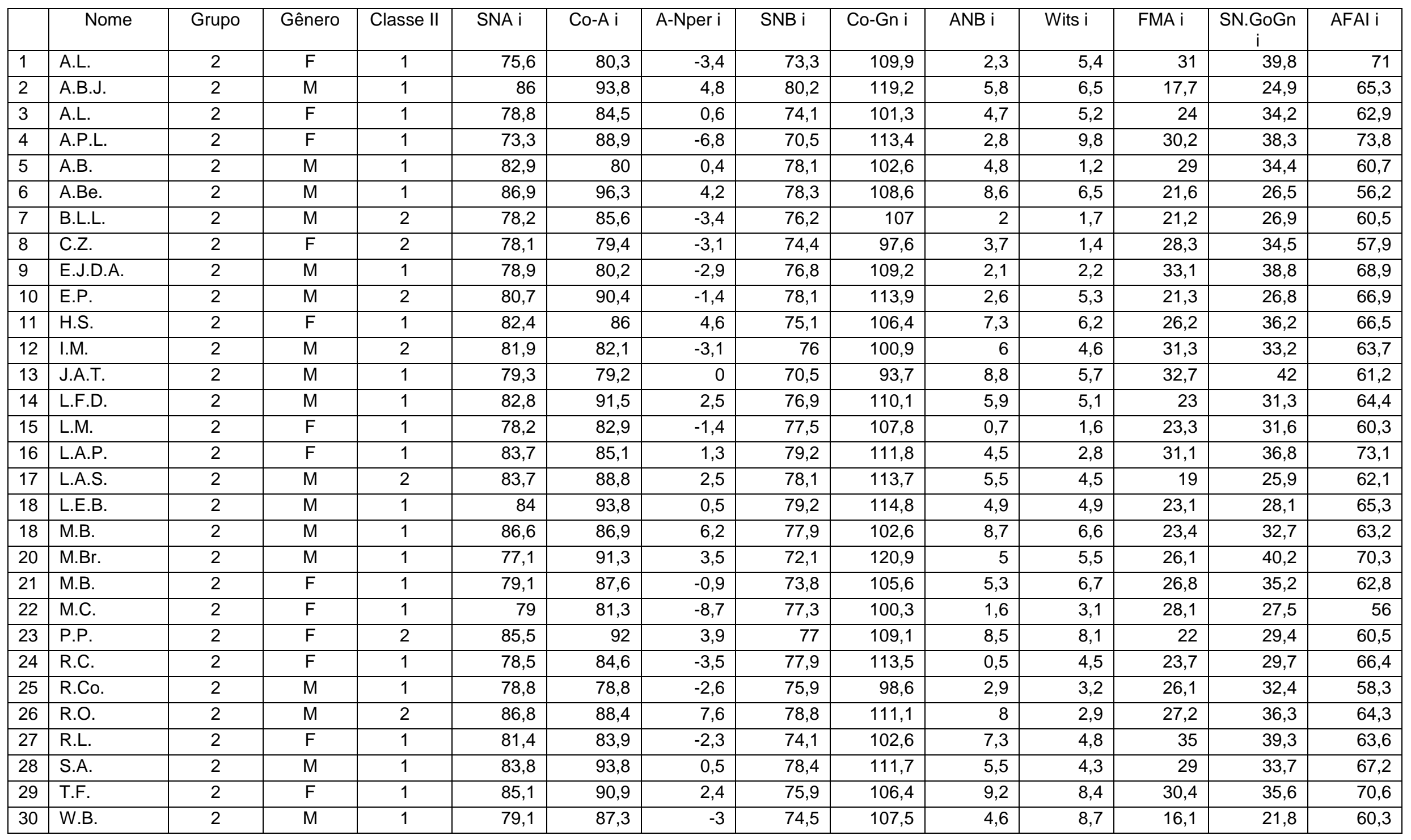


TABELA B-2

\begin{tabular}{|c|c|c|c|c|c|c|c|c|c|c|c|c|c|c|}
\hline & 1.PP i & $\begin{array}{c}1- \\
\text { ENAper i }\end{array}$ & 1-PP i & 6-PP i & $\begin{array}{c}6- \\
\text { ENAper i }\end{array}$ & IMPA i & 1-Pogper & 1-GoMe i & 6-Pogper & 6-GoMe i & Thor i & T vert $\mathrm{i}$ & Rel mol i & Rel can i \\
\hline 1 & 119 & 5,5 & 31,8 & 27,3 & $-25,3$ & 91,3 & -9 & 44,6 & $-29,7$ & 29,3 & 8,3 & 4,4 & 2,9 & 3,9 \\
\hline 2 & 107,8 & $-3,3$ & 29,5 & 23 & $-31,6$ & 97,3 & $-11,5$ & 42,4 & $-33,1$ & 30,6 & 8,3 & 8,6 & 2,5 & 5,3 \\
\hline 3 & 109,1 & $-3,9$ & 27,1 & 22,8 & $-30,4$ & 92,2 & $-7,8$ & 39,1 & $-28,5$ & 27,5 & 5,6 & 5,1 & 3,3 & 1,8 \\
\hline 4 & 116,9 & $-2,4$ & 30,7 & 26,9 & $-31,5$ & 84 & $-13,3$ & 43,2 & $-30,2$ & 31,3 & 11,7 & 3,5 & 3,4 & 4,8 \\
\hline 5 & 113,8 & $-1,8$ & 24 & 20,1 & $-26,8$ & 93,2 & $-9,5$ & 37,7 & $-31,9$ & 28,4 & 3,9 & 2,8 & 3,9 & 4,7 \\
\hline 6 & 112,9 & $-2,8$ & 24,5 & 18,8 & -29 & 106 & $-3,4$ & 36,7 & $-25,9$ & 27,5 & 7,3 & 7,2 & 4,8 & 2,4 \\
\hline 7 & 99,8 & $-3,9$ & 29,2 & 22,6 & -29 & 96,3 & -8 & 37,2 & $-30,4$ & 27,8 & 5,9 & 7,3 & 3,8 & 3,3 \\
\hline 8 & 104,4 & $-3,9$ & 27,8 & 22,2 & $-26,3$ & 90,8 & $-10,1$ & 34,3 & $-29,4$ & 24,9 & 5,6 & 6,1 & 4,5 & 4,1 \\
\hline 9 & 109,2 & $-1,9$ & 29,8 & 25,5 & -29 & 83 & $-13,7$ & 39,9 & $-35,8$ & 26 & 4,5 & 2,9 & 3,7 & 4,6 \\
\hline 10 & 109,4 & $-2,4$ & 30,1 & 25,5 & $-27,5$ & 91,8 & $-11,1$ & 40,8 & $-30,1$ & 30 & 6,1 & 5,1 & 3 & 4,7 \\
\hline 11 & 111 & 0,7 & 32,2 & 23,3 & $-25,9$ & 95,5 & $-8,7$ & 39,3 & $-29,1$ & 28 & 7 & 4 & 3,2 & 7,6 \\
\hline 12 & 96,3 & $-6,6$ & 29,9 & 22,4 & $-29,4$ & 88,2 & $-12,7$ & 37,7 & $-32,1$ & 26,3 & 5,4 & 7,2 & 4,6 & 4,3 \\
\hline 13 & 98,3 & $-4,4$ & 27,1 & 18,1 & $-28,9$ & 91,6 & -8 & 38,4 & $-29,2$ & 27,7 & 5,1 & 5,9 & 3,7 & 3,6 \\
\hline 14 & 112,8 & $-0,3$ & 29,6 & 22,7 & $-29,8$ & 95,1 & $-10,4$ & 38,7 & -32 & 28,8 & 9,4 & 4,3 & 4,2 & 8,3 \\
\hline 15 & 120,2 & 2,9 & 27,1 & 23 & $-26,3$ & 94 & $-12,6$ & 37 & $-34,2$ & 24,9 & 7,2 & 4,2 & 3,4 & 4,4 \\
\hline 16 & 102,9 & $-3,2$ & 35,8 & 30,3 & $-25,7$ & 91,9 & $-11,7$ & 40,5 & $-30,2$ & 29,2 & 5 & 2,5 & 4,2 & 1,8 \\
\hline 17 & 110,8 & $-3,3$ & 26,6 & 22,6 & $-30,4$ & 97,4 & $-12,3$ & 40,6 & $-34,6$ & 31 & 6,7 & 7,2 & 3,4 & 2,8 \\
\hline 18 & 110,8 & 0,4 & 28,4 & 24,3 & $-27,8$ & 102 & $-8,5$ & 40,7 & $-30,8$ & 30,5 & 6,6 & 4,6 & 3,3 & 5,2 \\
\hline 18 & 111,2 & 0,6 & 27,1 & 23,1 & $-28,6$ & 102,1 & -5 & 38,7 & $-27,9$ & 28,5 & 7 & 2,4 & 3,6 & 2,4 \\
\hline 20 & 127,7 & 1,4 & 25,9 & 25,8 & $-24,4$ & 92,2 & -13 & 39,5 & $-33,2$ & 31 & 6,5 & $-3,2$ & 3,9 & 4,7 \\
\hline 21 & 121,1 & 6,3 & 28,4 & 23,7 & $-26,7$ & 101,8 & $-4,9$ & 40,8 & $-27,4$ & 27,9 & 11,2 & 6,2 & 4,2 & 3,7 \\
\hline 22 & 124,1 & 2,8 & 24 & 21,4 & -27 & 88,1 & -12 & 35,4 & $-30,9$ & 25,5 & 11,1 & 6,9 & 4,2 & 3,5 \\
\hline 23 & 110,2 & 1,6 & 27 & 24,5 & $-25,7$ & 107,7 & $-3,4$ & 38,5 & $-26,2$ & 28,5 & 5,1 & 5 & 3,8 & 3,7 \\
\hline 24 & 116 & $-0,4$ & 29,1 & 26,5 & $-27,3$ & 89,9 & $-15,6$ & 36,1 & $-33,7$ & 26,4 & 8,9 & 0,7 & 3,6 & 2 \\
\hline 25 & 116,1 & 0,1 & 25,9 & 19,2 & $-24,7$ & 87 & $-11,4$ & 34 & $-30,6$ & 25,3 & 9,5 & 3,8 & 5,7 & 3 \\
\hline 26 & 99,5 & $-0,6$ & 30,7 & 21,5 & $-29,2$ & 88,3 & $-11,9$ & 38 & $-32,8$ & 27 & 8,5 & 6,1 & 3,4 & 4,7 \\
\hline 27 & 118,1 & 1,2 & 28,2 & 21,4 & $-27,8$ & 89,5 & $-12,7$ & 38 & $-30,4$ & 28,3 & 10,4 & 6,2 & 3,4 & 3 \\
\hline 28 & 116,7 & 0,5 & 29,3 & 24 & $-30,2$ & 105,2 & $-7,6$ & 42,9 & $-31,6$ & 30,2 & 5,9 & 4,8 & 3 & 3,9 \\
\hline 29 & 118 & 1,2 & 27,3 & 21,3 & $-32,1$ & 102,5 & $-6,6$ & 41,3 & $-30,7$ & 31,5 & 7,7 & $-1,8$ & 3,4 & 3,9 \\
\hline 30 & 116,1 & $-1,2$ & 29,9 & 23,1 & $-32,8$ & 98,9 & $-9,2$ & 35,5 & $-29,7$ & 26 & 13,8 & 7,4 & 3,9 & 4,6 \\
\hline
\end{tabular}


TABELA B-3

\begin{tabular}{|c|c|c|c|c|c|c|c|c|c|c|c|c|c|c|}
\hline & SNA f & Co-A f & A-Nper f & SNB f & Co-Gn f & ANB $f$ & Wits $f$ & FMA f & $\begin{array}{c}\text { SN.GoGn } \\
\mathrm{f}\end{array}$ & AFAl f & 1.PP f & $\begin{array}{c}1- \\
\text { ENAper } \mathrm{f}\end{array}$ & 1-PP f & 6-PP f \\
\hline 1 & 75,9 & 76,7 & $-3,6$ & 75,3 & 109,1 & 0,6 & 0,8 & 30,6 & 39,1 & 71,1 & 104,1 & 1,3 & 32,1 & 28 \\
\hline 2 & 81,7 & 93,3 & 1,1 & 79,7 & 122,4 & 2 & 2,6 & 14,9 & 22,6 & 65,7 & 126 & $-2,3$ & 25,7 & 24,5 \\
\hline 3 & 80,3 & 86,1 & 1,9 & 76 & 105,9 & 4,4 & 1,4 & 22,4 & 32,1 & 63,1 & 109,2 & $-4,6$ & 25,9 & 22 \\
\hline 4 & 71,7 & 89,4 & $-8,4$ & 70,6 & 119,1 & 1,2 & 2,5 & 30,7 & 39,2 & 77,3 & 99,3 & $-5,9$ & 33,1 & 27,5 \\
\hline 5 & 81,2 & 81,4 & 1,1 & 78,2 & 108,6 & 2,9 & 1,9 & 27 & 34,8 & 61,2 & 126 & $-0,4$ & 21,4 & 20,9 \\
\hline 6 & 85,4 & 96,1 & 1,6 & 80,1 & 114 & 5,3 & 3,5 & 19,5 & 23,9 & 57,6 & 110,7 & $-3,7$ & 23,6 & 20,4 \\
\hline 7 & 77,5 & 89,6 & $-3,4$ & 76,3 & 117,9 & 1,2 & 2,7 & 21 & 28,3 & 68,3 & 114,7 & $-5,4$ & 27,6 & 25,4 \\
\hline 8 & 73,1 & 75,8 & $-9,5$ & 72,5 & 99,4 & 0,7 & $-0,6$ & 33,6 & 38,2 & 63,3 & 112,8 & $-1,2$ & 28,6 & 24,7 \\
\hline 9 & 77,2 & 82 & $-6,3$ & 78,2 & 114,5 & -1 & -2 & 30,8 & 34,7 & 71,3 & 111 & -1 & 29,8 & 25,2 \\
\hline 10 & 79 & 88,3 & $-5,1$ & 78,2 & 114,2 & 0,8 & 4,3 & 21,5 & 25,3 & 67,1 & 110,6 & $-3,4$ & 27,1 & 25,4 \\
\hline 11 & 76,8 & 80,7 & $-2,1$ & 75 & 107,3 & 1,7 & 1,2 & 29,3 & 38,1 & 70,6 & 110,6 & $-0,8$ & 31,8 & 26,1 \\
\hline 12 & 78,5 & 83,8 & $-7,7$ & 74,7 & 107,8 & 3,7 & 4,5 & 34 & 34,9 & 68 & 103,2 & $-6,3$ & 28,1 & 23,5 \\
\hline 13 & 77,6 & 80,6 & $-2,2$ & 71,2 & 101,9 & 6,4 & 6,6 & 34,5 & 42 & 67,5 & 113,3 & $-4,1$ & 25,3 & 21,8 \\
\hline 14 & 79,5 & 91,5 & $-4,3$ & 77,2 & 117,8 & 2,3 & 4,9 & 27,1 & 31,8 & 69 & 116,4 & $-2,7$ & 26,5 & 25,3 \\
\hline 15 & 78,8 & 82 & $-1,4$ & 76,5 & 106,7 & 2,3 & 3,7 & 26,2 & 33,8 & 63,9 & 116,3 & 2,1 & 25,8 & 24,7 \\
\hline 16 & 82,7 & 84,5 & 0,7 & 80,1 & 112,5 & 2,6 & 0,8 & 28,3 & 35 & 73,2 & 107,4 & 0,8 & 35,9 & 30 \\
\hline 17 & 81,6 & 87,9 & $-0,9$ & 79,8 & 119 & 1,8 & 2,2 & 16 & 21,9 & 62,9 & 124,6 & $-1,3$ & 23,6 & 23,1 \\
\hline 18 & 82,1 & 91,7 & $-4,9$ & 80,4 & 121,5 & 1,7 & 2,7 & 20,1 & 21,8 & 67,7 & 120,1 & $-1,9$ & 25,8 & 24,7 \\
\hline 18 & 86,1 & 90,5 & 3,8 & 79,5 & 111,3 & 6,7 & 6,1 & 26,9 & 33,2 & 67,3 & 113,1 & $-1,7$ & 26,7 & 25 \\
\hline 20 & 76 & 91,2 & $-0,2$ & 71,4 & 119,9 & 4,6 & 3,5 & 27,7 & 40 & 69,8 & 118,8 & $-4,6$ & 26,8 & 25 \\
\hline 21 & 80,3 & 88,5 & 0,6 & 73,9 & 104,5 & 6,4 & 6,1 & 27,1 & 35,9 & 62,7 & 113,8 & $-3,5$ & 26,9 & 24,2 \\
\hline 22 & 78,6 & 80,6 & $-8,4$ & 76,7 & 102 & 1,8 & 4,6 & 27,2 & 27,3 & 58,7 & 119,4 & $-2,7$ & 23,8 & 23,9 \\
\hline 23 & 81,6 & 88,1 & 0,8 & 76,5 & 109,8 & 5 & 6,1 & 24,1 & 32,3 & 62,4 & 115,9 & 0,7 & 27,1 & 26,2 \\
\hline 24 & 78,6 & 82 & -4 & 78,6 & 112,1 & 0 & 1,3 & 23,3 & 29,1 & 67,1 & 105,2 & $-4,5$ & 29,1 & 25,7 \\
\hline 25 & 78,6 & 80,8 & $-5,2$ & 77,1 & 105,3 & 1,5 & 1,9 & 28,4 & 31,5 & 65,7 & 114 & $-2,1$ & 26,9 & 23 \\
\hline 26 & 84 & 92,8 & 5,1 & 78,3 & 120,7 & 5,7 & 0,4 & 30,4 & 39,8 & 73,6 & 103,4 & $-3,8$ & 32 & 25,6 \\
\hline 27 & 80,2 & 81,4 & $-4,1$ & 75,5 & 109,1 & 4,8 & 3,3 & 36,2 & 38,1 & 67,8 & 115,6 & $-4,2$ & 26,9 & 23,1 \\
\hline 28 & 82 & 94,2 & $-0,9$ & 79 & 120 & 3 & 3,3 & 30 & 35 & 71,8 & 122,2 & $-1,3$ & 27,2 & 26,8 \\
\hline 29 & 81,4 & 91,3 & $-1,7$ & 75,6 & 111,9 & 5,8 & 2,5 & 32 & 36,2 & 72,7 & 110,4 & $-4,3$ & 29,5 & 23 \\
\hline 30 & 73,8 & 85,2 & $-8,6$ & 74,3 & 112,1 & $-0,5$ & 3,4 & 17,9 & 21,7 & 65,6 & 100,6 & $-5,8$ & 29,5 & 26,5 \\
\hline
\end{tabular}


TABELA B-4

\begin{tabular}{|c|c|c|c|c|c|c|c|c|c|c|}
\hline & $\begin{array}{c}\text { 6- } \\
\text { ENAper } f\end{array}$ & IMPA f & $\begin{array}{c}\text { 1-Pogper } \\
\mathrm{f}\end{array}$ & $\begin{array}{c}\text { 1-GoMe } \\
\mathrm{f}\end{array}$ & $\begin{array}{c}\text { 6-Pogper } \\
\mathrm{f}\end{array}$ & $\begin{array}{c}\text { 6-GoMe } \\
\mathrm{f}\end{array}$ & Thor f & $T$ vert $\mathrm{f}$ & Rel mol f & Rel can f \\
\hline 1 & $-20,4$ & 89,6 & $-8,4$ & 41,9 & $-28,2$ & 30,4 & 3 & 1,9 & 3,8 & $-1,6$ \\
\hline 2 & -28 & 113,9 & $-10,6$ & 39,9 & $-34,7$ & 33,2 & 2,8 & 0,8 & 2,8 & $-1,8$ \\
\hline 3 & -27 & 93,4 & $-5,6$ & 37,5 & -28 & 29,8 & 2,3 & 1,2 & 4,4 & $-2,5$ \\
\hline 4 & $-25,4$ & 81 & $-15,4$ & 43,9 & $-31,8$ & 34,5 & 4,8 & 3,4 & 4,4 & $-2,2$ \\
\hline 5 & -25 & 90,3 & $-11,7$ & 39,9 & $-32,8$ & 29,6 & 4 & 1,5 & 3,6 & $-2,4$ \\
\hline 6 & $-27,7$ & 107,1 & $-3,7$ & 36,2 & $-29,3$ & 28,9 & 2,7 & 3,2 & 5,6 & $-2,1$ \\
\hline 7 & $-28,5$ & 96,5 & $-10,8$ & 41,5 & $-32,2$ & 32,9 & 3,8 & 2,4 & 4,3 & -2 \\
\hline 8 & $-22,9$ & 96,6 & $-10,2$ & 36,2 & $-29,8$ & 27,1 & 3,8 & 2,8 & 5 & -1 \\
\hline 9 & $-25,8$ & 83,2 & $-14,8$ & 41,6 & $-36,9$ & 30,1 & 3 & 1,8 & 4,1 & $-2,9$ \\
\hline 10 & -23 & 98 & $-10,5$ & 39,6 & $-28,9$ & 31,7 & 2,4 & 0,6 & 4 & $-1,9$ \\
\hline 11 & $-23,9$ & 97,7 & $-9,3$ & 41,3 & -30 & 30,5 & 3,1 & 0,2 & 3,9 & $-1,9$ \\
\hline 12 & $-29,7$ & 89,4 & $-12,9$ & 40,4 & $-33,4$ & 28,9 & 3,7 & 3,6 & 4,2 & $-1,3$ \\
\hline 13 & $-26,7$ & 88,6 & $-9,2$ & 42,4 & -29 & 31,3 & 3,7 & 1,8 & 4,6 & $-2,1$ \\
\hline 14 & $-26,2$ & 89,3 & $-12,5$ & 42,5 & $-33,3$ & 31,7 & 3,7 & 1,5 & 4,4 & $-2,1$ \\
\hline 15 & $-23,1$ & 104,6 & -10 & 39,1 & $-32,7$ & 27,7 & 3,1 & 1,1 & 4 & $-3,3$ \\
\hline 16 & $-22,8$ & 96,6 & -9 & 41,7 & $-29,6$ & 29,9 & 3,9 & 2,9 & 4,1 & $-2,5$ \\
\hline 17 & $-25,6$ & 99 & $-7,8$ & 39,8 & $-31,2$ & 33,2 & 4 & 1,7 & 3,9 & $-1,8$ \\
\hline 18 & -29 & 95,7 & $-11,1$ & 41,8 & $-34,8$ & 34,4 & 4,1 & 1,5 & 2,5 & $-1,8$ \\
\hline 18 & $-24,1$ & 99 & $-6,8$ & 41,8 & -27 & 31,7 & 3 & 1,1 & 4,2 & $-1,9$ \\
\hline 20 & $-24,3$ & 87,1 & $-15,3$ & 41,9 & $-34,3$ & 33,7 & 3 & 1,7 & 4,9 & 1,6 \\
\hline 21 & $-26,9$ & 108,8 & $-5,1$ & 37,3 & $-26,4$ & 27,9 & 2,7 & 1,9 & 3,5 & $-0,4$ \\
\hline 22 & $-24,4$ & 90,1 & $-11,8$ & 35,3 & $-30,3$ & 27 & 4,9 & 2,7 & 4,6 & $-2,6$ \\
\hline 23 & $-21,7$ & 102,1 & $-3,8$ & 38,8 & $-24,7$ & 28,4 & 2,3 & 2,9 & 3,9 & -2 \\
\hline 24 & $-24,7$ & 90,6 & $-12,5$ & 36,9 & $-32,7$ & 28,3 & 2,6 & 1 & 4,6 & $-3,7$ \\
\hline 25 & $-23,6$ & 94 & $-10,3$ & 39,6 & $-31,9$ & 30,1 & 2,1 & 1,4 & 4,2 & $-2,9$ \\
\hline 26 & $-26,7$ & 90,9 & -12 & 43,2 & $-33,4$ & 33 & 3,4 & 3,2 & 4,4 & $-1,4$ \\
\hline 27 & $-24,8$ & 87,4 & $-12,6$ & 40,5 & $-31,4$ & 29,9 & 3,2 & 2,3 & 4,6 & -2 \\
\hline 28 & $-25,5$ & 94,1 & $-8,5$ & 45,3 & -31 & 32,9 & 1,4 & 0,1 & 3,7 & $-2,7$ \\
\hline 29 & -27 & 100,3 & -8 & 44,2 & -31 & 34,7 & 2,2 & 1 & 5,2 & $-2,3$ \\
\hline 30 & $-27,8$ & 106,1 & $-8,4$ & 36,7 & $-30,1$ & 30 & 2,7 & 2,3 & 3,7 & $-2,4$ \\
\hline
\end{tabular}


TABELA B-5

\begin{tabular}{|c|c|c|c|c|c|c|c|c|c|c|c|c|c|c|}
\hline & SNA C & Co-A c & A-Nper C & SNB c & Co-Gn c & ANB c & Wits c & FMA C & $\begin{array}{c}\text { SN.GoGn } \\
\text { c }\end{array}$ & AFAI c & 1.PP C & $\begin{array}{c}1- \\
\text { ENAper } \\
C \\
\end{array}$ & 1-PP c & 6-PP c \\
\hline 1 & 79,7 & 81,4 & 0,3 & 73,9 & 106,4 & 5,8 & 6,9 & 29,2 & 37,7 & 70 & 113,4 & $-1,6$ & 30,3 & 27,5 \\
\hline 2 & 82,2 & 92,4 & $-1,7$ & 80,4 & 120,5 & 1,8 & 3,3 & 15,6 & 19,5 & 63,7 & 123,3 & $-2,4$ & 26,2 & 24,4 \\
\hline 3 & 79,7 & 86,9 & 2,2 & 75,3 & 106,9 & 4,4 & 1,8 & 20,8 & 31,9 & 64 & 117 & $-5,1$ & 26,9 & 23,4 \\
\hline 4 & 71,7 & 87,2 & $-5,6$ & 70 & 117,4 & 1,7 & 4 & 28,8 & 39,2 & 76,4 & 101,3 & $-9,5$ & 33,2 & 28,5 \\
\hline 5 & 82,4 & 86,3 & 1,3 & 80,8 & 118,1 & 1,6 & 3,2 & 21,6 & 28,1 & 63,1 & 125,8 & $-0,5$ & 22,3 & 24,6 \\
\hline 6 & 88,7 & 93,1 & 0,2 & 83,6 & 111,2 & 5,2 & 3,2 & 17,9 & 17,7 & 54,5 & 115 & $-3,6$ & 22,7 & 19 \\
\hline 7 & 80,8 & 92,9 & $-1,2$ & 79,3 & 121,8 & 1,5 & 2,5 & 17,9 & 23,5 & 67,6 & 118,5 & -4 & 25,7 & 24,5 \\
\hline 8 & 78,5 & 81,9 & $-2,2$ & 72,8 & 101,2 & 5,7 & 4,3 & 29,5 & 36,8 & 63,5 & 110,7 & $-2,7$ & 29 & 23,7 \\
\hline 9 & 81,8 & 88,8 & $-2,7$ & 79,2 & 118,8 & 2,7 & 5,1 & 28,2 & 30,6 & 74,9 & 108 & $-5,6$ & 28,7 & 26,3 \\
\hline 10 & 80 & 87,7 & $-4,1$ & 79,2 & 113,7 & 0,8 & 3,2 & 21,3 & 25,2 & 65,6 & 112,5 & $-3,6$ & 26,5 & 24,7 \\
\hline 11 & 83,9 & 84,2 & 1,9 & 77,9 & 105,8 & 6 & 4,3 & 26,4 & 31,2 & 72,2 & 109,3 & -4 & 33,4 & 25,9 \\
\hline 12 & 79,7 & 85,7 & $-4,3$ & 75,6 & 114,5 & 4,1 & 5,1 & 27,7 & 31,8 & 72 & 98 & $-9,7$ & 30,6 & 26,3 \\
\hline 13 & 79,2 & 83,3 & $-1,5$ & 73,3 & 109,6 & 6 & 5,2 & 32,5 & 39,8 & 68,2 & 109,1 & $-3,4$ & 27 & 22,4 \\
\hline 14 & 81,7 & 95,5 & 2,6 & 78,2 & 123,5 & 3,5 & 5,6 & 19,7 & 28,2 & 70 & 111,9 & -6 & 28,4 & 26 \\
\hline 15 & 82,1 & 82,8 & 1,6 & 76,7 & 108 & 5,4 & 5 & 25,8 & 33 & 66 & 117,8 & $-1,6$ & 28 & 24 \\
\hline 16 & 84,6 & 87,7 & 5,3 & 79,4 & 114,2 & 5,2 & 5,1 & 26,5 & 33,4 & 73,4 & 112 & 0,2 & 34,4 & 30,3 \\
\hline 17 & 84,6 & 87,9 & $-3,9$ & 82,8 & 117,3 & 1,8 & 1,3 & 18 & 17,3 & 64 & 124,9 & $-0,7$ & 24,1 & 22,7 \\
\hline 18 & 84,8 & 97,9 & $-1,4$ & 82,3 & 125,4 & 2,5 & 3,9 & 18,8 & 20,6 & 65,2 & 125,4 & 0,1 & 24,4 & 24,5 \\
\hline 18 & 85,6 & 91,5 & 2,6 & 80,8 & 115,8 & 4,8 & 4,1 & 21,4 & 26,1 & 68,3 & 111,4 & 0,9 & 27,1 & 25,8 \\
\hline 20 & 76,4 & 92,6 & 2,4 & 71,5 & 120,6 & 4,8 & 3,2 & 26,4 & 40,4 & 70,3 & 116 & $-3,9$ & 29,1 & 25,2 \\
\hline 21 & 80,4 & 87,5 & 2,1 & 74,1 & 106,4 & 6,3 & 2,5 & 24,1 & 33,4 & 61,5 & 117,1 & $-2,3$ & 27,9 & 21,8 \\
\hline 22 & 80 & 82,2 & $-3,2$ & 77,1 & 105,1 & 2,9 & 2,5 & 23,5 & 27,2 & 57,9 & 113,5 & $-3,2$ & 24,1 & 21,4 \\
\hline 23 & 82,9 & 88,3 & 1,7 & 77,1 & 107,3 & 5,8 & 1,7 & 23,5 & 30,5 & 61,5 & 113,6 & 1,6 & 27,9 & 24,1 \\
\hline 24 & 79,1 & 80,4 & $-5,6$ & 76,7 & 112,7 & 2,3 & 4,4 & 30,4 & 33,2 & 71,5 & 107 & $-2,1$ & 30,6 & 28,2 \\
\hline 25 & 77,7 & 84,2 & 2 & 75,2 & 111,9 & 2,5 & 3,5 & 19,6 & 31,3 & 66,2 & 113,9 & $-1,2$ & 27,2 & 23,4 \\
\hline 26 & 85,3 & 96,2 & 6,9 & 79,1 & 124,8 & 6,2 & 1,3 & 28,6 & 36,6 & 77,1 & 106,7 & $-7,1$ & 33,8 & 26,6 \\
\hline 27 & 80,7 & 84,9 & 0,1 & 74,5 & 109,7 & 6,2 & 2,4 & 35,8 & 43,1 & 68,9 & 115,9 & $-3,2$ & 29,9 & 23,9 \\
\hline 28 & 83,7 & 98,6 & 2,1 & 81 & 126,6 & 2,7 & 3,3 & 27 & 33,2 & 73,6 & 123,6 & 1,2 & 28,1 & 27,9 \\
\hline 29 & 83,7 & 90,4 & $-0,4$ & 77,9 & 114,3 & 5,8 & 2,5 & 28,2 & 30,7 & 74,7 & 108,7 & $-5,2$ & 31,2 & 24,5 \\
\hline 30 & 77,1 & 88,1 & $-1,7$ & 75,2 & 115,1 & 1,9 & 4,9 & 12,3 & 22,3 & 64 & 99,8 & $-7,9$ & 29,2 & 24,1 \\
\hline
\end{tabular}


TABELA B-6

\begin{tabular}{|c|c|c|c|c|c|c|c|c|c|c|}
\hline & $\begin{array}{c}6- \\
\text { ENAper } \\
\text { C }\end{array}$ & IMPA C & $\begin{array}{c}\text { 1-Pogper } \\
\text { c }\end{array}$ & $\begin{array}{c}\text { 1-GoMe } \\
\text { c }\end{array}$ & $\begin{array}{c}\text { 6-Pogper } \\
\text { c }\end{array}$ & $\begin{array}{c}\text { 6-GoMe } \\
\text { c }\end{array}$ & Thor c & T vert $\mathrm{c}$ & $\begin{array}{c}\text { Rel mol } \\
\text { C }\end{array}$ & $\begin{array}{c}\text { Rel can } \\
\text { c }\end{array}$ \\
\hline 1 & $-24,5$ & 93,8 & $-6,9$ & 41,6 & $-26,9$ & 30,6 & 4,3 & 2,5 & 4,3 & $-1,1$ \\
\hline 2 & $-25,9$ & 110 & -10 & 39,8 & $-31,8$ & 32 & 4,2 & 3,6 & 4,3 & $-0,9$ \\
\hline 3 & $-26,2$ & 95,7 & -6 & 38,5 & $-27,1$ & 31,3 & 3 & 2,4 & 4,4 & 1,6 \\
\hline 4 & $-28,3$ & 83,4 & $-14,7$ & 42,8 & $-32,9$ & 32,1 & 5 & 3,5 & 6,8 & $-0,1$ \\
\hline 5 & $-22,6$ & 93,4 & $-12,6$ & 40,1 & $-32,2$ & 30,2 & 2,1 & 0,6 & 2,3 & $-1,1$ \\
\hline 6 & $-25,5$ & 103,5 & $-5,9$ & 34,4 & -26 & 29,2 & 5,4 & 4,4 & 4,6 & 0,4 \\
\hline 7 & $-25,8$ & 97,8 & $-8,6$ & 42,8 & $-29,9$ & 35 & 2 & 1,9 & 3 & $-4,4$ \\
\hline 8 & $-25,2$ & 101,3 & $-7,8$ & 36,4 & $-28,1$ & 27,4 & 4,4 & 3,3 & 4,4 & $-1,5$ \\
\hline 9 & $-24,6$ & 80,5 & $-13,8$ & 45,1 & $-31,1$ & 34,4 & 2,7 & 1,7 & 4,2 & 0,2 \\
\hline 10 & -24 & 92,5 & $-9,9$ & 41,3 & $-28,9$ & 32 & 3,4 & 3,6 & 4 & $-0,7$ \\
\hline 11 & $-24,1$ & 98,9 & $-5,6$ & 42,1 & $-24,6$ & 32,9 & 3,6 & 2,7 & 3,6 & 0 \\
\hline 12 & $-28,6$ & 91,1 & $-13,8$ & 41,7 & $-31,3$ & 32,6 & 3,8 & 4,5 & 4,5 & 0,7 \\
\hline 13 & $-24,1$ & 90,3 & $-8,2$ & 44,2 & $-27,4$ & 32,7 & 3,5 & 4,1 & 5,2 & -1 \\
\hline 14 & $-26,3$ & 92,1 & $-7,9$ & 43,1 & $-28,2$ & 33 & 3,4 & 3,1 & 4,8 & 0,1 \\
\hline 15 & $-24,6$ & 97,6 & -10 & 40 & $-30,2$ & 29,6 & 4,9 & 2,8 & 4,7 & 0,1 \\
\hline 16 & $-22,6$ & 94,7 & $-7,2$ & 42,4 & $-27,2$ & 30,5 & 3,8 & 2 & 4,1 & $-4,2$ \\
\hline 17 & $-25,2$ & 101,5 & $-10,8$ & 41,5 & $-34,1$ & 35,3 & 3,2 & 2,7 & 3,6 & $-1,1$ \\
\hline 18 & $-23,7$ & 98,6 & -9 & 43,9 & -30 & 35 & 4,3 & 4,1 & 3,8 & 0,5 \\
\hline 18 & $-20,1$ & 101,1 & -4 & 43,9 & $-25,3$ & 35,2 & 3,2 & 2,4 & 5,5 & $-1,2$ \\
\hline 20 & $-21,9$ & 85 & $-15,4$ & 41 & $-32,4$ & 33,1 & 3,4 & 2,4 & 4,4 & 0,5 \\
\hline 21 & $-25,3$ & 106,2 & $-2,9$ & 37,1 & $-23,8$ & 30,2 & 4,9 & 4,1 & 4 & $-1,3$ \\
\hline 22 & -24 & 92,8 & $-9,8$ & 35,3 & $-29,5$ & 27,5 & 3,4 & 3,2 & 4,3 & $-0,1$ \\
\hline 23 & $-19,2$ & 107,1 & $-1,8$ & 37,2 & $-23,3$ & 30,9 & 2,9 & 2,7 & 5,5 & 0,6 \\
\hline 24 & $-23,1$ & 87,6 & $-13,4$ & 37,8 & $-31,5$ & 29,6 & 6 & $-1,1$ & 5,9 & $-0,9$ \\
\hline 25 & $-22,5$ & 100,5 & $-11,6$ & 40,9 & $-30,8$ & 31,4 & 3,5 & 2,7 & 3,4 & $-1,2$ \\
\hline 26 & $-29,1$ & 88 & $-10,8$ & 43,8 & $-31,3$ & 34,4 & 4,7 & 3,7 & 4,8 & $-1,1$ \\
\hline 27 & $-22,7$ & 95,5 & $-11,5$ & 40,9 & $-28,9$ & 31,5 & 4,4 & 3,7 & 4,6 & $-0,7$ \\
\hline 28 & $-23,6$ & 90,6 & $-8,7$ & 47 & -30 & 34,4 & 2,3 & 1,5 & 2,6 & $-2,5$ \\
\hline 29 & $-26,9$ & 100,3 & $-5,3$ & 45,6 & $-27,2$ & 36,8 & 2,4 & 2,3 & 3,6 & $-1,4$ \\
\hline 30 & $-27,8$ & 99,8 & $-8,8$ & 38,4 & $-28,2$ & 30,4 & 3,8 & 5,7 & 3,2 & $-1,1$ \\
\hline
\end{tabular}


TABELA B-7

\begin{tabular}{|c|c|c|c|c|c|c|c|c|c|c|c|c|c|c|}
\hline & SNA c-f & Co-A c-f & $\begin{array}{c}\text { A-Nper } \\
\text { C-f }\end{array}$ & SNB c-f & $\underset{f}{\text { Co-Gn c- }}$ & ANB c-f & Wits $c-f$ & FMA c-f & $\begin{array}{c}\text { SN.GoGn } \\
c-f\end{array}$ & AFAI c-f & 1-PP c-f & $\begin{array}{c}1- \\
\text { ENAper } \\
c-f\end{array}$ & 1-PP c-f & 6-PP c-f \\
\hline 1 & 3,8 & 4,7 & 3,9 & $-1,4$ & $-2,7$ & 5,2 & 6,1 & $-1,4$ & $-1,4$ & $-1,1$ & 9,3 & $-2,9$ & $-1,8$ & $-0,5$ \\
\hline 2 & 0,5 & $-0,9$ & $-2,8$ & 0,7 & $-1,9$ & $-0,2$ & 0,7 & 0,7 & $-3,1$ & -2 & $-2,7$ & $-0,1$ & 0,5 & $-0,1$ \\
\hline 3 & $-0,6$ & 0,8 & 0,3 & $-0,7$ & 1 & 0 & 0,4 & $-1,6$ & $-0,2$ & 0,9 & 7,8 & $-0,5$ & 1 & 1,4 \\
\hline 4 & 0 & $-2,2$ & 2,8 & $-0,6$ & $-1,7$ & 0,5 & 1,5 & $-1,9$ & 0 & $-0,9$ & 2 & $-3,6$ & 0,1 & 1 \\
\hline 5 & 1,2 & 4,9 & 0,2 & 2,6 & 9,5 & $-1,3$ & 1,3 & $-5,4$ & $-6,7$ & 1,9 & $-0,2$ & $-0,1$ & 0,9 & 3,7 \\
\hline 6 & 3,3 & -3 & $-1,4$ & 3,5 & $-2,8$ & $-0,1$ & $-0,3$ & $-1,6$ & $-6,2$ & $-3,1$ & 4,3 & 0,1 & $-0,9$ & $-1,4$ \\
\hline 7 & 3,3 & 3,3 & 2,2 & 3 & 3,9 & 0,3 & $-0,2$ & $-3,1$ & $-4,8$ & $-0,7$ & 3,8 & 1,4 & $-1,9$ & $-0,9$ \\
\hline 8 & 5,4 & 6,1 & 7,3 & 0,3 & 1,8 & 5 & 4,9 & $-4,1$ & $-1,4$ & 0,2 & $-2,1$ & $-1,5$ & 0,4 & -1 \\
\hline 9 & 4,6 & 6,8 & 3,6 & 1 & 4,3 & 3,7 & 7,1 & $-2,6$ & $-4,1$ & 3,6 & -3 & $-4,6$ & $-1,1$ & 1,1 \\
\hline 10 & 1 & $-0,6$ & 1 & 1 & $-0,5$ & 0 & $-1,1$ & $-0,2$ & $-0,1$ & $-1,5$ & 1,9 & $-0,2$ & $-0,6$ & $-0,7$ \\
\hline 11 & 7,1 & 3,5 & 4 & 2,9 & $-1,5$ & 4,3 & 3,1 & $-2,9$ & $-6,9$ & 1,6 & $-1,3$ & $-3,2$ & 1,6 & $-0,2$ \\
\hline 12 & 1,2 & 1,9 & 3,4 & 0,9 & 6,7 & 0,4 & 0,6 & $-6,3$ & $-3,1$ & 4 & $-5,2$ & $-3,4$ & 2,5 & 2,8 \\
\hline 13 & 1,6 & 2,7 & 0,7 & 2,1 & 7,7 & $-0,4$ & $-1,4$ & -2 & $-2,2$ & 0,7 & $-4,2$ & 0,7 & 1,7 & 0,6 \\
\hline 14 & 2,2 & 4 & 6,9 & 1 & 5,7 & 1,2 & 0,7 & $-7,4$ & $-3,6$ & 1 & $-4,5$ & $-3,3$ & 1,9 & 0,7 \\
\hline 15 & 3,3 & 0,8 & 3 & 0,2 & 1,3 & 3,1 & 1,3 & $-0,4$ & $-0,8$ & 2,1 & 1,5 & $-3,7$ & 2,2 & $-0,7$ \\
\hline 16 & 1,9 & 3,2 & 4,6 & $-0,7$ & 1,7 & 2,6 & 4,3 & $-1,8$ & $-1,6$ & 0,2 & 4,6 & $-0,6$ & $-1,5$ & 0,3 \\
\hline 17 & 3 & 0 & -3 & 3 & $-1,7$ & 0 & $-0,9$ & 2 & $-4,6$ & 1,1 & 0,3 & 0,6 & 0,5 & $-0,4$ \\
\hline 18 & 2,7 & 6,2 & 3,5 & 1,9 & 3,9 & 0,8 & 1,2 & $-1,3$ & $-1,2$ & $-2,5$ & 5,3 & 2 & $-1,4$ & $-0,2$ \\
\hline 18 & $-0,5$ & 1 & $-1,2$ & 1,3 & 4,5 & $-1,9$ & -2 & $-5,5$ & $-7,1$ & 1 & $-1,7$ & 2,6 & 0,4 & 0,8 \\
\hline 20 & 0,4 & 1,4 & 2,6 & 0,1 & 0,7 & 0,2 & $-0,3$ & $-1,3$ & 0,4 & 0,5 & $-2,8$ & 0,7 & 2,3 & 0,2 \\
\hline 21 & 0,1 & -1 & 1,5 & 0,2 & 1,9 & $-0,1$ & $-3,6$ & -3 & $-2,5$ & $-1,2$ & 3,3 & 1,2 & 1 & $-2,4$ \\
\hline 22 & 1,4 & 1,6 & 5,2 & 0,4 & 3,1 & 1,1 & $-2,1$ & $-3,7$ & $-0,1$ & $-0,8$ & $-5,9$ & $-0,5$ & 0,3 & $-2,5$ \\
\hline 23 & 1,3 & 0,2 & 0,9 & 0,6 & $-2,5$ & 0,8 & $-4,4$ & $-0,6$ & $-1,8$ & $-0,9$ & $-2,3$ & 0,9 & 0,8 & $-2,1$ \\
\hline 24 & 0,5 & $-1,6$ & $-1,6$ & $-1,9$ & 0,6 & 2,3 & 3,1 & 7,1 & 4,1 & 4,4 & 1,8 & 2,4 & 1,5 & 2,5 \\
\hline 25 & $-0,9$ & 3,4 & 7,2 & $-1,9$ & 6,6 & 1 & 1,6 & $-8,8$ & $-0,2$ & 0,5 & $-0,1$ & 0,9 & 0,3 & 0,4 \\
\hline 26 & 1,3 & 3,4 & 1,8 & 0,8 & 4,1 & 0,5 & 0,9 & $-1,8$ & $-3,2$ & 3,5 & 3,3 & $-3,3$ & 1,8 & 1 \\
\hline 27 & 0,5 & 3,5 & 4,2 & -1 & 0,6 & 1,4 & $-0,9$ & $-0,4$ & 5 & 1,1 & 0,3 & 1 & 3 & 0,8 \\
\hline 28 & 1,7 & 4,4 & 3 & 2 & 6,6 & $-0,3$ & 0 & -3 & $-1,8$ & 1,8 & 1,4 & 2,5 & 0,9 & 1,1 \\
\hline 29 & 2,3 & $-0,9$ & 1,3 & 2,3 & 2,4 & 0 & 0 & $-3,8$ & $-5,5$ & 2 & $-1,7$ & $-0,9$ & 1,7 & 1,5 \\
\hline 30 & 3,3 & 2,9 & 6,9 & 0,9 & 3 & 2,4 & 1,5 & $-5,6$ & 0,6 & $-1,6$ & $-0,8$ & $-2,1$ & $-0,3$ & $-2,4$ \\
\hline
\end{tabular}


TABELA B-8

\begin{tabular}{|c|c|c|c|c|c|c|c|c|c|c|}
\hline & $\begin{array}{c}6- \\
\text { ENAper } \\
c-f\end{array}$ & IMPA c-f & $\begin{array}{c}\text { 1-Pogper } \\
c-f\end{array}$ & $\begin{array}{c}\text { 1-GoMe } \\
c-f\end{array}$ & $\begin{array}{c}\text { 6-Pogper } \\
\text { C-f }\end{array}$ & $\begin{array}{c}\text { 6-GoMe } \\
c-f\end{array}$ & T hor c-f & T vert c-f & $\begin{array}{c}\text { Rel mol } \\
\mathrm{C}-\mathrm{f}\end{array}$ & $\begin{array}{c}\text { Rel can } \\
c-f\end{array}$ \\
\hline 1 & $-4,1$ & 4,2 & 1,5 & $-0,3$ & 1,3 & 0,2 & 1,3 & 0,6 & 0,5 & 0,5 \\
\hline 2 & 2,1 & $-3,9$ & 0,6 & $-0,1$ & 2,9 & $-1,2$ & 1,4 & 2,8 & 1,5 & 0,9 \\
\hline 3 & 0,8 & 2,3 & $-0,4$ & 1 & 0,9 & 1,5 & 0,7 & 1,2 & 0 & 4,1 \\
\hline 4 & $-2,9$ & 2,4 & 0,7 & $-1,1$ & $-1,1$ & $-2,4$ & 0,2 & 0,1 & 2,4 & 2,1 \\
\hline 5 & 2,4 & 3,1 & $-0,9$ & 0,2 & 0,6 & 0,6 & $-1,9$ & $-0,9$ & $-1,3$ & 1,3 \\
\hline 6 & 2,2 & $-3,6$ & $-2,2$ & $-1,8$ & 3,3 & 0,3 & 2,7 & 1,2 & -1 & 2,5 \\
\hline 7 & 2,7 & 1,3 & 2,2 & 1,3 & 2,3 & 2,1 & $-1,8$ & $-0,5$ & $-1,3$ & $-2,4$ \\
\hline 8 & $-2,3$ & 4,7 & 2,4 & 0,2 & 1,7 & 0,3 & 0,6 & 0,5 & $-0,6$ & $-0,5$ \\
\hline 9 & 1,2 & $-2,7$ & 1 & 3,5 & 5,8 & 4,3 & $-0,3$ & $-0,1$ & 0,1 & 3,1 \\
\hline 10 & -1 & $-5,5$ & 0,6 & 1,7 & 0 & 0,3 & 1 & 3 & 0 & 1,2 \\
\hline 11 & $-0,2$ & 1,2 & 3,7 & 0,8 & 5,4 & 2,4 & 0,5 & 2,5 & $-0,3$ & 1,9 \\
\hline 12 & 1,1 & 1,7 & $-0,9$ & 1,3 & 2,1 & 3,7 & 0,1 & 0,9 & 0,3 & 2 \\
\hline 13 & 2,6 & 1,7 & 1 & 1,8 & 1,6 & 1,4 & $-0,2$ & 2,3 & 0,6 & 1,1 \\
\hline 14 & $-0,1$ & 2,8 & 4,6 & 0,6 & 5,1 & 1,3 & $-0,3$ & 1,6 & 0,4 & 2,2 \\
\hline 15 & $-1,5$ & -7 & 0 & 0,9 & 2,5 & 1,9 & 1,8 & 1,7 & 0,7 & 3,4 \\
\hline 16 & 0,2 & $-1,9$ & 1,8 & 0,7 & 2,4 & 0,6 & $-0,1$ & $-0,9$ & 0 & $-1,7$ \\
\hline 17 & 0,4 & 2,5 & -3 & 1,7 & $-2,9$ & 2,1 & $-0,8$ & 1 & $-0,3$ & 0,7 \\
\hline 18 & 5,3 & 2,9 & 2,1 & 2,1 & 4,8 & 0,6 & 0,2 & 2,6 & 1,3 & 2,3 \\
\hline 18 & 4 & 2,1 & 2,8 & 2,1 & 1,7 & 3,5 & 0,2 & 1,3 & 1,3 & 0,7 \\
\hline 20 & 2,4 & $-2,1$ & $-0,1$ & $-0,9$ & 1,9 & $-0,6$ & 0,4 & 0,7 & $-0,5$ & $-1,1$ \\
\hline 21 & 1,6 & $-2,6$ & 2,2 & $-0,2$ & 2,6 & 2,3 & 2,2 & 2,2 & 0,5 & $-0,9$ \\
\hline 22 & 0,4 & 2,7 & 2 & 0 & 0,8 & 0,5 & $-1,5$ & 0,5 & $-0,3$ & 2,5 \\
\hline 23 & 2,5 & 5 & 2 & $-1,6$ & 1,4 & 2,5 & 0,6 & $-0,2$ & 1,6 & 2,6 \\
\hline 24 & 1,6 & -3 & $-0,9$ & 0,9 & 1,2 & 1,3 & 3,4 & $-2,1$ & 1,3 & 2,8 \\
\hline 25 & 1,1 & 6,5 & $-1,3$ & 1,3 & 1,1 & 1,3 & 1,4 & 1,3 & $-0,8$ & 1,7 \\
\hline 26 & $-2,4$ & $-2,9$ & 1,2 & 0,6 & 2,1 & 1,4 & 1,3 & 0,5 & 0,4 & 0,3 \\
\hline 27 & 2,1 & 8,1 & 1,1 & 0,4 & 2,5 & 1,6 & 1,2 & 1,4 & 0 & 1,3 \\
\hline 28 & 1,9 & $-3,5$ & $-0,2$ & 1,7 & 1 & 1,5 & 0,9 & 1,4 & $-1,1$ & 0,2 \\
\hline 29 & 0,1 & 0 & 2,7 & 1,4 & 3,8 & 2,1 & 0,2 & 1,3 & $-1,6$ & 0,9 \\
\hline 30 & 0 & $-6,3$ & $-0,4$ & 1,7 & 1,9 & 0,4 & 1,1 & 3,4 & $-0,5$ & 1,3 \\
\hline
\end{tabular}


TABELA B-9

\begin{tabular}{|c|c|c|c|c|c|c|c|c|c|c|c|c|c|c|}
\hline & SNA f-i & Co-A f-i & A-Nper $\mathrm{f}-$ & SNB f-i & Co-Gn f-i & ANB f-i & Wits $f-i$ & FMA f-i & $\underset{f-i}{\text { SN.GoGn }}$ & AFAl f-i & 1-PP f-i & $\begin{array}{c}1- \\
\text { ENAper } \\
f-i\end{array}$ & 1-PP f-i & $6-P P \mathrm{f}-\mathrm{i}$ \\
\hline 1 & 0,3 & $-3,6$ & $\begin{array}{l}-0,2 \\
\end{array}$ & 2 & $\begin{array}{l}-0,8 \\
\end{array}$ & $-1,7$ & $-4,6$ & $-0,4$ & $-0,7$ & 0,1 & $-14,9$ & $-4,2$ & 0,3 & 0,7 \\
\hline 2 & $-4,3$ & $-0,5$ & $-3,7$ & $-0,5$ & 3,2 & $-3,8$ & $-3,9$ & $-2,8$ & $-2,3$ & 0,4 & 18,2 & 1 & $-3,8$ & 1,5 \\
\hline 3 & 1,5 & 1,6 & 1,3 & 1,9 & 4,6 & $-0,3$ & $-3,8$ & $-1,6$ & $-2,1$ & 0,2 & 0,1 & $-0,7$ & $-1,2$ & $-0,8$ \\
\hline 4 & $-1,6$ & 0,5 & $-1,6$ & 0,1 & 5,7 & $-1,6$ & $-7,3$ & 0,5 & 0,9 & 3,5 & $-17,6$ & $-3,5$ & 2,4 & 0,6 \\
\hline 5 & $-1,7$ & 1,4 & 0,7 & 0,1 & 6 & $-1,9$ & 0,7 & -2 & 0,4 & 0,5 & 12,2 & 1,4 & $-2,6$ & 0,8 \\
\hline 6 & $-1,5$ & $-0,2$ & $-2,6$ & 1,8 & 5,4 & $-3,3$ & -3 & $-2,1$ & $-2,6$ & 1,4 & $-2,2$ & $-0,9$ & $-0,9$ & 1,6 \\
\hline 7 & $-0,7$ & 4 & 0 & 0,1 & 10,9 & $-0,8$ & 1 & $-0,2$ & 1,4 & 7,8 & 14,9 & $-1,5$ & $-1,6$ & 2,8 \\
\hline 8 & -5 & $-3,6$ & $-6,4$ & $-1,9$ & 1,8 & -3 & -2 & 5,3 & 3,7 & 5,4 & 8,4 & 2,7 & 0,8 & 2,5 \\
\hline 9 & $-1,7$ & 1,8 & $-3,4$ & 1,4 & 5,3 & $-3,1$ & $-4,2$ & $-2,3$ & $-4,1$ & 2,4 & 1,8 & 0,9 & 0 & $-0,3$ \\
\hline 10 & $-1,7$ & $-2,1$ & $-3,7$ & 0,1 & 0,3 & $-1,8$ & -1 & 0,2 & $-1,5$ & 0,2 & 1,2 & -1 & -3 & $-0,1$ \\
\hline 11 & $-5,6$ & $-5,3$ & $-6,7$ & $-0,1$ & 0,9 & $-5,6$ & -5 & 3,1 & 1,9 & 4,1 & $-0,4$ & $-1,5$ & $-0,4$ & 2,8 \\
\hline 12 & $-3,4$ & 1,7 & $-4,6$ & $-1,3$ & 6,9 & $-2,3$ & $-0,1$ & 2,7 & 1,7 & 4,3 & 6,9 & 0,3 & $-1,8$ & 1,1 \\
\hline 13 & $-1,7$ & 1,4 & $-2,2$ & 0,7 & 8,2 & $-2,4$ & 0,9 & 1,8 & 0 & 6,3 & 15 & 0,3 & $-1,8$ & 3,7 \\
\hline 14 & $-3,3$ & 0 & $-6,8$ & 0,3 & 7,7 & $-3,6$ & $-0,2$ & 4,1 & 0,5 & 4,6 & 3,6 & $-2,4$ & $-3,1$ & 2,6 \\
\hline 15 & 0,6 & $-0,9$ & 0 & -1 & $-1,1$ & 1,6 & 2,1 & 2,9 & 2,2 & 3,6 & $-3,9$ & $-0,8$ & $-1,3$ & 1,7 \\
\hline 16 & -1 & $-0,6$ & $-0,6$ & 0,9 & 0,7 & $-1,9$ & -2 & $-2,8$ & $-1,8$ & 0,1 & 4,5 & 4 & 0,1 & $-0,3$ \\
\hline 17 & $-2,1$ & $-0,9$ & $-3,4$ & 1,7 & 5,3 & $-3,7$ & $-2,3$ & -3 & -4 & 0,8 & 13,8 & 2 & -3 & 0,5 \\
\hline 18 & $-1,9$ & $-2,1$ & $-5,4$ & 1,2 & 6,7 & $-3,2$ & $-2,2$ & -3 & $-6,3$ & 2,4 & 9,3 & $-2,3$ & $-2,6$ & 0,4 \\
\hline 18 & $-0,5$ & 3,6 & $-2,4$ & 1,6 & 8,7 & -2 & $-0,5$ & 3,5 & 0,5 & 4,1 & 1,9 & $-2,3$ & $-0,4$ & 1,9 \\
\hline 20 & $-1,1$ & $-0,1$ & $-3,7$ & $-0,7$ & -1 & $-0,4$ & -2 & 1,6 & $-0,2$ & $-0,5$ & $-8,9$ & -6 & 0,9 & $-0,8$ \\
\hline 21 & 1,2 & 0,9 & 1,5 & 0,1 & $-1,1$ & 1,1 & $-0,6$ & 0,3 & 0,7 & $-0,1$ & $-7,3$ & $-9,8$ & $-1,5$ & 0,5 \\
\hline 22 & $-0,4$ & $-0,7$ & 0,3 & $-0,6$ & 1,7 & 0,2 & 1,5 & $-0,9$ & $-0,2$ & 2,7 & $-4,7$ & $-5,5$ & $-0,2$ & 2,5 \\
\hline 23 & $-3,9$ & $-3,9$ & $-3,1$ & $-0,5$ & 0,7 & $-3,5$ & -2 & 2,1 & 2,9 & 1,9 & 5,7 & $-0,9$ & 0,1 & 1,7 \\
\hline 24 & 0,1 & $-2,6$ & $-0,5$ & 0,7 & $-1,4$ & $-0,5$ & $-3,2$ & $-0,4$ & $-0,6$ & 0,7 & $-10,8$ & $-4,1$ & 0 & $-0,8$ \\
\hline 25 & $-0,2$ & 2 & $-2,6$ & 1,2 & 6,7 & $-1,4$ & $-1,3$ & 2,3 & $-0,9$ & 7,4 & $-2,1$ & $-2,2$ & 1 & 3,8 \\
\hline 26 & $-2,8$ & 4,4 & $-2,5$ & $-0,5$ & 9,6 & $-2,3$ & $-2,5$ & 3,2 & 3,5 & 9,3 & 3,9 & $-3,2$ & 1,3 & 4,1 \\
\hline 27 & $-1,2$ & $-2,5$ & $-1,8$ & 1,4 & 6,5 & $-2,5$ & $-1,5$ & 1,2 & $-1,2$ & 4,2 & $-2,5$ & $-5,4$ & $-1,3$ & 1,7 \\
\hline 28 & $-1,8$ & 0,4 & $-1,4$ & 0,6 & 8,3 & $-2,5$ & -1 & 1 & 1,3 & 4,6 & 5,5 & $-1,8$ & $-2,1$ & 2,8 \\
\hline 29 & $-3,7$ & 0,4 & $-4,1$ & $-0,3$ & 5,5 & $-3,4$ & $-5,9$ & 1,6 & 0,6 & 2,1 & $-7,6$ & $-5,5$ & 2,2 & 1,7 \\
\hline 30 & $-5,3$ & $-2,1$ & $-5,6$ & $-0,2$ & 4,6 & $-5,1$ & $-5,3$ & 1,8 & $-0,1$ & 5,3 & $-15,5$ & $-4,6$ & $-0,4$ & 3,4 \\
\hline
\end{tabular}


TABELA B-10

\begin{tabular}{|c|c|c|c|c|c|c|c|c|c|c|}
\hline & $\begin{array}{c}\text { 6-ENAper } \\
f-i\end{array}$ & IMPA f-i & 1-Pogper & $\underset{f-i}{1-G o M e}$ & 6-Pogper & $\underset{f-i}{\text { 6-GoMe }}$ & Thor f-i & T vert $\mathrm{f}-\mathrm{i}$ & Rel mol f- & Rel can f- \\
\hline 1 & 4,9 & $-1,7$ & 0,6 & $-2,7$ & 1,5 & 1,1 & $-5,3$ & $-2,5$ & 0,9 & $-5,5$ \\
\hline 2 & 3,6 & 16,6 & 0,9 & $-2,5$ & $-1,6$ & 2,6 & $-5,5$ & $-7,8$ & 0,3 & $-7,1$ \\
\hline 3 & 3,4 & 1,2 & 2,2 & $-1,6$ & 0,5 & 2,3 & $-3,3$ & $-3,9$ & 1,1 & $-4,3$ \\
\hline 4 & 6,1 & -3 & $-2,1$ & 0,7 & $-1,6$ & 3,2 & $-6,9$ & $-0,1$ & 1 & -7 \\
\hline 5 & 1,8 & $-2,9$ & $-2,2$ & 2,2 & $-0,9$ & 1,2 & 0,1 & $-1,3$ & $-0,3$ & $-7,1$ \\
\hline 6 & 1,3 & 1,1 & $-0,3$ & $-0,5$ & $-3,4$ & 1,4 & $-4,6$ & -4 & 0,8 & $-4,5$ \\
\hline 7 & 0,5 & 0,2 & $-2,8$ & 4,3 & $-1,8$ & 5,1 & $-2,1$ & $-4,9$ & 0,5 & $-5,3$ \\
\hline 8 & 3,4 & 5,8 & $-0,1$ & 1,9 & $-0,4$ & 2,2 & $-1,8$ & $-3,3$ & 0,5 & $-5,1$ \\
\hline 9 & 3,2 & 0,2 & $-1,1$ & 1,7 & $-1,1$ & 4,1 & $-1,5$ & $-1,1$ & 0,4 & $-7,5$ \\
\hline 10 & 4,5 & 6,2 & 0,6 & $-1,2$ & 1,2 & 1,7 & $-3,7$ & $-4,5$ & 1 & $-6,6$ \\
\hline 11 & 2 & 2,2 & $-0,6$ & 2 & $-0,9$ & 2,5 & $-3,9$ & $-3,8$ & 0,7 & $-9,5$ \\
\hline 12 & $-0,3$ & 1,2 & $-0,2$ & 2,7 & $-1,3$ & 2,6 & $-1,7$ & $-3,6$ & $-0,4$ & $-5,6$ \\
\hline 13 & 2,2 & -3 & $-1,2$ & 4 & 0,2 & 3,6 & $-1,4$ & $-4,1$ & 0,9 & $-5,7$ \\
\hline 14 & 3,6 & $-5,8$ & $-2,1$ & 3,8 & $-1,3$ & 2,9 & $-5,7$ & $-2,8$ & 0,2 & $-10,4$ \\
\hline 15 & 3,2 & 10,6 & 2,6 & 2,1 & 1,5 & 2,8 & $-4,1$ & $-3,1$ & 0,6 & $-7,7$ \\
\hline 16 & 2,9 & 4,7 & 2,7 & 1,2 & 0,6 & 0,7 & $-1,1$ & 0,4 & $-0,1$ & $-4,3$ \\
\hline 17 & 4,8 & 1,6 & 4,5 & $-0,8$ & 3,4 & 2,2 & $-2,7$ & $-5,5$ & 0,5 & $-4,6$ \\
\hline 18 & $-1,2$ & $-6,3$ & $-2,6$ & 1,1 & -4 & 3,9 & $-2,5$ & $-3,1$ & $-0,8$ & -7 \\
\hline 18 & 4,5 & $-3,1$ & $-1,8$ & 3,1 & 0,9 & 3,2 & -4 & $-1,3$ & 0,6 & $-4,3$ \\
\hline 20 & 0,1 & $-5,1$ & $-2,3$ & 2,4 & $-1,1$ & 2,7 & $-3,5$ & 4,9 & 1 & $-3,1$ \\
\hline 21 & $-0,2$ & 7 & $-0,2$ & $-3,5$ & 1 & 0 & $-8,5$ & $-4,3$ & $-0,7$ & $-4,1$ \\
\hline 22 & 2,6 & 2 & 0,2 & $-0,1$ & 0,6 & 1,5 & $-6,2$ & $-4,2$ & 0,4 & $-6,1$ \\
\hline 23 & 4 & $-5,6$ & $-0,4$ & 0,3 & 1,5 & $-0,1$ & $-2,8$ & $-2,1$ & 0,1 & $-5,7$ \\
\hline 24 & 2,6 & 0,7 & 3,1 & 0,8 & 1 & 1,9 & $-6,3$ & 0,3 & 1 & $-5,7$ \\
\hline 25 & 1,1 & 7 & 1,1 & 5,6 & $-1,3$ & 4,8 & $-7,4$ & $-2,4$ & $-1,5$ & $-5,9$ \\
\hline 26 & 2,5 & 2,6 & $-0,1$ & 5,2 & $-0,6$ & 6 & $-5,1$ & $-2,9$ & 1 & $-6,1$ \\
\hline 27 & 3 & $-2,1$ & 0,1 & 2,5 & -1 & 1,6 & $-7,2$ & $-3,9$ & 1,2 & -5 \\
\hline 28 & 4,7 & $-11,1$ & $-0,9$ & 2,4 & 0,6 & 2,7 & $-4,5$ & $-4,7$ & 0,7 & $-6,6$ \\
\hline 29 & 5,1 & $-2,2$ & $-1,4$ & 2,9 & $-0,3$ & 3,2 & $-5,5$ & 2,8 & 1,8 & $-6,2$ \\
\hline 30 & 5 & 7,2 & 0,8 & 1,2 & $-0,4$ & 4 & $-11,1$ & $-5,1$ & $-0,2$ & -7 \\
\hline
\end{tabular}

